\author{
Universidade de São Paulo \\ Instituto de Física
}

\title{
Modelagem de mecânica estatística de processos de transporte através da membrana celular
}

\author{
Yan Borges Barreto
}

Orientador: Prof. Dr. Adriano Mesquita Alencar

\begin{abstract}
Dissertação de mestrado apresentada ao Instituto de Física da Universidade de São Paulo, como requisito parcial para a obtenção do título de Mestre em Ciências.
\end{abstract}

Banca Examinadora:

Prof. Dr. Adriano Mesquita Alencar (IFUSP)

Prof. Dr. Reynaldo Daniel Pinto (IFSC)

Prof. Dr. Manoel Arcisio Miranda Filho (UNIFESP)

São Paulo 


\section{FICHA CATALOGRÁFICA}

\section{Preparada pelo Serviço de Biblioteca e Informação}

do Instituto de Física da Universidade de São Paulo

\section{Barreto, Yan Borges}

Modelagem de mecânica estatística de processos de transporte através da membrana celular. São Paulo, 2019.

Dissertação (Mestrado) - Universidade de São Paulo. Instituto de Física. Depto. de Física Geral.

Orientador: Prof. Dr. Adriano Mesquita Alencar

Área de Concentração: Física.

Unitermos: 1. Mecânica estatística clássica; 2. Física computacional; 3. Biofísica; 4. Fenômenos microbiológicos. 


\author{
University of São Paulo \\ Physics Institute
}

\title{
Statistical mechanical modeling of transport processes across the cell membrane
}

\author{
Yan Borges Barreto
}

Supervisor: Prof. Dr. Adriano Mesquita Alencar

\begin{abstract}
Dissertation submitted to the Physics Institute of the University of São Paulo in partial fulfillment of the requirements for the degree of Master of Science.
\end{abstract}

Examining Committee:

Prof. Dr. Adriano Mesquita Alencar (IFUSP)

Prof. Dr. Reynaldo Daniel Pinto (IFSC)

Prof. Dr. Manoel Arcisio Miranda Filho (UNIFESP) 



\section{Agradecimentos}

Em primeiro lugar, gostaria de agradecer a Deus por tudo aquilo que Ele fez em minha vida.

Gostaria também de agradecer à minha esposa, Caroline Lopes Barreto, pela constante presença e apoio incondicional.

Gostaria de agradecer aos meus familiares por acreditarem em mim e se alegrarem com as minhas vitórias.

Gostaria de agradecer ao meu orientador, Prof. Dr. Adriano Mesquita Alencar, por me ensinar a ser cada dia mais independente no meio científico e ter sempre confiado em meu trabalho.

Gostaria de agradecer ao Prof. Dr. Béla Suki por ter me recebido e orientado durante a minha visita à Boston University.

Gostaria de agradecer aos meus amigos e colegas pelos momentos de descontração e conselhos que me ajudaram a chegar até aqui.

Gostaria de agradecer ao CNPq por ter financiado parte da presente pesquisa através do processo 131109/2017-0.

Por fim, gostaria de agradecer à FAPESP por ter financiado parte da presente pesquisa através do processo 2017/16910-7 e a minha visita à Boston University através do processo 2018/11904-1 . 



\section{Epígrafe}

"Confia em lahweh com todo o teu coração, não te fies em tua própria inteligência; em todos os teus caminhos, reconhece-o, e ele endireitará as tuas veredas."

Provérbios 3: 5, 6 



\section{Resumo}

No presente trabalho, nós desenvolvemos um modelo de mecânica estatística para a dinâmica do cotransporte. Em particular, foram analisados o simporte de lactose $\mathrm{e}^{+}$ catalisado pela LacY, e o antiporte de triose-P e $\mathrm{P}_{\mathrm{i}}$ catalisado pelo TPT. Em ambos os casos, nosso ponto de partida foi determinar a curva de energia livre do ciclo de transporte com base na estrutura bioquímica de cada estado. Então, usando o algoritmo de Metropolis em um modelo do caminho aleatório não-homogêneo, nós determinamos a dinâmica do ciclo expressa na curva de energia livre obtida anteriormente. Tanto no caso da LacY quanto no caso do TPT, a concordância entre as predições do nosso modelo e os dados experimentais sugere que a nossa curva de energia livre é apropriada para descrever os processos de transporte através da membrana plasmática.

Palavras-chave: mecânica estatística, simulação de Monte Carlo, cotransporte, simporte, antiporte. 



\section{Abstract}

In the present work, we developed a statistical mechanical model for the dynamics of cotransport. In particular, the symport of lactose and $\mathrm{H}^{+}$and the antiport of triose-P and $P_{i}$ were analyzed. In both cases, our starting point was to determine the free-energy curve of the transport cycle based on the biochemical structure of each state. Then, using the Metropolis algorithm in a nonhomogeneous random walk model, we determined the dynamics of the cycle expressed in the free-energy curve obtained previously. Both in the case of LacY and TPT, the agreement between our model predictions and the experimental data suggests that our free-energy curve is appropriate for describing the transport process across the plasma membrane.

Keywords: statistical mechanics, Monte Carlo simulation, cotransport, symport, antiport. 



\section{Lista de figuras}

1.1 Desenho que Robert Hooke apresentou em sua obra Micrographia de um corte fino de cortiça visto sob o microscópio mostrando a multidão de minúsculos poros que ele chamou de células. . . . . . . . . . . . . . .

1.2 Desenho que Seymour J. Singer e Garth L. Nicolson apresentaram em seu artigo The fluid mosaic model of the structure of cell membranes. Nesse desenho, a bicamada lipídica de uma membrana celular é mostrada de forma esquemática. Além disso, também são mostrados exemplos de proteínas periféricas, integrais, e integrais transmembranares.

1.3 Difusão facilitada através da membrana celular. Na esquerda, uma proteína de canal transportando partículas para dentro da célula é mostrada. Na direita, veem-se proteínas carregadoras em três conformações diferentes. . . . . . . . . . . . . . . . . . . . . .

1.4 Difusão simples versus difusão facilitada. No caso da difusão simples, a taxa de transporte $V$ é sempre proporcional à concentração do substrato $C$, enquanto que na difusão facilitada, essa taxa é governada pela equação de Michaelis-Menten . . . . . . . . . . . . . . . . . . .

1.5 Os três principais tipos de estímulo que causam a abertura de canais iônicos. Esses estímulos são: (a) A ligação de um ligante; (b) Uma mudança na voltagem através da membrana; e (c) Um estresse mecânico.

1.6 O ciclo de transporte da bomba de sódio/potássio. Íons de sódio $\left(\mathrm{Na}^{+}\right)$ e íons de potássio $\left(\mathrm{K}^{+}\right)$são ilustrados como hexágonos laranjas e elipses amarelas, respectivamente. Também estão indicados o ATP, ADP e grupo fosfato 
1.7 Os dois tipos de transporte ativo secundário. Na esquerda, mostramos uma proteína simportadora, que transporta ambos os solutos na mesma direção. Na direita, vê-se uma proteína antiportadora transportando dois solutos em direções opostas.

1.8 Modelo simplificado da ligação ligante-receptor. (a) Possível microestado com o receptor desocupado. (b) Possível microestado com o receptor ocupado.

1.9 Probabilidade de que o receptor esteja ocupado, $P_{\mathrm{oc}}$, como função da razão entre o número de ligantes $L$ e o número total de caixas da rede $\Omega$. O gráfico mostra curvas para três valores de $\Delta \varepsilon,-2.5,0$ e $2.5 k_{\mathrm{B}} T$. .

$1.10 \mathrm{O}$ problema do caminho aleatório, no qual um indivíduo se desloca a partir da origem ao longo do eixo $x$ com passos de comprimento $\ell$. . . .

1.11 Reações de transporte catalisadas pela LacY. (a) Transporte ativo de lactose, L, contra o seu gradiente de concentração em resposta a um gradiente eletroquímico de prótons gerado tanto pela respiração de $\mathrm{H}^{+}$, como pela hidrólise do ATP. (b) e (c) Na ausência de $\Delta \tilde{\mu}_{\mathrm{H}^{+}}$, o gradiente de concentração de lactose gera um gradiente eletroquímico de $\mathrm{H}^{+}$, cuja polaridade depende do sinal de $\Delta \mu_{\mathrm{L}} \ldots \ldots \ldots \ldots \ldots \ldots$

1.12 Esquema cinético simplificado para o simporte de lactose e $\mathrm{H}^{+}$. Aqui, $\mathrm{Y}$ representa a LacY, e $L$ a lactose. . . . . . . . . . . . . . . . 53

1.13 A função do TPT nos cloroplastos. . . . . . . . . . . . . . . . . 54

1.14 Esquema cinético simplificado para o antiporte de triose-fosfato, TP, e fosfato inorgânico, $\mathrm{P}_{\mathrm{i}}$. Aqui, T representa o TPT. . . . . . . . . . . 55

2.1 Estrutura geral da LacY. (a) Representação do mutante C154G em sua conformação voltada-para-dentro visto paralelamente à membrana celular. Esse mutante consiste de 12 hélices organizadas em dois pacotes com seis hélices cada. As hélices transmembranares são coloridas a partir do domínio $\mathrm{N}$-terminal em roxo até o domínio C-terminal em rosa. O TDG é representado por esferas pretas. (b) Representação do mutante $\mathrm{C} 154 \mathrm{G}$ em sua conformação voltada-para-dentro visto ao longo da normal da membrana celular do lado citoplasmático. As 12 hélices estão numeradas com algarismos romanos. 
2.2 Esquema da estrutura secundária da LacY. Os domínios N- e C-terminal são mostrados em azul e vermelho, respectivamente. Os resíduos representados por círculos verdes e amarelos estão envolvidos na ligação do substrato e na translocação do próton, respectivamente. O resíduo $\mathrm{Glu}_{269}$, representado por um círculo azul claro, está envolvido tanto na ligação do substrato, quanto na transferência do próton. A cavidade hidrofílica é mostrada como um triângulo azul claro, e o TDG como dois círculos pretos. . . . . . . . . . . . . . . . . . .

2.3 O sítio de ligação do substrato da LacY. São mostrados os resíduos envolvidos na ligação do TDG vistos ao longo da normal da membrana do lado citoplasmático. Possíveis ligações de hidrogênio e pontes salinas são representadas por linhas pretas tracejadas. As hélices transmembranares dos domínios $\mathrm{N}$ - e C- terminal estão coloridas em azul e vermelho, respectivamente.

2.4 Mecanismo de transporte de lactose pela LacY. Os resíduos chave estão identificados. Um potencial elétrico de membrana de $-100 \mathrm{mV}$ está indicado. Ligações de hidrogênio e Van der Waals são mostradas como linhas tracejadas e sólidas, respectivamente. Também é mostrada a ligação de hidrogênio entre os resíduos $\mathrm{ASP}_{240}$ e $\mathrm{Lys}_{319}$, que são representados como pequenos círculos brancos. Esses resíduos não são essenciais para o modelo de Kaback, mas eles afetam a nossa curva de energia livre. A lactose e o $\mathrm{H}^{+}$são representados como círculos cinza claro e escuro, respectivamente. . . . . . . . . . . . . . . . . .

2.5 Evolução temporal do influxo de lactose em um experimento realizado por Ujwal e outros. . . . . . . . . . . . . . . . . . . . . . .

2.6 Evolução temporal do efluxo de lactose em um experimento realizado por Ujwal e outros. . . . . . . . . . . . . . . . . . . . .

2.7 Taxa inicial de transporte, $V$, para concentrações de lactose variando de $40 \mathrm{umoll}^{-1}$ a $5 \mathrm{mmoll}^{-1}$. A equação de Michaelis-Menten foi ajustada aos dados. . . . . . . . . . . . . . . . . . . . . . . . . . . 
2.8 Estrutura geral do TPT. Representação do homólogo GsGPT em sua conformação oclusa com um 3-PGA ligado (a) e um $\mathrm{P}_{\mathrm{i}}$ ligado (b). (c), (d) Detalhes do sítio de ligação central. (e) Modelo de ligação da triose-P. 67

2.9 O modelo de Takemoto. Os resíduos principais estão identificados. Ligações de hidrogênio e de Van der Waals são mostradas como linhas verdes e vermelhas, respectivamente. O fosfato inorgânico, $\mathrm{P}_{\mathrm{i}}$, é representado como um círculo ondulado verde . . . . . . . . . . . . . . 68

2.10 Curva de energia livre do modelo de Takemoto. . . . . . . . . . . . 69

2.11 Resultados experimentais para o TPT. (a) Evolução temporal do influxo do fosfato inorgânico, $\mathrm{P}_{\mathrm{i}}$, em um experimento realizado por Linka e outros. (b) Quantidade de $\mathrm{P}_{\mathrm{i}} \mathrm{s}$ transportados para o estroma como função da concentração externa de $\mathrm{P}_{\mathrm{i}} \ldots \ldots \ldots \ldots \ldots$. . . . . . . . 70

3.1 Integração de Monte Carlo. O gráfico mostra a curva da função $y(x)=$ $\operatorname{sen}\left(\frac{\pi}{2} x\right)$ no intervalo $x \in[0,1]$ e o quadrado definido por $x \in[0,1]$ e $y \in$ $[0,1]$. Nós sorteamos 500 pontos aleatórios uniformemente distribuídos dentro do quadrado, e apresentamos em azul os 316 pontos que estão sob a curva, e em vermelho os que estão sobre a curva. . . . . . . . . . .

3.2 Função de distribuição gaussiana $\varphi(x ; \mu, \sigma)$ para diversos valores da média $\mu$ e do desvio padrão $\sigma$ da variável $x$.

3.3 Variações de energia livre entre os estados da LacY e o estado fundamental. Também são mostrados os intervalos de valores possíveis para cada $\Delta E_{S}=E_{S}-E_{2}>0$ que foram usados para encontrar a melhor curva de energia livre. . . . . . . . . . . . . . . . . . 85

3.4 Modelo do caminho aleatório para a LacY. . . . . . . . . . . . . . 86

3.5 Mecanismo do transporte de triose-fosfato pelo TPT. Os resíduos principais estão identificados. Ligações de hidrogênio e de Van der Waals são mostradas como linhas verdes e vermelhas, respectivamente. A triosefosfato (TP) e o fosfato inorgânico $\left(\mathrm{P}_{\mathrm{i}}\right)$ são representados como círculos ondulados azul e verde, respectivamente. 
3.6 Variações de energia livre entre os estados do TPT e o seu estado fundamental. Também são mostrados os intervalos de valores possíveis para $\Delta E_{1}$ e $\Delta E_{7}$ que foram usados para encontrar a melhor curva de energia livre. . . . . . . . . . . . . . . . .

4.1 Dinâmica do transporte de lactose pela LacY. Nesta simulação, as probabilidades de encontrar uma lactose ou $\mathrm{um}^{+}$perto da entrada da LacY não dependem do tempo. (a) Número de moléculas de lactose no citoplasma e periplasma. (b) Número de prótons no citoplasma e periplasma. (c) Ciclos de influxo (total de 53) e efluxo (total de 22) versus passo de Monte Carlo em que cada ciclo foi concluído. No início da simulação, Caminhada do Ciclo é igual a zero, e nós adicionamos +1 para cada passo na direção de influxo, e -1 para cada passo na direção de efluxo. . . . . . . . . . . . . . . . . . . . .

4.2 Dinâmica do transporte de lactose pela LacY. Nesta simulação, as concentrações dos substratos no citoplasma e periplasma podem variar no tempo. (a) Frações de lactose no citoplasma e periplasma. (b) Frações de prótons no citoplasma e periplasma. (c) Probabilidade do sistema ser encontrado em cada um dos seus seis estados.

4.3 Curso temporal do transporte de lactose pela LacY. Círculos correspondem a dados experimentais, enquanto linhas sólidas correspondem às nossas simulações. Aqui, um passo de Monte Carlo é equivalente a 2.9 us. (a) Evolução temporal do influxo de lactose. (b) Evolução temporal do efluxo de lactose. . . . . . . . . . . . . . . . . . . . . . 100

4.4 Simulações para um experimento realizado por Ujwal e outros usando várias curvas de energia livre. Círculos correspondem a dados experimentais, enquanto linhas sólidas pretas correspondem às simulações com a curva de energia livre do nosso modelo, mostrada em preto à direita. Linhas sólidas vermelhas correspondem às simulações para os quatro valores do parâmetro $\gamma$ indicados. Para mais detalhes, ver o texto. 103 
4.5 Dinâmica do transporte de triose-P pelo TPT. Nesta simulação, as probabilidades de encontrar uma triose-P ou um $\mathrm{P}_{\mathrm{i}}$ perto da entrada do TPT não dependem do tempo. (a) Número de $\mathrm{P}_{\mathrm{i}} \mathrm{s}$ no estroma e espaço intermembranar. (b) Número de TPs no espaço intermembranar e estroma. (c) Ciclos de influxo (total de 18) e efluxo (total de 47) versus passo de Monte Carlo em que cada ciclo foi concluído. No início da simulação, Caminhada do Ciclo é igual a zero, e nós adicionamos +1 para cada passo na direção de influxo, e -1 para cada passo na direção de efluxo. 105

4.6 Dinâmica do transporte de triose-fosfato pelo TPT. Nesta simulação, as concentrações dos substratos no estroma e espaço intermembranar podem variar no tempo. (a) Frações de $\mathrm{P}_{\mathrm{i}}$ no estroma e espaço intermembranar. (b) Frações de TP no estroma e espaço intermembranar. (c) Probabilidade do sistema ser encontrado em cada um dos seus sete estados. A probabilidade do Estado 4, que não está mostrada por inteiro, é $0.9 \ldots \ldots \ldots$. . . . . . . . . . . . . . . 106 


\section{Lista de tabelas}

4.1 Número total de ciclos de influxo, $N_{\text {in }}$, e efluxo, $N_{\text {ef }}$, para diversos valores da razão entre as concentrações de lactose no citoplasma e periplasma. Foram usados $5 \times 10^{5}$ passos de Monte Carlo e $10^{3}$ réplicas em cada simulação.

4.2 Tempo de ocupação da LacY em cada um dos seus seis estados para diversos valores da razão $C_{\mathrm{L}, c}\left(C_{\mathrm{L}, \mathrm{c}}+C_{\mathrm{L}, \mathrm{p}}\right)^{-1}$, onde $C_{\mathrm{L}, \mathrm{c}}$ e $C_{\mathrm{L}, \mathrm{p}}$ são as concentrações de lactose no citoplasma e periplasma, respectivamente. Nestas simulações, $C_{\mathrm{H}^{+}, \mathrm{c}}=C_{\mathrm{H}^{+}, \mathrm{p}}$. Além disso, foram usados $2 \times 10^{6}$ passos de Monte Carlo. . . . . . . . . . . . . . . . . . . 97

4.3 Número total de ciclos de influxo, $N_{\text {in }}$, e efluxo, $N_{\text {ef }}$, para diversos valores da razão entre as concentrações de triose-fosfato no estroma e espaço intermembranar. Foram usados $5 \times 10^{6}$ passos de Monte Carlo e $10^{3}$ réplicas em cada simulação. 



\section{Nomenclatura}

\section{Símbolos romanos}

$A(\boldsymbol{x})$ Observável macroscópico, Eq. (3.1)

$A_{\mathrm{q}} \quad$ Área do quadrado na Integração de Monte Carlo

C Concentração da substância

$C_{\mathrm{C}} \quad$ Concentração da substância no citoplasma

$C_{\mathrm{p}} \quad$ Concentração da substância no periplasma

D Coeficiente de difusão

d Dimensão do espaço

$E_{i} \quad$ Energia do microestado $i$

e $\quad$ Carga elementar, $1.602177 \times 10^{-19} \mathrm{C}$

$f(x) \quad$ Função densidade de probabilidade

G Energia livre de Gibbs

$H(\boldsymbol{x})$ Hamiltoniana

I Valor da integral, Eq. (3.4)

$k_{\mathrm{B}} \quad$ Constante de Boltzmann, $1.380658 \times 10^{-23} \mathrm{JK}^{-1}$

$K_{\mathrm{M}} \quad$ Constante de Michaelis-Menten, Eq. (1.4)

L $\quad$ Número de ligantes, Fig. 1.8 
$\ell \quad$ Comprimento do passo no problema do caminho aleatório

$m \quad$ Diferença entre $n_{>}$e $n_{<}$

$N \quad$ Número total de pontos

$N_{\text {ef }} \quad$ Número total de ciclos de efluxo

$N_{\text {in }} \quad$ Número total de ciclos de influxo

n Número de passos no problema do caminho aleatório; número de pontos sob a curva na Integração de Monte Carlo; $n=0,1,2, \ldots$

$n_{<} \quad$ Número de passos para a esquerda

$n_{>} \quad$ Número de passos para a direita

$n_{i} \quad$ Variável aleatória que assume o valor 1 se o ponto $i$ estiver sob a curva, e 0 caso contrário

P Solução estacionária, Eq. (3.25)

$\mathbf{P}_{n} \quad$ Matriz coluna cujos elementos são $P_{n}\left(x_{n}\right)$, Eq. (3.23)

$P\left(E_{i}\right)$ Probabilidade de estar em um microestado $i$ com energia $E_{i}$, Eq. (1.7)

$P(x)$ Função de distribuição de probabilidade da variável aleatória $x$

$P_{n}(m)$ Probabilidade de encontrar a partícula na posição $x=m \ell$ depois de ter dado $n$ passos, Eq. (1.14)

$P_{n}\left(n_{>}\right)$Probabilidade de que a partícula tenha dado $n_{>}$passos para a direita em um total de $n$ passos, Eq. (1.13)

$P_{n}\left(x_{n}\right)$ Probabilidade de que a variável $x$ assuma o valor $x_{n}$ no instante $t_{n}$ independente dos valores que ela tenha assumido nos instantes anteriores, Eq. (3.16)

$P_{\text {oc }} \quad$ Probabilidade de que o receptor esteja ocupado por um ligante, Eq. (1.10)

$p \quad$ Probabilidade da partícula se mover para a direita

$q \quad$ Probabilidade da partícula se mover para a esquerda 
$R \quad$ Número aleatório uniformemente distribuído entre 0 e 1

$T \quad$ Temperatura

T Matriz estocástica, Eq. (3.19)

$t \quad$ Instante de tempo

V Taxa de transporte, Eq. (1.4)

$V_{\mathrm{c}} \quad$ Volume do citoplasma

$V_{\text {máx }}$ Taxa de transporte máxima, Eq. (1.4)

$V_{p} \quad$ Volume do periplasma

$v_{\mathrm{m}} \quad$ Velocidade média da partícula

$W(i, j)$ Taxa de transição do estado $j$ para o estado $i$, Eq. (3.27)

$W_{\mathrm{M}}(j, i)$ Taxa de transição do algoritmo de Metropolis, Eq. (3.41)

x Posição da partícula

$\boldsymbol{x} \quad$ Vetor do espaço de fase

Z Função de partição canônica, Eq. (1.8)

\section{Símbolos gregos}

$\beta \quad$ Temperatura inversa

$\gamma \quad$ Parâmetro múltiplo de 0.5, Eq. (4.1)

$\Delta C \quad$ Gradiente de concentração

$\Delta E_{i j}$ Diferença entre a energia do estado $j$ e a energia do estado $i$

$\Delta E_{S}$ Diferença entre a energia do estado $S$ e a energia do estado fundamental

$\Delta G \quad$ Gradiente de energia livre de Gibbs

$\Delta \mathrm{pH}$ Gradiente de $\mathrm{pH}$

$\Delta \varepsilon \quad$ Diferença entre $\varepsilon_{\text {lig }}$ e $\varepsilon_{\text {liv }}$ 
$\Delta \mu \quad$ Gradiente de potencial químico, Eq. (1.1)

$\Delta \tilde{\mu} \quad$ Gradiente eletroquímico, Eq. (1.3)

$\Delta \tilde{\mu}_{\mathrm{H}^{+}}$Gradiente eletroquímico de $\mathrm{H}^{+}$

$\Delta \mu_{\mathrm{L}} \quad$ Gradiente de concentração de lactose

$\Delta \mu_{\mathrm{P}_{\mathrm{i}}}$ Gradiente de concentração de $\mathrm{P}_{\mathrm{i}}$

$\Delta \mu_{\mathrm{TP}}$ Gradiente de concentração de triose-fosfato

$\Delta \mu_{\Psi} \quad$ Gradiente elétrico transmembranar, Eq. (1.3)

$\Delta \Psi \quad$ Diferença de potencial elétrico transmembranar

$\delta \quad$ Parâmetro livre

$\varepsilon_{\text {lig }} \quad$ Energia de um ligante ligado ao receptor

$\varepsilon_{\text {liv }} \quad$ Energia de um ligante livre na solução

$\eta \quad$ Parâmetro auxiliar, Eq. (3.49)

$\mu_{x} \quad$ Média da variável $x$

$\xi \quad$ Parâmetro auxiliar, Eq. (3.49)

П $\quad$ Probabilidade de que haja um soluto próximo da entrada da proteína carregadora disponível para ser capturado, Eq. (1.12)

$\sigma_{x} \quad$ Desvio padrão de $x$

$\sigma_{x}^{2} \quad$ Variância de $x$

$\tau \quad$ Intervalo de tempo no problema do caminho aleatório

$\varphi(x ; \mu, \sigma)$ Função de distribuição gaussiana, Eq. (3.12)

$\Omega \quad$ Número de caixas da rede, Fig. 1.8

$\Omega_{\mathrm{C}} \quad$ Número de caixas da rede do citoplasma

$\Omega_{\mathrm{p}} \quad$ Número de caixas da rede do periplasma 


\section{Abreviaturas}

CC Condição de contorno

$\mathrm{C}_{\text {dentro }}$ Conformação voltada-para-dentro

$\mathrm{C}_{\text {fora }}$ Conformação voltada-para-fora

Coclusa Conformação oclusa

MC Monte Carlo

MFS Superfamília dos facilitadores maioritários

PDF Função de distribuição de probabilidade

TC Teoria Celular 



\section{Sumário}

1 Introdução 31

1.1 Contextualização do trabalho . . . . . . . . . . . . . . . 32

1.1 .1 A célula . . . . . . . . . . . . . . . . . . 32

1.1.2 A membrana celular . . . . . . . . . . . . . 35

1.2 Proteínas de transporte $\ldots \ldots \ldots \ldots \ldots \ldots \ldots$

1.2 .1 Visão geral . . . . . . . . . . . . . . . . 38

1.2.2 Proteínas de canal . . . . . . . . . . . . . . . . 41

1.2.3 Proteínas carregadoras . . . . . . . . . . . . . . . 42

1.3 Mecânica estatística de sistemas biológicos . . . . . . . . . . . . . 45

1.3.1 Conceitos básicos . . . . . . . . . . . . . . . . 45

1.3.2 Introdução ao problema do caminho aleatório . . . . . . . . . 48

1.4 Proposta deste trabalho . . . . . . . . . . . . . . . . . . 51

1.4.1 Considerações gerais . . . . . . . . . . . . . . 51

1.4.2 O simporte de lactose $\mathrm{e}^{+} \ldots \ldots \ldots \ldots \ldots \ldots$

1.4.3 O antiporte de triose-fosfato e $\mathrm{P}_{\mathrm{i}} \ldots \ldots \ldots \ldots \ldots$

1.5 Organização da dissertação . . . . . . . . . . . . . . . . . . 54

2 Levantamento bibliográfico $\quad 56$

2.1 A permease de lactose da Escherichia coli . . . . . . . . . . . 57

2.1 .1 Visão geral . . . . . . . . . . . . . . . . . . 57

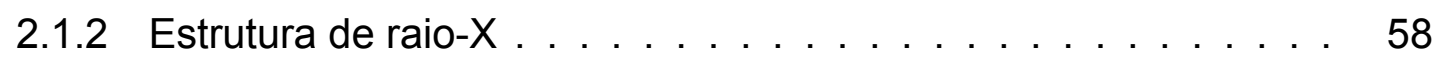

2.1 .3 O modelo de Kaback . . . . . . . . . . . . . . 61 
2.1.4 Síntese dos resultados experimentais . . . . . . . . . . 63

$2.2 \bigcirc$ translocador de triose-fosfato/fosfato $\ldots \ldots \ldots \ldots 6$

2.2 .1 Visão geral . . . . . . . . . . . . . . . . . . 66

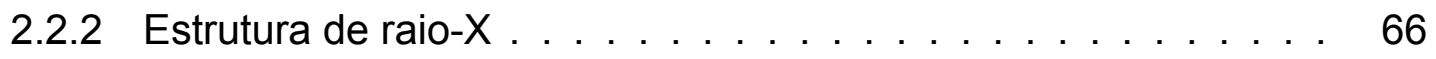

2.2.3 O modelo de Takemoto . . . . . . . . . . . . . . . . . . 67

2.2.4 Síntese dos resultados experimentais . . . . . . . . . 69

3 Metodologia $\quad 71$

3.1 Métodos de Monte Carlo . . . . . . . . . . . . . . . . . . . . 72

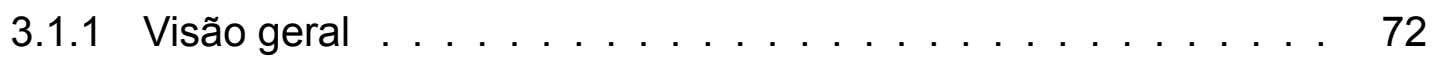

3.1 .2 Erro de Monte Carlo . . . . . . . . . . . . . . . . . 73

3.1.3 Gerador de números aleatórios . . . . . . . . . . . . 75

3.1.4 Função de distribuição de probabilidade . . . . . . . . . . . 76

3.2 Cadeias de Markov . . . . . . . . . . . . . . . . . . . . . 77

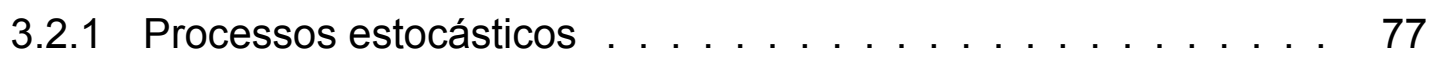

3.2.2 A matriz estocástica . . . . . . . . . . . . . . . . . . . 79

3.2 .3 A equação mestra . . . . . . . . . . . . . . . . . 80

3.2 .4 O algoritmo de Metropolis . . . . . . . . . . . . . . . 82

3.3 Hipóteses de trabalho $\ldots \ldots \ldots \ldots$

3.3.1 Modelo do caminho aleatório para a LacY . . . . . . . . . . . 84

3.3.2 Modelo do caminho aleatório para o TPT . . . . . . . 88

4 Resultados $\quad 93$

4.1 O simporte de lactose $\mathrm{H}^{+} \ldots \ldots \ldots \ldots \ldots$

4.1.1 Condições de contorno . . . . . . . . . . . . . . . . 94

4.1 .2 Comentários e discussão . . . . . . . . . . . . . . . . 98

4.1.3 Reprodução de dados experimentais . . . . . . . . . . 100

4.1.4 Outras curvas de energia livre . . . . . . . . . . . . 101

$4.2 \mathrm{O}$ antiporte de triose-fosfato e $\mathrm{P}_{\mathrm{i}} \ldots \ldots \ldots \ldots \ldots \ldots$

4.2.1 Condições de contorno . . . . . . . . . . . . . . . . . 104 
4.2 .2 Comentários e discussão . . . . . . . . . . . . . . . . 107

5 Conclusão 110

5.1 Considerações gerais . . . . . . . . . . . . . . . . . . . . . 111

5.2 Sobre os resultados . . . . . . . . . . . . . . . . . . . 111

5.2.1 A permease de lactose da Escherichia coli . . . . . . . . . . . . 111

5.2.2 O translocador de triose-fosfato/fosfato . . . . . . . . . . 113

5.3 Sugestões para trabalhos futuros . . . . . . . . . . . . . . . . . . 113

Apêndice A Código Python para a LacY 122

Apêndice B Código Python para o TPT 126 



\section{Capítulo 1}

\section{Introdução}

Neste capítulo, é feita uma contextualização do presente trabalho. Primeiramente, o leitor é esclarecido sobre o que é uma célula através de sua definição, um breve histórico e as principais aplicações da citologia em várias áreas do conhecimento, as quais incluem a biotecnologia, a medicina, e outras. Em seguida, as proteínas de transporte da membrana celular, as quais foram escolhidas para serem abordadas neste trabalho, são brevemente descritas, destacando-se a necessidade de uma descrição probabilística da dinâmica dessas proteínas. Por fim, são apresentados os fundamentos dessa descrição probabilística, a qual é feita por meio da mecânica estatística. 


\subsection{Contextualização do trabalho}

A superfície do planeta Terra é habitada por uma grande diversidade de seres vivos. Nela, encontram-se desde os seres mais simples, como bactérias e fungos, até os mais complexos, como o ser humano. A despeito dessa diversidade, todos os seres vivos, dos mais simples aos mais complexos, possuem pelo menos uma coisa em comum: todos eles são constituídos por células. Esse é o primeiro dos três grandes pilares da Teoria Celular (TC). No próximo item, traçamos um breve histórico e apresentamos os conceitos fundamentais dessa teoria.

\subsubsection{A célula}

Assim como o átomo é a unidade básica da matéria, a célula é a unidade básica da vida. Ela é a menor unidade estrutural e funcional dos organismos vivos que pode existir por conta própria. Existem diversos tipos de células que se distinguem pelas suas formas e funções específicas. A título de exemplo, o ser humano possui as células epiteliais, musculares, ósseas, nervosas, dentre outras. Todas as células possuem três coisas em comum: a membrana celular, que delimita a célula; o citoplasma, que constitui o ambiente intracelular; e o DNA, que armazena toda a informação genética do organismo. Existem duas categorias principais de células: procariontes e eucariontes. As células procariontes, também chamadas de protocélulas, são caracterizadas pela ausência de carioteca, uma estrutura que envolve o núcleo e é responsável por separar o conteúdo nuclear do citosol. Já as células eucariontes possuem membrana nuclear individualizada, além de várias organelas ausentes nas células procariontes, como o retículo endoplasmático, aparelho de Golgi, cloroplasto, e a mitocôndria.

De acordo com o número de células, os seres vivos podem ser divididos em unicelulares e pluricelulares. Os seres unicelulares são constituídos por uma única célula. Seus representantes incluem bactérias, arqueobactérias, protozoários, algas e fungos. Já os seres pluricelulares, que representam a maioria dos seres vivos, são constituídos por mais de uma célula, como é o caso do ser humano, formado por cerca de 37 trilhões de células [1]. Diferente dos organismos unicelulares, onde uma única célula executa todas as funções vitais, nos organismos pluricelulares, várias células se unem para formar tecidos e órgãos, como o tecido nervoso, os ossos, o coração e os pul- 
mões. Assim, cada célula individual exerce um papel importante na manutenção da fisiologia do organismo maior. No caso das células animais, mitocôndrias processam substâncias orgânicas como a glicose, convertendo-as em energia sob a forma de trifosfato de adenosina (ATP, do inglês adenosine triphosphate), que será então usada para a maioria das atividades celulares, incluindo o reparo, crescimento e reprodução das células, e consequentemente do organismo. De modo semelhante, os cloroplastos das células vegetais transformam a luz solar em energia química que a planta usa no seu metabolismo, em um processo conhecido como fotossíntese [2].

A primeira descrição de uma estrutura que foi chamada de célula foi feita em 1665 pelo físico inglês Robert Hooke (1635-1703) em seu livro intitulado Micrographia, uma das primeiras obras onde o microscópio foi aplicado ao estudo dos seres vivos [3]. Nesse livro, Hooke apresenta dezenas de descrições detalhadas, acompanhadas de desenhos, de alguns dos espécimes que ele observou sob o microscópio, como a cabeça de uma mosca, uma pulga, uma formiga, o ferrão de uma abelha, os dentes de um caracol, superfície de folhas, dentre outros [4, 5]. Nele, o autor escreve que viu uma multidão de minúsculos poros ao examinar uma fina seção de um pedaço de cortiça, conforme reproduzimos na Figura 1.1. Ele chamou esses poros de pequenas celas, ou células, pois eles o faziam lembrar das celas habitadas por monges nos mosteiros. Na verdade, o que Hooke havia observado eram apenas as paredes celulares de células vegetais mortas [6]. O primeiro homem a testemunhar uma célula viva sob um microscópio foi o naturalista e microscopista holandês Anton Van Leeuwenhoek (1632 -1723), que em 1674 escreveu sobre as minúsculas formas de vida que havia observado nas águas de um lago. Dois anos mais tarde, em uma carta datada de 9 de outubro de 1676, Leeuwenhoek viria a descrever o que atualmente chamamos de protozoários [7].

Desde a publicação da Micrographia, foram necessários 174 anos para que aparecesse a TC do botânico Matthias Jakob Schleiden (1804-1881) e do fisiologista e anatomista Theodor Schwann (1810 - 1882), ambos alemães, evidenciando a possibilidade de que as células fossem estruturas fundamentais para o processo da vida [8]. Em 1838, Schleiden havia estabelecido, com base em observações de tecidos vegetais, que as diferentes partes de uma planta são constituídas por células ou derivados celulares. No ano seguinte, essa conclusão foi estendida para animais por Schwann, 


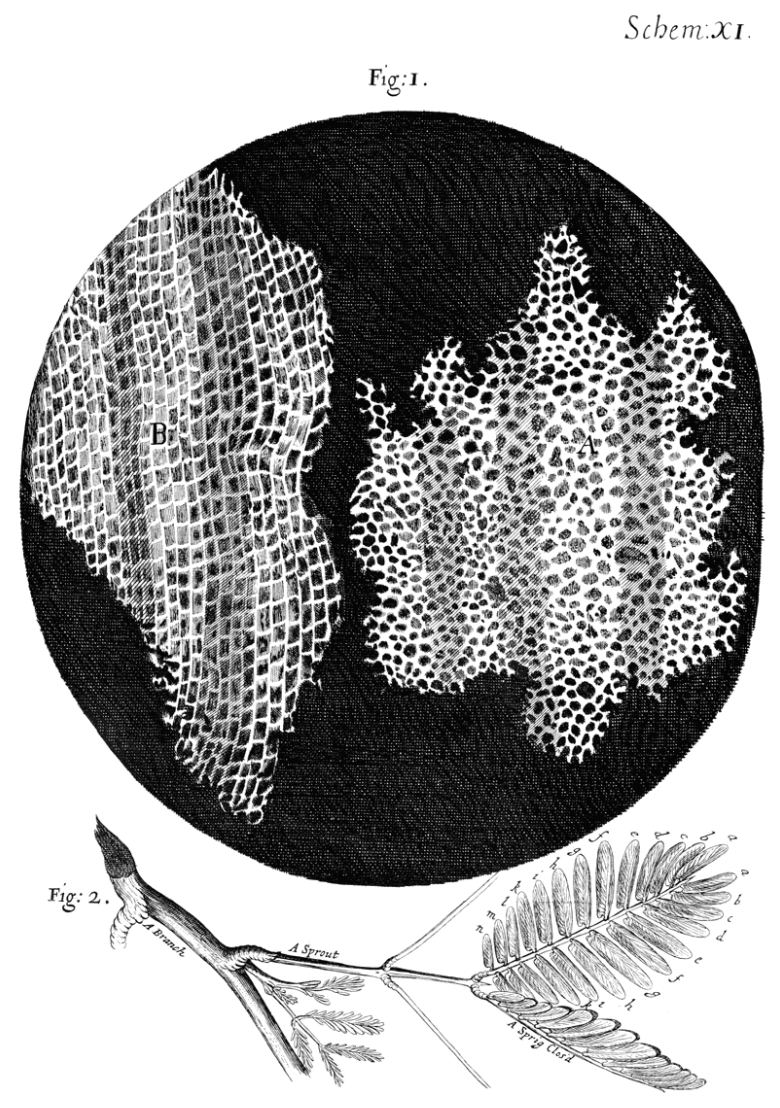

Figura 1.1: Desenho que Robert Hooke apresentou em sua obra Micrographia de um corte fino de cortiça visto sob o microscópio mostrando a multidão de minúsculos poros que ele chamou de células. Fonte: Ref. [3].

ao afirmar que todos os tecidos, vegetais e também animais, são formados por células [9]. As ideias de Schleiden e Schwann deram origem aos dois primeiros pilares da TC, que são: (i) Todos os organismos são constituídos por uma ou mais células; e (ii) A célula é a unidade estrutural da vida. O terceiro pilar viria a ser descoberto somente 19 anos mais tarde pelo patologista alemão Rudolf Ludwig Karl Virchow (1821 - 1902), que em 1858, após um extenso estudo de patologia celular, estabeleceu que: (iii) Uma célula só pode surgir a partir de uma outra célula preexistente. Além desses três grandes pilares, a TC moderna inclui outros quatro pilares, que não serão abordados aqui.

O estudo das células, isto é, a biologia celular, ou citologia, é altamente relevante para várias áreas do conhecimento [10]. Por exemplo, a biotecnologia utiliza técnicas e informações da biologia celular para modificar geneticamente as colheitas e garantir que alimentos de alta qualidade estejam disponíveis a preços acessíveis. Já na medicina, células podem ser usadas para encontrar tratamentos para doenças e mutações, como é o caso das constantes tentativas de se encontrar uma cura para o câncer. 
Além disso, as células podem ser usadas até mesmo na ciência forense para resolver crimes e ajudar a capturar criminosos!

\subsubsection{A membrana celular}

Todas as células possuem em comum uma estrutura chamada membrana celular, ou membrana plasmática, que define a fronteira entre os ambientes intra e extracelular. Essa estrutura está envolvida direta e indiretamente em diversas atividades complexas, como a regulagem dos movimentos transmembranares de solutos para dentro $\mathrm{e}$ para fora da célula, ou as interações da célula com moléculas provenientes do exterior através de receptores específicos, ou ainda os processos de endocitose e exocitose. Além disso, ela também fornece suporte físico para a atividade de enzimas e possibilita o deslocamento de substâncias pelo citoplasma através da formação de pequenas vesículas transportadoras. As organelas no interior das células eucariontes também são envolvidas por membranas semelhantes à membrana celular. A título de exemplo, os cloroplastos das células vegetais possuem nas suas delimitações duas membranas lipoproteicas separadas por um espaço intermembranar. Seria difícil exagerar a importância de todas essas membranas para as células, uma vez que sem elas a vida não poderia existir.

A explicação atualmente aceita para a estrutura da membrana celular é a do modelo do mosaico fluido, que foi proposto em 1972 pelo biólogo celular Seymour J. Singer (1924-2017) e o bioquímico Garth L. Nicolson (1943-) na Universidade da Califórnia, em San Diego [11]. De acordo com esse modelo, os lipídeos que compõem a membrana estão organizados na forma de uma bicamada que se comporta de maneira fluida e na qual diversas proteínas estão inseridas, conforme reproduzimos na Figura 1.2. Na verdade, a organização de qualquer membrana biológica, incluindo as que envolvem as organelas, pode ser explicada por meio do modelo do mosaico fluido. Isso ocorre pois todas elas possuem estruturas muito parecidas, compostas predominantemente por proteínas e lipídeos, sendo que, na maioria das células eucariontes, estes últimos representam cerca de metade da massa total da membrana, o que corresponde a algo entre 50 e 100 moléculas de lipídeos para cada proteína [12, 13]. Além disso, a membrana celular também é constituída por uma pequena quantidade de açúcares na forma de oligossacarídeos [10]. 


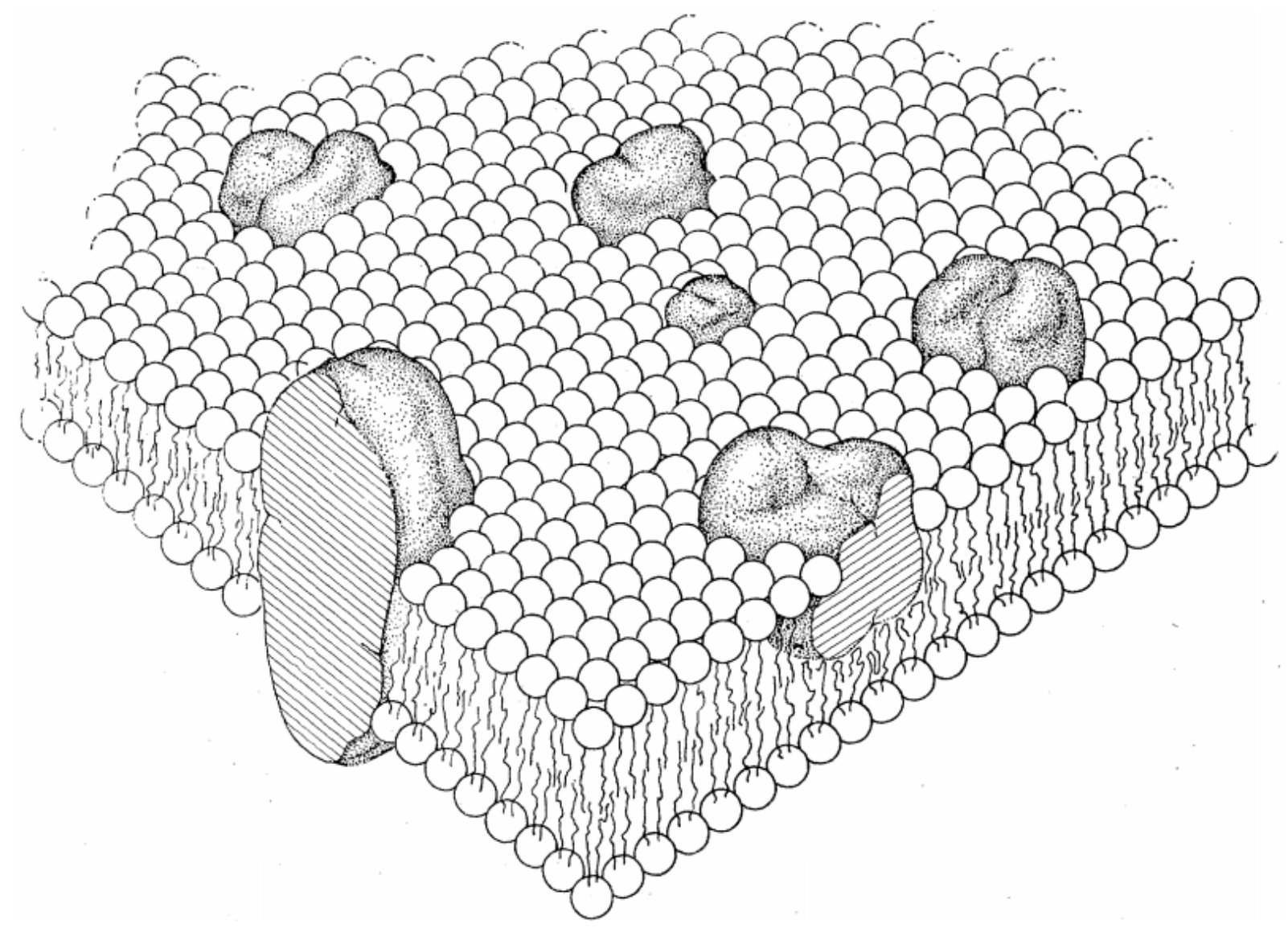

Figura 1.2: Desenho que Seymour J. Singer e Garth L. Nicolson apresentaram em seu artigo The fluid mosaic model of the structure of cell membranes. Nesse desenho, a bicamada lipídica de uma membrana celular é mostrada de forma esquemática. Além disso, também são mostrados exemplos de proteínas periféricas, integrais, e integrais transmembranares. Fonte: Ref. [11].

O modelo de Singer e Nicolson estabelece que os lipídios são os elementos estruturais fundamentais das membranas. Sabe-se que eles são divididos em três classes de lipídios anfipáticos, que são os fosfolipídeos, os glicolipídeos, e o colesterol. Na maioria dos casos, os fosfolipídeos são os mais abundantes, contribuindo com mais de $50 \%$. O colesterol também é um dos principais constituintes da membrana, diferente dos glicolipídeos, que contribuem com apenas cerca de $2 \%$. A estrutura de bicamada do modelo do mosaico fluido é atribuída exclusivamente às propriedades especiais da molécula de fosfolipídeo. Essa molécula possui duas regiões bem distintas: a região da cabeça e a região das caudas, como se pode ver na Figura 1.2. A região da cabeça é hidrofílica e consiste em um grupo fosfato, enquanto que a região das caudas é hidrofóbica e formada por cadeias de ácidos graxos. É essa característica anfipática que faz com que as moléculas de fosfolipídeos, ao entrarem em contato com água, formem 
espontaneamente uma bicamada, de modo que as cabeças hidrofílicas fiquem viradas para o lado exterior da membrana e as caudas hidrofóbicas para o interior. Portanto, a membrana funciona como uma barreira semipermeável para a passagem da maioria das moléculas solúveis em água.

Embora a bicamada lipídica forneça a estrutura básica das membranas celulares, são as proteínas que estão inseridas nela que desempenham a maioria das funções membranares, e que portanto conferem a cada tipo de membrana suas características e propriedades funcionais [14]. Existem duas classes dessas proteínas, que são as proteínas periféricas e as integrais. As proteínas periféricas não estão inseridas no interior hidrofóbico da bicamada fosfolipídica, mas ficam nas regiões superficiais da bicamada ou se associam indiretamente à membrana por meio de interações com as proteínas integrais, e por isso podem ser dissociadas da membrana após tratamentos com reagentes polares que não destroem a bicamada. Já as proteínas integrais estão inseridas no interior da bicamada, de tal modo que elas se encontram firmemente ligadas à membrana e só podem ser extraídas com grande dificuldade. Muitas proteínas integrais são proteínas transmembranares, que abrangem toda a bicamada fosfolipídica com porções expostas em ambos os lados da membrana [13]. As proteínas transmembranares desempenham papéis importantes na fisiologia celular. Por exemplo, algumas delas servem como ligações estruturais que conectam o citoesqueleto à matriz extracelular ou a alguma célula adjacente. Outras servem como receptores para detectar e transduzir sinais químicos no ambiente celular. Além dessas, uma classe específica de proteínas transmembranares, as chamadas proteínas de transporte, atuam no movimento de íons, pequenas moléculas, e até mesmo macromoléculas, tais como outras proteínas, para dentro e para fora das células.

São necessários diversos tipos diferentes de proteínas membranares para o funcionamento normal das células, tanto em suas atividades intracelulares, quanto em suas interações com o ambiente que a cerca. Dentre esses tipos de proteínas, nós escolhemos estudar no presente trabalho as proteínas de transporte da membrana celular, principalmente pelo fato de que elas têm uma importância significativa para a vida da célula, além de possuírem um comportamento interessante do ponto de vista da mecânica estatística, o qual iremos explorar com mais detalhes ao longo do texto. 


\subsection{Proteínas de transporte}

\subsubsection{Visão geral}

Devido ao seu interior hidrofóbico, a bicamada fosfolipídica que compõe a membrana celular possui uma baixa permeabilidade a passagem da maioria das moléculas polares. No entanto, dado tempo suficiente, praticamente qualquer substância seria capaz de atravessar a membrana por difusão simples. O problema é que a taxa de difusão, especialmente a das substâncias polares, pode ser tão baixa, que torna essa travessia impossível na prática. Essa taxa de difusão depende majoritariamente da hidrofobicidade das moléculas, mas depende também do seu tamanho. Por exemplo, pequenas moléculas apolares difundem-se rapidamente através da bicamada, ao passo que a passagem de íons de qualquer tamanho é impedida [14].

Por esse motivo, as células precisam de formas alternativas à difusão simples para movimentar através de suas membranas as moléculas solúveis em água e os íons. Para tanto, são utilizadas as proteínas de transporte da membrana celular, que permitem que uma substância atravesse a bicamada a favor ou contra o seu gradiente de concentração sem entrar em contato direto com o interior hidrofóbico da membrana [15]. Esse gradiente é dado por $\Delta C=C_{c}-C_{p}$, onde $C_{c}$ e $C_{p}$ são as concentrações da substância no citoplasma e periplasma, respectivamente. Tais concentrações estão relacionados com o gradiente de potencial químico, $\Delta \mu$, através de

$$
\Delta \mu=k_{\mathrm{B}} T \ln \left(\frac{C_{\mathrm{C}}}{C_{\mathrm{p}}}\right)
$$

onde $k_{\mathrm{B}}$ é a constante de Boltzmann e $T$ é temperatura $[16,17]$. É importante observar que, diferente da definição usual de gradiente, que é a taxa de variação de uma determinada grandeza em relação à distância, neste trabalho, será chamado de gradiente a diferença de uma propriedade física ou química entre o citoplasma e o periplasma da célula.

As proteínas de transporte podem ser divididas em duas classes principais: as proteínas de canal e as proteínas carregadoras, conforme mostra a Figura 1.3. As proteínas de canal formam poros estreitos altamente seletivos que se estendem através da bicamada e que se abrem transitoriamente em resposta a um estímulo específico, 


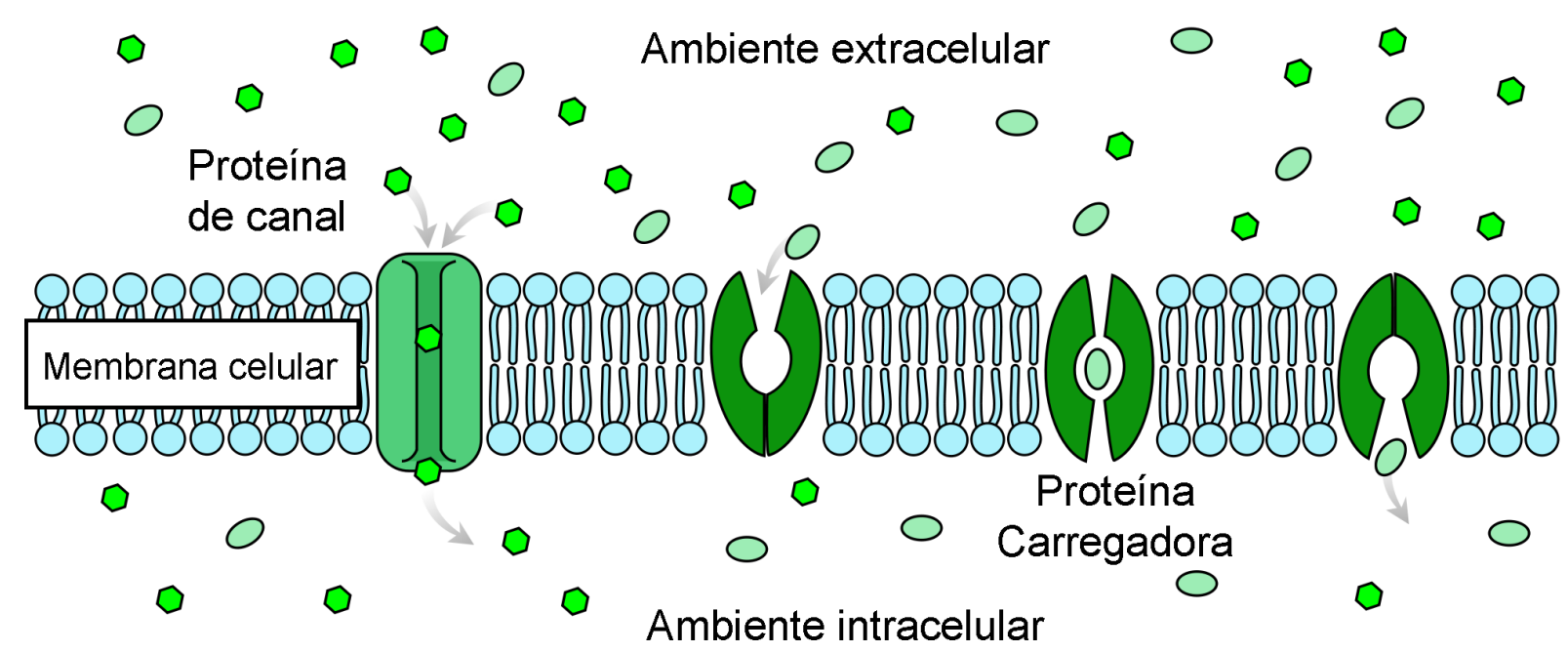

Figura 1.3: Difusão facilitada através da membrana celular. Na esquerda, uma proteína de canal transportando partículas para dentro da célula é mostrada. Na direita, veemse proteínas carregadoras em três conformações diferentes.

permitindo o movimento de solutos para dentro ou para fora da célula [18]. Já as proteínas carregadoras, também chamadas de permeases, possuem sítios de ligação onde um soluto específico a ser transportado se liga, levando a uma série de mudanças na conformação da proteína para transferir o soluto através da membrana.

Todas as proteínas de canal, além de muitas das proteínas carregadoras, permitem que os solutos atravessem a membrana unicamente a favor de seus gradientes de concentração, em um processo conhecido como difusão facilitada, que não requer energia além daquela armazenada no próprio gradiente. Na verdade, como quase todas as membranas celulares possuem uma diferença de potencial elétrico $\Delta \Psi$ através delas, o gradiente de concentração, ou gradiente químico, e o gradiente elétrico transmembranar,

$$
\Delta \mu_{\Psi}=e \Delta \Psi,
$$

se combinam para formar uma força motriz líquida que determina a direção do transporte, o chamado gradiente eletroquímico, dado por

$$
\Delta \tilde{\mu}=\Delta \mu+\Delta \mu_{\Psi} .
$$

Aqui, e é a carga elementar. Em contraste com a difusão facilitada, diversas proteínas carregadoras fazem uso de alguma forma de energia química para catalisar o transporte de solutos no sentido contrário ao de seus gradientes de concentração. Esse 


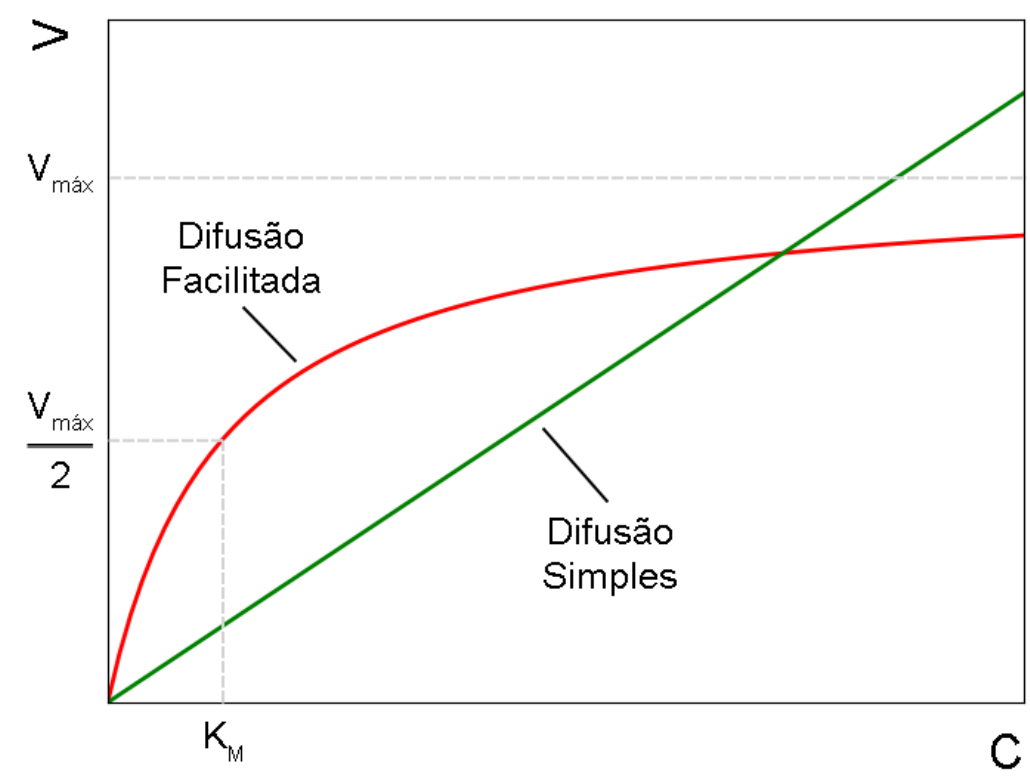

Figura 1.4: Difusão simples versus difusão facilitada. No caso da difusão simples, a taxa de transporte $V$ é sempre proporcional à concentração do substrato $C$, enquanto que na difusão facilitada, essa taxa é governada pela equação de Michaelis-Menten [19].

transporte é denominado transporte ativo, e geralmente está associado ao acúmulo de altas concentrações de moléculas que a célula necessita, como íons e aminoácidos. Um exemplo de proteína carregadora que faz esse tipo de transporte é o trocador de sódio/cálcio (NCX), que remove $\mathrm{Ca}^{2+}$ das células usando a energia armazenada no gradiente eletroquímico de $\mathrm{Na}^{+}$.

Diferente da difusão simples, onde a taxa de transporte $V$ é sempre proporcional à concentração do substrato sendo transportado, $C$, na difusão facilitada, a taxa $V$ atinge um valor máximo, $V_{\text {máx }}$, quando o transportador está saturado, isto é, quando a concentração do substrato é alta. Essa taxa é governada pela cinética de MichaelisMenten, dada pela equação [19]

$$
V=\frac{V_{\text {máx }} C}{K_{M}+C}
$$

onde $K_{\mathrm{M}}$ é a constante de Michaelis-Menten, que equivale à concentração do substrato quando $V$ atinge metade de $V_{\text {máx }}$. Um $K_{M}$ baixo implica em uma alta afinidade entre a proteína de transporte e o substrato. Na Figura 1.4, é apresentada uma comparação entre as taxas de transporte da difusão simples e da difusão facilitada como função da 


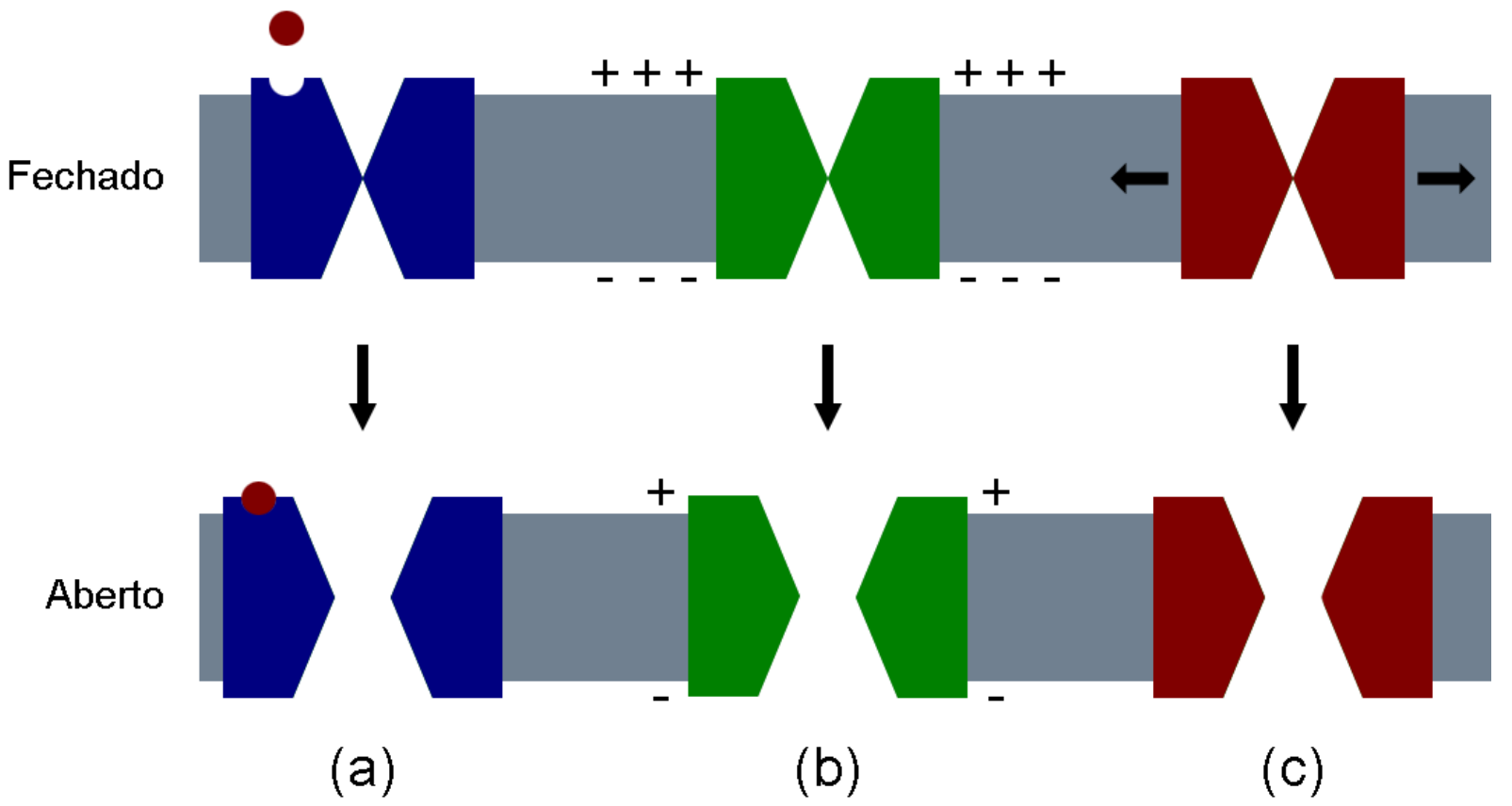

Figura 1.5: Os três principais tipos de estímulo que causam a abertura de canais iônicos. Esses estímulos são: (a) A ligação de um ligante; (b) Uma mudança na voltagem através da membrana; e (c) Um estresse mecânico.

concentração do substrato.

\subsubsection{Proteínas de canal}

As proteínas de canal da membrana plasmática, que muitas vezes são chamadas de canais iônicos por lidarem com o transporte de íons inorgânicos, consistem em poros hidrofílicos que conectam o citosol ao exterior da célula e que podem se abrir ou se fechar em resposta a um determinado estímulo. Elas são uma classe amplamente difundida de proteínas membranares que medeiam diversos fenômenos fisiológicos fundamentais para a vida da célula, como o controle do batimento cardíaco e, portanto, de todas as formas de contração muscular; ou a regulação da pressão arterial; ou ainda a recepção sensorial de sons, luzes e odores, além da geração e propagação de todos os sinais elétricos no cérebro; dentre outros [20]. A função desses canais é permitir que íons específicos, principalmente $\mathrm{Na}^{+}, \mathrm{K}^{+}, \mathrm{Ca}^{2+}$, ou $\mathrm{Cl}^{-}$, difundam-se rapidamente através da bicamada fosfolipídica. Essa difusão ocorre espontaneamente a favor do gradiente eletroquímico do íon, fornecendo carga líquida para a célula e, consequentemente, alterando a voltagem da membrana. 
Existem duas propriedades que distinguem uma proteína de canal de um simples poro aquoso. A primeira propriedade é a seletividade iônica, que faz com que um determinado canal permita a passagem de alguns íons, mas bloqueie a passagem de outros. A segunda propriedade é a de que os canais não estão continuamente abertos, mas funcionam como uma espécie de portão que se abre mediante um estímulo e então se fecha novamente, uma característica que lembra as portas automáticas utilizadas em edifícios comerciais. Os canais iônicos podem ser classificados pelo tipo de estímulo que causa a abertura do mesmo, sendo que os três principais estímulos são: a ligação de um ligante; uma mudança na voltagem através da membrana; ou um estresse mecânico, conforme mostra a Figura 1.5 [2].

\subsubsection{Proteínas carregadoras}

Diferente dos canais iônicos, as proteínas carregadoras que catalisam o transporte ativo estão acopladas a uma fonte de energia que é usada para transportar um determinado soluto na contramão do seu gradiente eletroquímico. Esse tipo de transporte se assemelha a uma reação enzimática, e de muitas maneiras os carregadores se comportam como enzimas. Por causa disso, muitas vezes dizemos que as proteínas carregadoras "catalisam" o movimento de substratos através da membrana plasmática.

O transporte ativo pode ser dividido em dois tipos: transporte ativo primário e transporte ativo secundário. A principal diferença entre eles está no tipo de fonte energética acoplada.

Os transportadores ativos primários usam ATP como fonte de energia para mover moléculas através da membrana celular, e, por isso, são conhecidos como ATPases. Eles hidrolisam ATP em difosfato de adenosina (ADP, do inglês adenosine diphosphate) e fosfato inorgânico $\left(P_{i}\right)$, liberando no processo energia utilizável. Um dos exemplos mais importantes de transportador ativo primário é a bomba de sódio/potássio, ou $\mathrm{Na}^{+} / \mathrm{K}^{+}$ATPase, que é responsável por manter os gradientes de concentração dos íns de sódio e potássio através da membrana. O transporte desses íons ocorre de tal modo que são bombeados três $\mathrm{Na}^{+}$para fora e dois $\mathrm{K}^{+}$para dentro da célula a cada ATP consumido. O ciclo de transporte dessa bomba está ilustrado na Figura 1.6.

Esse ciclo começa com a proteína na conformação voltada-para-dentro $\left(\mathrm{C}_{\text {dentro }}\right)$. Nessa conformação, ela possui uma grande afinidade por $\mathrm{Na}^{+}$, fazendo com que três 


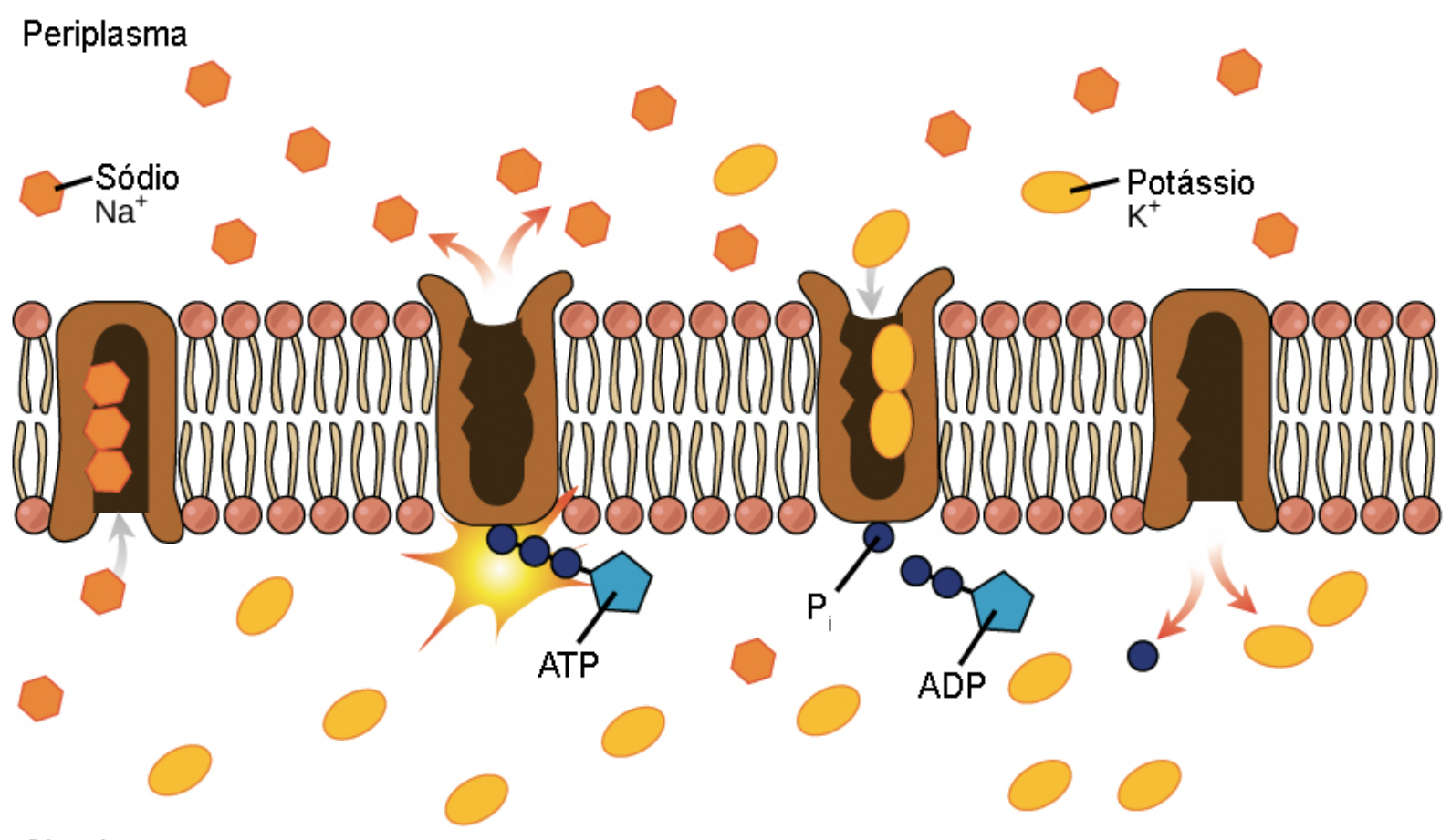

Citoplasma

Figura 1.6: $\mathrm{O}$ ciclo de transporte da bomba de sódio/potássio. Íons de sódio $\left(\mathrm{Na}^{+}\right)$e íons de potássio $\left(\mathrm{K}^{+}\right)$são ilustrados como hexágonos laranjas e elipses amarelas, respectivamente. Também estão indicados o ATP, ADP e grupo fosfato. Fonte: modificado da Ref. [21].

íns de sódio se liguem nela. Após essas ligações, ocorre a hidrólise do ATP, sendo que um $\mathrm{P}_{\mathrm{i}}$ fica ligado à bomba. Isso faz com que a proteína mude para a conformação voltada-para-fora $\left(\mathrm{C}_{\mathrm{fora}}\right)$ e libere os três íons de sódio no periplasma. Então, dois íons $\mathrm{K}^{+}$se ligam à permease, causando a liberação do $\mathrm{P}_{\mathrm{i}}$ no interior da célula, e fazendo a proteína retornar para a conformação $C_{\text {dentro }}$. Por último, os dois íons de potássio são liberados no citoplasma, encerrando assim o ciclo de transporte. Outros exemplos igualmente importantes de transportadores ativos primários são a bomba de prótons, - $\mathrm{Ca}^{2+}$ ATPase, dentre outros.

No transporte ativo secundário, que também é conhecido como transporte acoplado, ou cotransporte, não há um acoplamento direto com o ATP, mas a permease usa o gradiente eletroquímico criado pelo bombeamento de um determinado íon, frequentemente $\mathrm{oH}^{+}$, para dentro ou para fora da célula como fonte de energia para mover moléculas através da membrana celular. Esse transporte pode ser de dois tipos, a saber, um simporte ou um antiporte. As proteínas simportadoras fazem uso do movimento de um soluto a favor do seu gradiente eletroquímico para transportar um 


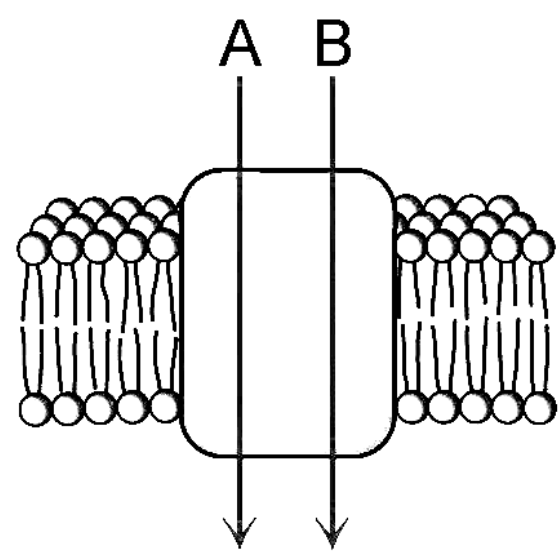

Simporte

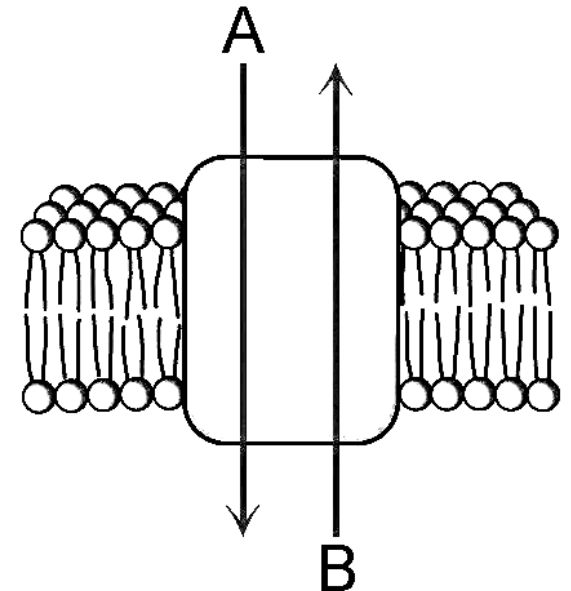

Antiporte

Figura 1.7: Os dois tipos de transporte ativo secundário. Na esquerda, mostramos uma proteína simportadora, que transporta ambos os solutos na mesma direção. $\mathrm{Na}$ direita, vê-se uma proteína antiportadora transportando dois solutos em direções opostas. Fonte: modificado da Ref. [22].

outro soluto contra o seu gradiente e na mesma direção, ou seja, ambos os solutos são transportados ou para dentro, ou para fora da célula. Por sua vez, as proteínas antiportadoras catalisam o transporte de solutos em direções opostas, conforme está esquematizado na Figura 1.7. Um exemplo de uma proteína simportadora é a permease de lactose da Escherichia coli (LacY), que faz o transporte de lactose usando a energia armazenada em um gradiente eletroquímico de prótons. Já um exemplo de proteína antiportadora é o translocador de triose-P/P $\mathrm{P}_{\mathrm{i}}(\mathrm{TPT})$, que exporta triose-fosfato (TP) do cloroplasto das células vegetais mediante a importação de fosfato inorgânico.

Qualquer processo de transporte através da membrana celular é um processo que envolve um número grande de moléculas interagindo, e, consequentemente, uma descrição probabilística se faz necessária [23]. A ferramenta adequada para fazer essa descrição é a mecânica estatística, que vem sendo usada para a reproduzir a dinâmica de uma série de sistemas biológicos $[24,25,26]$. Por isso, no próximo item, abordamos os fundamentos da mecânica estatística, bem como algumas aplicações que serão úteis ao longo do nosso trabalho. 


\subsection{Mecânica estatística de sistemas biológicos}

\subsubsection{Conceitos básicos}

A modelagem científica de um sistema biológico consiste em uma simplificação do fenômeno real, na qual são consideradas apenas as características fundamentais e essenciais do problema, sendo as demais características abstraídas. Por isso, o desenvolvimento de um modelo começa com a reunião de uma série de fatos a respeito do sistema biológico em questão, e neste ponto é preciso ater-se aos fatos que foram repetidamente confirmados por décadas de experimentação. Em particular, no campo da biofísica, esses modelos científicos precisam fornecer previsões quantitativas experimentalmente testáveis sobre os fenômenos biológicos.

Muitos desses fenômenos envolvem um grande número de moléculas interagindo, como é o caso dos processos de transporte através da membrana plasmática. A mecânica estatística é a ferramenta adequada para descrever esse tipo de fenômeno. Nela, as funções de estado de um sistema termodinâmico são interpretadas através do conceito de microestados que são compatíveis com um dado macroestado. Um microestado consiste na especificação detalhada de uma configuração microscópica de um sistema, ou, em outras palavras, um microestado é um ponto do espaço de fase do sistema [27]. Por sua vez, um macroestado é identificado por um conjunto particular de parâmetros macroscópicos, como por exemplo a energia, o número de partículas e o volume para um sistema isolado. Os microestados compatíveis com um dado macroestado são as diferentes possibilidades pelas quais o sistema pode alcançar esse macroestado.

Para introduzir o conceito de microestado na prática, iremos abordar o mesmo exemplo dado pela Ref. [23], que é o exemplo da ligação ligante-receptor, conforme mostra a Figura 1.8. Essa figura ilustra um modelo desse sistema biológico, no qual $L$ ligantes em solução estão na presença de um receptor, onde um único ligante pode se ligar por vez. Nesse modelo, a solução é dividida em uma rede de $\Omega$ células, ou minúsculas caixas, cujo volume é da mesma ordem de grandeza do volume do ligante. Cada uma dessas caixas pode conter, no máximo, um ligante por vez, isto é, as caixas determinam as posições que os ligantes podem ocupar. Neste caso, um microestado do sistema corresponde a um determinado arranjo dos $L$ ligantes livres na solução 
(a)

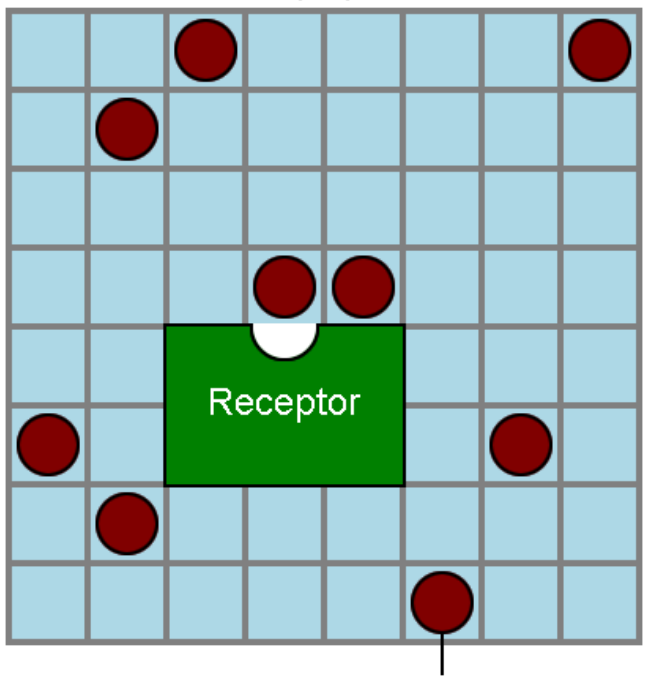

Ligante (b)

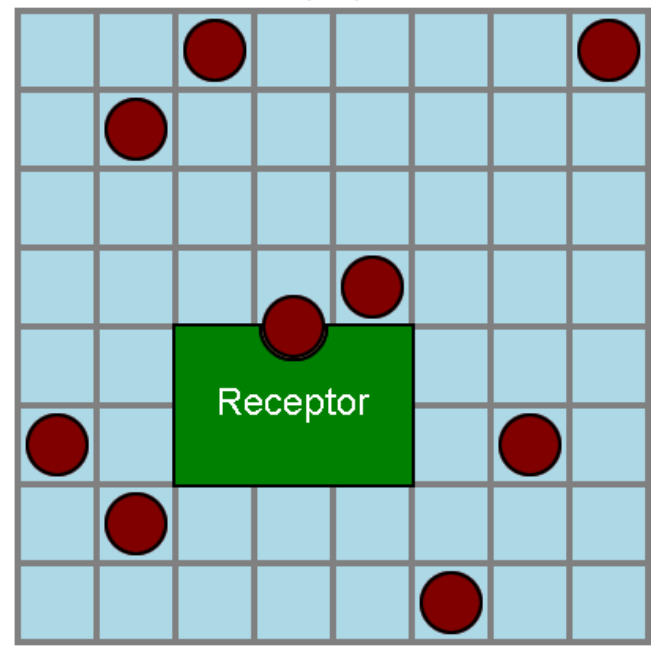

Figura 1.8: Modelo simplificado da ligação ligante-receptor. (a) Possível microestado com o receptor desocupado. (b) Possível microestado com o receptor ocupado.

com o receptor desocupado, conforme mostra a Figura 1.8 (a), ou um arranjo de $L-1$ ligantes livres com o receptor ocupado, conforme mostra a Figura 1.8 (b). No primeiro caso, isto é, quando o receptor está desocupado, o número total de microestados é

$$
\text { número de microestados com o receptor desocupado }=\frac{\Omega !}{L !(\Omega-L) !},
$$

enquanto que, no segundo caso, quando o receptor está ocupado, esse número é

$$
\text { número de microestados com o receptor ocupado }=\frac{\Omega !}{(L-1) !(\Omega-L+1) !} .
$$

O número total de microestados acessíveis ao sistema é igual a soma do número de microestados com o receptor desocupado e com o receptor ocupado.

A mecânica estatística nos dá a probabilidade de um sistema estar em um determinado microestado $i$ com energia $E_{i}$ como sendo

$$
P\left(E_{i}\right)=\frac{1}{Z} \exp \left(-\beta E_{i}\right)
$$

onde $\beta=\left(k_{\mathrm{B}} T\right)^{-1}$ é a temperatura inversa, e $Z$ é a função de partição canônica, definida pela exigência de que, quando somamos todas as probabilidades, o resultado 
é 1 , o que resulta em

$$
Z=\sum_{i} \exp \left(-\beta E_{i}\right) .
$$

Uma vez que a função de partição é conhecida, pode-se calcular diversos observáveis importantes, como por exemplo a energia livre de Gibbs, dada por $G=-k_{\mathrm{B}} T \ln Z$.

Retomando o exemplo da ligação ligante-receptor, vamos calcular a probabilidade de que o receptor esteja ocupado por um ligante, $P_{\text {oc }}$. Para isso, considere que a energia de um ligante livre na solução é $\varepsilon_{\text {liv }}$, e que a energia de um ligante ligado ao

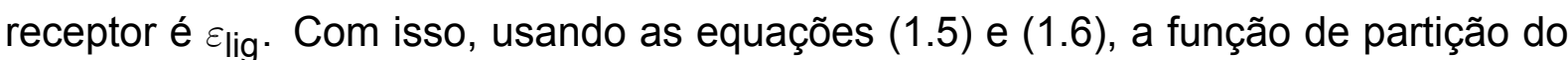
sistema fica

$$
Z=\frac{\Omega^{L}}{L !} \exp \left(-\beta L \varepsilon_{\text {liv }}\right)+\frac{\Omega^{L-1}}{(L-1) !} \exp \left\{-\beta\left[(L-1) \varepsilon_{\text {liv }}+\varepsilon_{\text {lig }}\right]\right\}
$$

onde utilizamos a aproximação $\Omega ! /(\Omega-L) ! \approx \Omega^{L}$, válida para $\Omega \gg L$. Assim, substituindo a Equação (1.9) na Equação (1.7) e somando sobre todos os microestados nos quais o receptor está ocupado, obtemos

$$
P_{\mathrm{oc}}=\frac{(L / \Omega) e^{-\beta \Delta \varepsilon}}{1+(L / \Omega) e^{-\beta \Delta \varepsilon}},
$$

onde definimos $\Delta \varepsilon=\varepsilon_{\text {lig }}-\varepsilon_{\text {liv }}$.

Com o intuito de dar uma noção do comportamento de $P_{\mathrm{oc}}$, nós apresentamos na Figura 1.9 essa probabilidade como função de $L / \Omega$ para três valores diferentes de $\Delta \varepsilon$. Esse resultado clássico pode ser aplicado a uma série de problemas que envolvem a ligação de ligantes a um receptor. No nosso caso, iremos usar ele para calcular a probabilidade de que haja um soluto próximo da entrada da proteína carregadora disponível para ser capturado, П. Para fazer isso, vamos expandir o lado direito da Equação (1.10) em uma série de Maclaurin e reter apenas o termo linear, uma vez que, nas nossas simulações, $L / \Omega \ll 1$. Assim, temos que

$$
P_{\mathrm{oc}} \approx \frac{L}{\Omega} e^{-\beta \Delta \varepsilon} .
$$

Na equação acima, $\exp (-\beta \Delta \varepsilon)$ é o chamado fator de Boltzmann, que abordaremos em detalhes na Seção 3.2.4, e $L / \Omega$ é a probabilidade П que estamos procurando, isto 


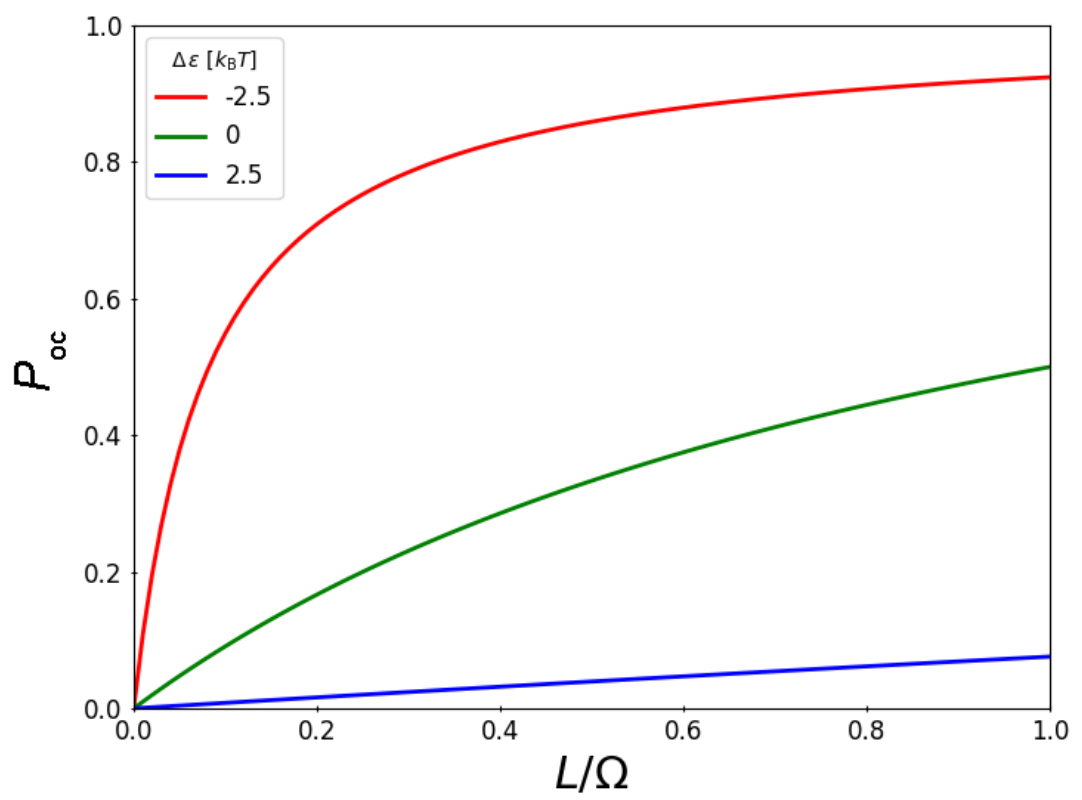

Figura 1.9: Probabilidade de que o receptor esteja ocupado, $P_{\text {oc }}$, como função da razão entre o número de ligantes $L$ e o número total de caixas da rede $\Omega$. $O$ gráfico mostra curvas para três valores de $\Delta \varepsilon,-2.5,0$ e $2.5 k_{\mathrm{B}} T$.

é,

$$
\Pi=\frac{L}{\Omega},
$$

o que indica que essa probabilidade é proporcional à concentração do soluto, algo bastante intuitivo.

\subsubsection{Introdução ao problema do caminho aleatório}

Como será visto mais adiante, a dinâmica dos transportadores ativos secundários que iremos estudar no presente trabalho é similar à dinâmica do caminho aleatório, que é um dos problemas clássicos da mecânica estatística [28]. Esse problema consiste em um partícula que se desloca ao longo de um eixo a partir da origem dando passos de comprimento $\ell$ para a direita com probabilidade $p$, ou passos de mesmo comprimento para a esquerda com probabilidade $q=1-p$, conforme está esquematizado na Figura 1.10. O objetivo desse problema é calcular a probabilidade $P_{n}(m)$ de que a partícula se encontre na posição $x=m \ell$ depois de ter dado $n$ passos, onde $m$ é um inteiro que pertence ao conjunto $[-n, n]$.

Para calcularmos essa probabilidade, sabe-se que, em uma determinada sequen- 


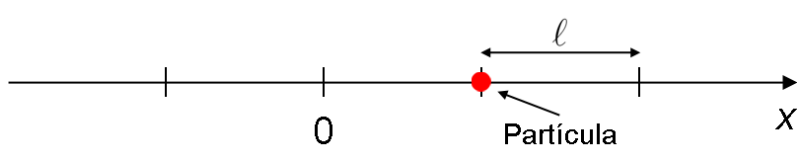

Figura 1.10: O problema do caminho aleatório, no qual um indivíduo se desloca a partir da origem ao longo do eixo $x$ com passos de comprimento $\ell$.

cia de $n$ passos, a probabilidade de que a partícula tenha dado $n_{>}$passos para a direita e $n_{<}=n-n_{>}$passos para a esquerda é $p^{n_{>}} q^{n_{<}}$. Além disso, o número de sequências possíveis é igual a $n ! /\left(n_{>} ! n_{<} !\right)$. Com isso, em qualquer sequência de $n$ passos, a probabilidade de que a partícula tenha dado $n_{>}$passos para a direita e $n_{<}$passos para a esquerda é dada por

$$
P_{n}\left(n_{>}\right)=\frac{n !}{n_{>} !\left(1-n_{>}\right) !} p^{n_{>}} q^{1-n_{>}},
$$

que é a distribuição binomial. Então, como $m=n_{>}-n_{<}$, obtemos a probabilidade $P_{n}(m)$ como sendo

$$
P_{n}(m)=\frac{n !}{\left(\frac{n+m}{2}\right) !\left(\frac{n-m}{2}\right) !} p^{(n+m) / 2} q^{(n-m) / 2} .
$$

Note que $P_{n}(m)$ já está devidamente normalizada, uma vez que

$$
\sum_{m=-n}^{n} P_{n}(m)=\sum_{n_{>}=0}^{n} \frac{n !}{n_{>} !\left(1-n_{>}\right) !} p^{n_{>}} q^{1-n_{>}}=(p+q)^{n}=1 .
$$

O problema do caminho aleatório também pode ser formulado em termos de uma relação de recorrência. Para fazer isso, suponha que cada passo seja dado em um intervalo de tempo $\tau$, de tal modo que a probabilidade $P_{n}(m)$ é a probabilidade de que a partícula seja encontrada na posição $m \ell$ no instante de tempo $t=n \tau$. Dessa forma, sabendo que, para atingir a posição $m \ell$ no tempo $(n+1) \tau$, a partícula deve estar, no tempo $n \tau$, ou na posição $(m+1) \ell$, ou na posição $(m-1) \ell$, temos a seguinte relação de recorrência:

$$
P_{n+1}(m)=p P_{n}(m-1)+q P_{n}(m+1) .
$$

Essa relação nos mostra que, no problema do caminho aleatório, a probabilidade de encontrar a partícula em uma determinada posição em um dado instante de tempo 
depende apenas de probabilidades do instante imediatamente anterior. Os problemas que apresentam essa propriedade são conhecidos como cadeias de Markov, as quais são altamente relevantes em uma série de aplicações biológicas. O formalismo matemático das cadeias de Markov será visto mais adiante neste trabalho.

A partir da probabilidade $P_{n}\left(n_{>}\right)$expressa na Equação (1.13), pode-se calcular o valor esperado da posição da partícula. Para isso, temos

$$
\begin{aligned}
\left\langle n_{>}\right\rangle & =\sum_{n_{>}=0}^{n} n_{>} P_{n}\left(n_{>}\right)=\sum_{n_{>}=0}^{n} n_{>} \frac{n !}{n_{>} !\left(1-n_{>}\right) !} p^{n_{>}} q^{1-n_{>}}= \\
& =p \frac{\partial}{\partial p} \sum_{n_{>}=0}^{n} \frac{n !}{n_{>} !\left(1-n_{>}\right) !} p^{n_{>}} q^{1-n_{>}}=p \frac{\partial}{\partial p}(p+q)^{n}= \\
& =p n(p+q)^{n-1}=p n .
\end{aligned}
$$

De modo análogo, é possível mostrar que $\left\langle n_{<}\right\rangle=q$ n. Com isso, o valor esperado que procuramos fica $\langle x\rangle=v_{\mathrm{m}} t$, onde $v_{\mathrm{m}}=\ell(p-q) / \tau$ é a velocidade média da partícula. Além disso, com o objetivo calcular a variância da posição, temos

$$
\begin{aligned}
\left\langle n_{>}^{2}\right\rangle & =\sum_{n_{>}=0}^{n} n_{>}^{2} P_{n}\left(n_{>}\right)= \\
& =\left(p \frac{\partial}{\partial p}\right)\left\{\left(p \frac{\partial}{\partial p}\right)\left[\sum_{n_{>}=0}^{n} \frac{n !}{n_{>} !\left(1-n_{>}\right) !} p^{n_{>}} q^{1-n_{>}}\right]\right\}= \\
& =\left(p \frac{\partial}{\partial p}\right)\left\{p n(p+q)^{n-1}\right\}=p n+p^{2}(n-1) n
\end{aligned}
$$

e

$$
\left\langle n_{>} n_{<}\right\rangle=n\left\langle n_{>}\right\rangle-\left\langle n_{>}^{2}\right\rangle=p q(n-1) n .
$$

Dessa forma, a variância fica $\sigma_{x}^{2}=\left\langle x^{2}\right\rangle-\langle x\rangle^{2}=D t$, onde $D=4 \ell^{2} p q / \tau$ é o coeficiente de difusão. 
(a) Transporte ativo

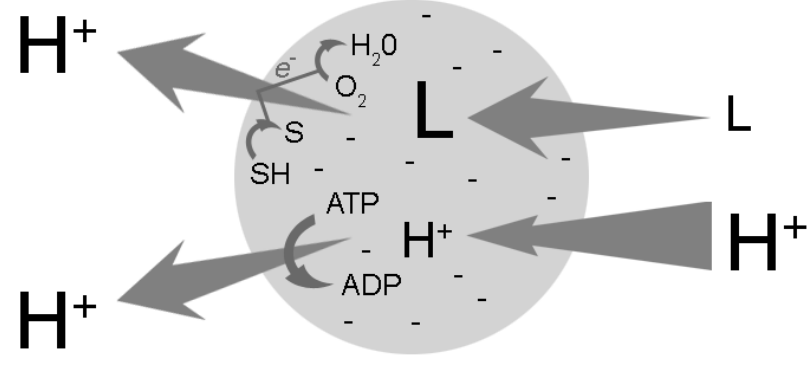

(b) Influxo

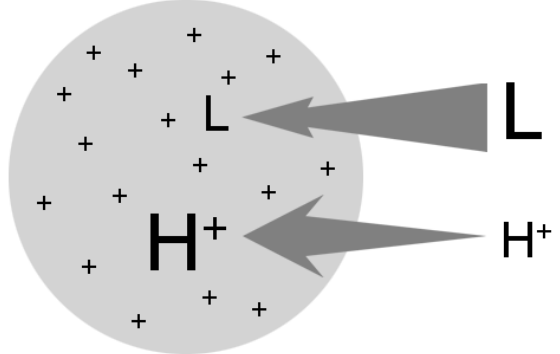

(c) Efluxo

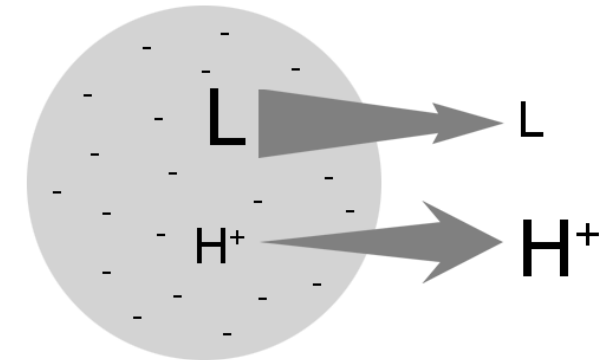

Figura 1.11: Reações de transporte catalisadas pela LacY. (a) Transporte ativo de lactose, L, contra o seu gradiente de concentração em resposta a um gradiente eletroquímico de prótons gerado tanto pela respiração de $\mathrm{H}^{+}$, como pela hidrólise do ATP. (b) e (c) Na ausência de $\Delta \tilde{\mu}_{\mathrm{H}^{+}}$, o gradiente de concentração de lactose gera um gradiente eletroquímico de $\mathrm{H}^{+}$, cuja polaridade depende do sinal de $\Delta \mu_{\mathrm{L}}$.

\subsection{Proposta deste trabalho}

\subsubsection{Considerações gerais}

A mecânica estatística ocupa um espaço importante na modelagem de diversos sistemas biológicos. Assim, optou-se neste trabalho por desenvolver um modelo de Monte Carlo (MC) para o transporte ativo secundário. Para que o nosso estudo seja representativo, iremos trabalhar com uma proteína simportadora e uma antiportadora. A proteína simportadora que escolhemos foi a LacY, que é responsável pelo simporte de lactose $\mathrm{e}^{+}$através da membrana plasmática, conforme mencionado anteriormente. A proteína antiportadora que iremos estudar é o TPT, que faz o antiporte de TP e $P_{i}$ através da membrana interna dos cloroplastos. A seguir, apresentamos o funcionamento básico dessas duas proteínas de transporte. 


\subsubsection{O simporte de lactose e $\mathrm{H}^{+}$}

A permease de lactose da E. coli, ou simplesmente LacY, é uma proteína de transporte que facilita a passagem de lactose, um dos nutrientes essenciais para todas as formas de vida, através da bicamada fosfolipídica da membrana celular [29, 30]. As reações de transporte catalisadas pela LacY são mostradas na Figura 1.11. Ela usa a energia livre armazenada em um gradiente eletroquímico de prótons, $\Delta \tilde{\mu}_{\mathrm{H}^{+}}$, para transportar $\beta$-galactosídeos, como a lactose, contra o seu gradiente de concentração, conforme mostra a Figura 1.11 (a). Além disso, como o acoplamento entre a translocação da lactose e do $\mathrm{H}^{+}$é obrigatória, na ausência de $\Delta \tilde{\mu}_{\mathrm{H}^{+}}$, a LacY usa a energia livre armazenada no gradiente de concentração de lactose para transportar $\mathrm{H}^{+}$com a geração de $\Delta \tilde{\mu}_{\mathrm{H}^{+}}$, cuja polaridade depende do sinal de $\Delta \mu_{\mathrm{L}}$. Como é possível ver na Figura 1.11, quando o sinal desse gradiente é negativo, $\Delta \tilde{\mu}_{\mathrm{H}^{+}}$aponta do periplasma para o citoplasma, e ocorre o influxo de lactose, conforme mostra a Figura 1.11 (b). Por outro lado, quando o sinal é positivo, $\Delta \tilde{\mu}_{\mathrm{H}^{+}}$aponta no sentido inverso, e o efluxo de lactose ocorre, conforme mostra a Figura 1.11 (c).

A LacY é um membro intensivamente estudado da superfamília dos facilitadores majoritários (MFS, do inglês major facilitator superfamily), uma superfamília que atualmente contêm mais de 1000 membros [32, 33]. Um dos grandes interesses por trás desses estudos se deve ao fato de que o mecanismo da LacY é representativo para as demais proteínas de transporte da MFS. Por isso, não é exagero afirmar que podemos estudar o comportamento das proteínas simportadoras em geral usando a LacY como um paradigma. A Figura 1.12 mostra um esquema cinético simplificado para o simporte de lactose e $\mathrm{H}^{+}$. Conforme será discutido em detalhes posteriormente, esse simporte começa com a protonação da LacY (Passo 1). Após isso, a ligação da lactose à LacY protonada (Passo 2) provoca uma mudança conformacional para a conformação $C_{\text {dentro }}$ (Passo 3). Então, a lactose é liberada no citoplasma (Passo 4), seguida pelo $\mathrm{H}^{+}$(Passo 5). Por último, a LacY retorna para a conformação $\mathrm{C}_{\text {fora }}$ (Passo 6), encerrando assim o ciclo de transporte. 


\section{Citoplasma Periplasma}

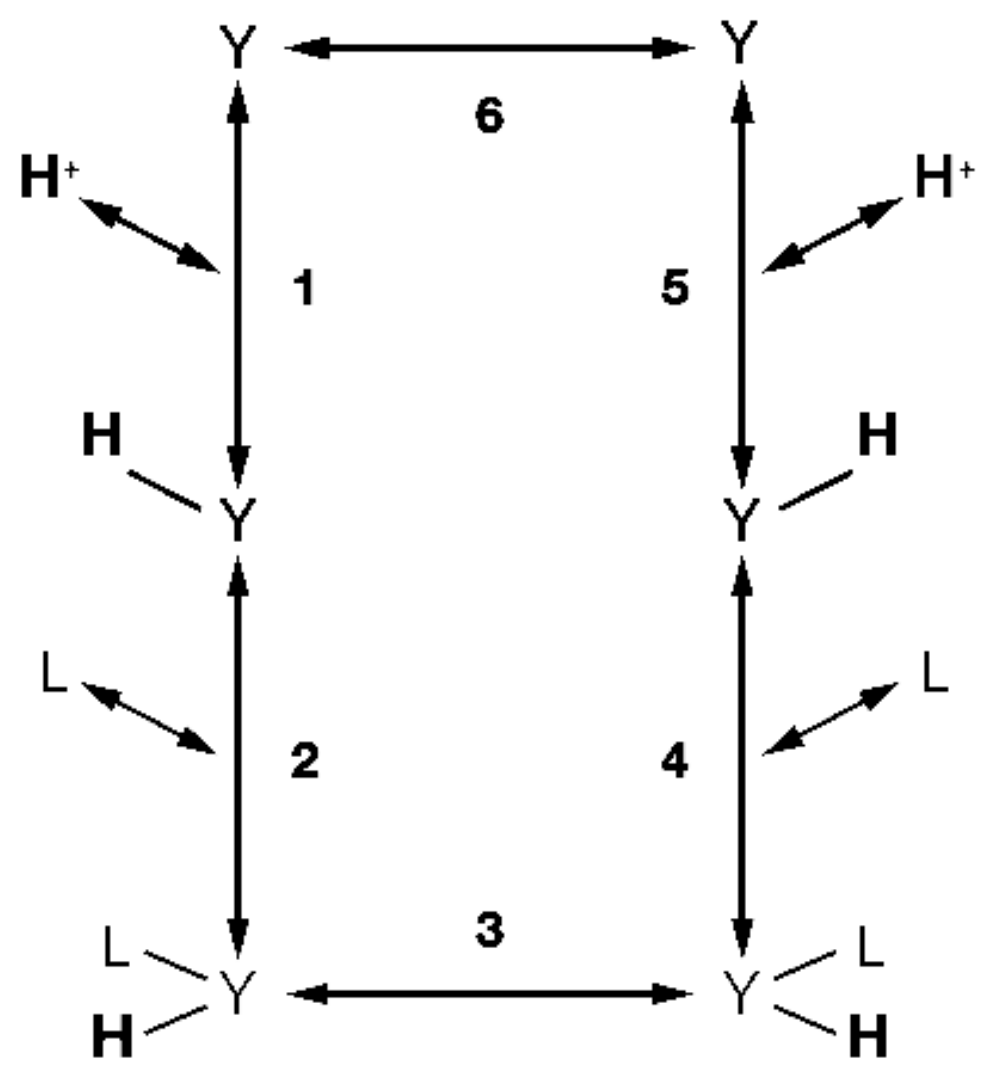

Figura 1.12: Esquema cinético simplificado para o simporte de lactose e $\mathrm{H}^{+}$. Aqui, $\mathrm{Y}$ representa a LacY, e L a lactose. Fonte: modificado da Ref. [31].

\subsubsection{O antiporte de triose-fosfato e $P_{i}$}

O translocador de triose-fosfato/fosfato, ou simplesmente TPT, exporta TP produzida pela fotossíntese e importa ou 3-fosfoglicerato (3-PGA), ou fosfato inorgânico, através da membrana interna dos cloroplastos, conforme reproduzimos na Figura 1.13 $[35,36,37]$. O TPT contribui para a fixação eficiente de carbono e o crescimento da planta, além de desempenhar um papel crucial na fotossíntese [38, 39, 40]. Ele usa a energia livre armazenada em um gradiente de concentração de $\mathrm{P}_{\mathrm{i}}, \Delta \mu_{P_{\mathrm{i}}}$, para transportar TP contra o seu gradiente de concentração.

A Figura 1.14 mostra um esquema cinético simplificado para o antiporte de TP e $P_{i}$. Esse antiporte começa com a captura de um $P_{i}$ pelo TPT com uma TP ligada a ele (Passo 1). Após isso, a liberação da TP no espaço intermembranar (Passo 2) provoca uma mudança conformacional para a conformação $C_{\text {dentro }}$ (Passo 3). Então, uma TP é capturada (Passo 4) e o $\mathrm{P}_{\mathrm{i}}$ é liberado no estroma (Passo 5). Por último, o TPT retorna para a conformação $C_{\text {fora }}$ (Passo 6), encerrando assim o ciclo de transporte. 


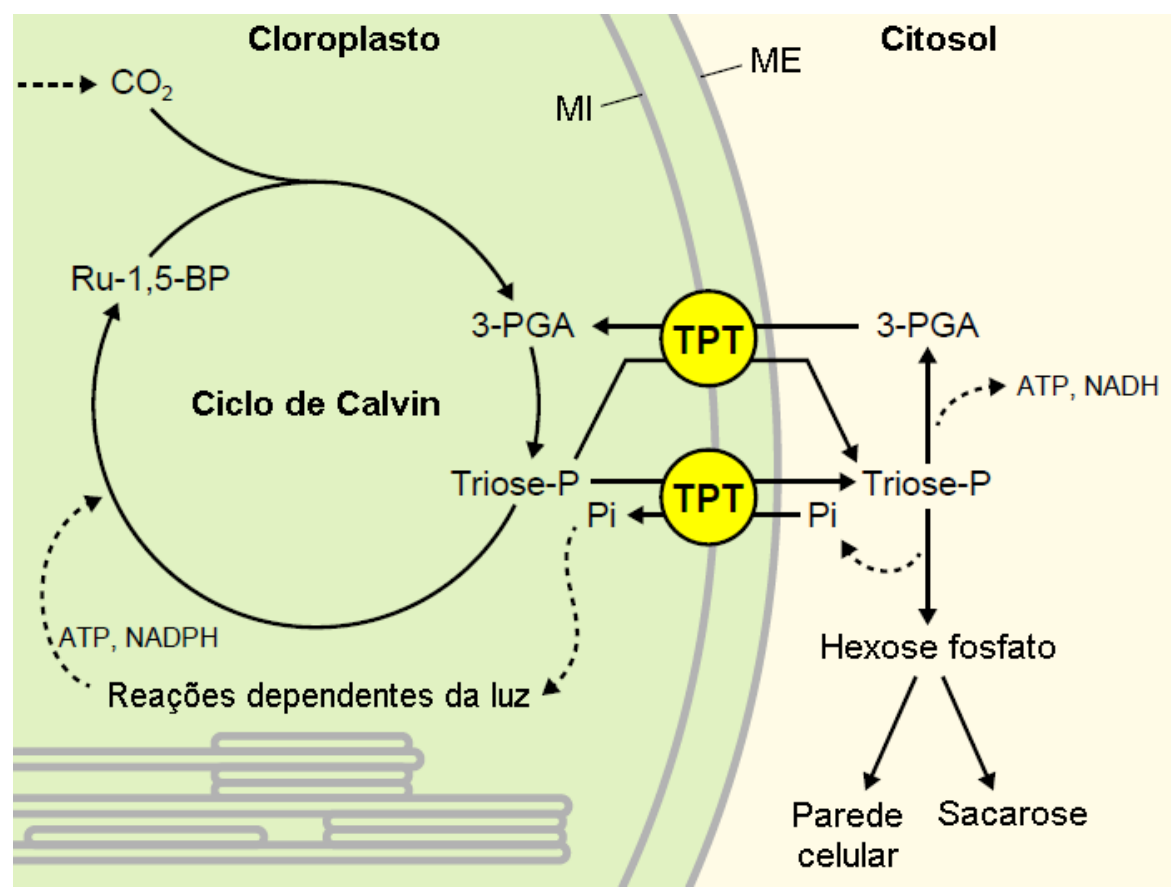

Figura 1.13: A função do TPT nos cloroplastos. Fonte: modificado da Ref. [34].

\subsection{Organização da dissertação}

O restante deste trabalho é dividido nos capítulos descritos abaixo.

- Capítulo 2. Levantamento bibliográfico. Neste capítulo, é feito o levantamento bibliográfico do presente trabalho. Primeiramente, apresentamos uma visão geral, os principais fatos estabelecidos na literatura e uma síntese dos resultados experimentais referentes à permease de lactose da Escherichia coli. Em seguida, fazemos o mesmo para o translocador de triose-fosfato/fosfato. Essas informações são a base sobre a qual nossos modelos de mecânica estatística serão construídos no capítulo seguinte.

- Capítulo 3. Metodologia. Este capítulo apresenta todo o arcabouço teórico que utilizamos para o propor o nosso modelo de mecânica estatística para o transporte ativo secundário. Em um primeiro momento, introduzimos as bases do método de Monte Carlo por meio de um exemplo de integração numérica. Em seguida, falamos sobre os processos markovianos, onde deduzimos a equação mestra e descrevemos o algoritmo de Metropolis, que é essencial neste trabaIho. Por fim, apresentamos o nosso modelo, elencando as diversas hipóteses que fizemos nele. 


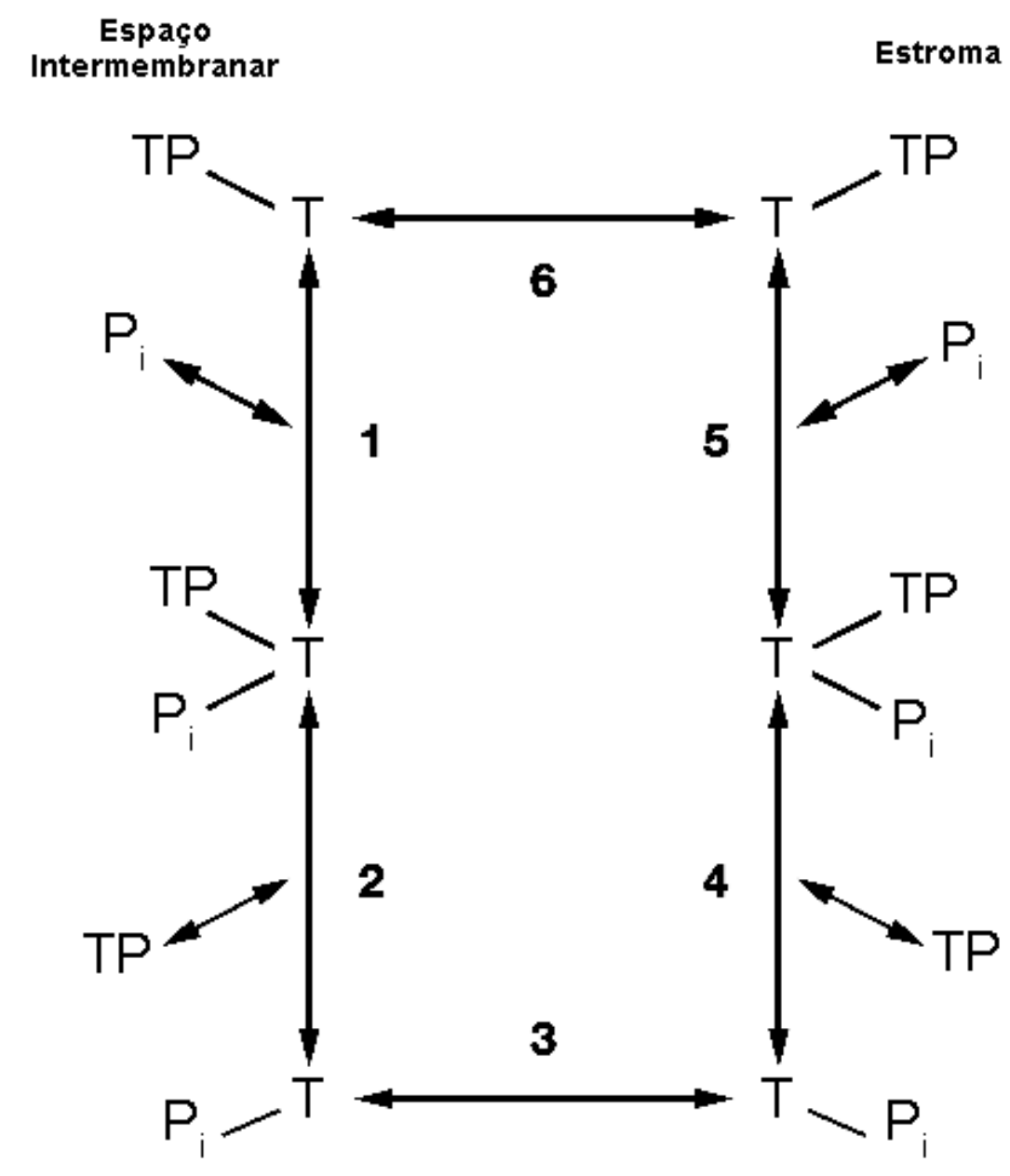

Figura 1.14: Esquema cinético simplificado para o antiporte de triose-fosfato, TP, e fosfato inorgânico, $\mathrm{P}_{\mathrm{i}}$. Aqui, T representa o TPT.

- Capítulo 4. Resultados. Este capítulo apresenta os resultados que obtivemos para a permease de lactose da Escherichia coli e o translocador de triose-fosfato/ fosfato. Em um primeiro momento, mostramos que as curvas de energia livre de ambos os nossos modelos estão de acordo com as condições de contorno estabelecidas na literatura. Em seguida, os modelos são validados por meio da reprodução de diversos experimentos. Por fim, mostramos que nossas curvas de energia livre são as que melhor reproduzem os dados experimentais.

- Capítulo 5. Conclusão Neste último capítulo, um resumo geral sobre o que foi realizado nesta dissertação é apresentado, com comentários sobre a motivação do trabalho, sobre os resultados obtidos, as dificuldades encontradas e os próximos passos possíveis na pesquisa. 


\section{Capítulo 2}

\section{Levantamento bibliográfico}

Neste capitulo, é feito o levantamento bibliográfico do presente trabalho. Primeiramente, apresentamos uma visão geral, os principais fatos estabelecidos na literatura e uma síntese dos resultados experimentais referentes à permease de lactose da Escherichia coli. Em seguida, fazemos o mesmo para o translocador de triose-fosfato/fosfato. Essas informações são a base sobre a qual nossos modelos de mecânica estatística serão construídos no capítulo seguinte. 


\subsection{A permease de lactose da Escherichia coli}

\subsubsection{Visão geral}

A existência de um sistema de bombeamento de moléculas de lactose através da membrana plasmática da E. coli foi descoberta por Cohen e Rickenberg em 1955 [41, 42]. Esse sistema de bombeamento faz parte do famoso operon lac, um operon requerido para o transporte e metabolismo da lactose na $E$. coli e outras bactérias [43]. Esse operon contém três genes estruturais: (i) $O$ gene lacZ, que codifica a $\beta$-galactosidade (LacZ), uma enzima intracelular que catalisa a clivagem da lactose em galactose e glicose; (ii) $O$ gene lacY, que codifica a permease de $\beta$-galactosídeos (LacY); e (iii) $O$ gene lacA, que codifica a transacetilase de $\beta$-galactosídeos (LacA). Com o advento da biologia molecular, o gene lacY tornou-se o primeiro gene que codifica uma proteína de transporte da membrana celular a ser clonado e sequenciado [44]. Por isso, a LacY tem sido usada como um paradigma dentre as proteínas que catalisam o transporte ativo secundário para explorar o mecanismo da transdução de energia.

Sabe-se que para a LacY transportar lactose contra o seu gradiente de concentração, $\Delta \mu_{\mathrm{L}}$, uma fonte de energia externa se faz necessária. Essa fonte de energia é o gradiente eletroquímico de $\mathrm{H}^{+}$, dado por [31]

$$
\Delta \tilde{\mu}_{\mathrm{H}^{+}}=e \Delta \Psi-2.3 k_{\mathrm{B}} T \Delta \mathrm{pH} .
$$

Esse gradiente é composto de uma componente elétrica, o potencial elétrico transmembranar, $\Delta \Psi$, sendo o interior da célula negativo, elou um gradiente de $\mathrm{pH}, \Delta \mathrm{pH}$, sendo o interior da célula alcalino. Assim, a energia total do processo de transporte de lactose é $\Delta \tilde{\mu}_{\mathrm{H}^{+}}+\Delta \mu_{\mathrm{L}}$, que é igual à variação da energia livre de Gibbs através da membrana, $\Delta G$. Desta discussão apresentada acima, vê-se que a LacY funciona de forma similar ao Demônio de Maxwell, que percebe um tipo específico de molécula, no caso a lactose, e abre um portão para elas, permitindo o movimento dessas moléculas contra o seu gradiente de concentração. Portanto, a entropia das moléculas de lactose diminui durante o processo de transporte, enquanto que a entropia total aumenta para satisfazer a Segunda Lei da termodinâmica. 


\subsubsection{Estrutura de raio-X}

A estrutura geral da LacY é mostrada na Figura 2.1. Para obter essa estrutura, Abramson e outros usaram o mutante C154G, que liga o substrato com alta afinidade mas catalisa pouco ou nenhum transporte, além de ser termoestável e possuir pouca tendência de agregação [45]. De acordo com os autores, essas propriedades são essenciais para uma cristalização bem sucedida da LacY. A estrutura do mutante C154G foi resolvida com resolução de $3.5 \AA$ usando um homólogo da lactose conhecido como TDG. Na Figura 2.1, a estrutura da LacY é mostrada com um TDG ligado no sítio de ligação central. A unidade assimétrica da LacY é composta por um dímero artificial, com duas moléculas orientadas em direções opostas, o que leva a conclusão de que o monômero é a unidade funcional da LacY $[46,47]$. Quando vista paralelamente à membrana, na Figura 2.1 (a), a LacY revela uma cavidade hidrofílica aberta para o lado citoplasmático e fortemente fechada para o lado periplasmático, com dimensões de 25 por $15 \AA$, o que sugere que a estrutura representa a conformação $C_{\text {dentro. As }}$ maiores dimensões da proteína são $60 \AA$ na direção ao longo da membrana e $60 \AA$ na direção perpendicular à membrana. Já quando vista do citoplasma, na Figura 2.1 (b), a proteína tem um formado oval com dimensões de 35 por $60 \AA$.

O monômero é composto por 12 hélices transmembranares organizadas em dois pacotes com seis hélices cada, conforme está esquematizado na Figura 2.2. Esses dois pacotes estão conectados por meio das hélices VI e VII. As hélices I-VI constituem o domínio N-terminal, enquanto que as hélices VII-XII constituem o domínio C-terminal. A cavidade hidrofilica é formada entre as hélices I, II, IV e V do domínio N-terminal e as hélices VII, VIII, Xe XI do domínio C-terminal. As demais hélices ficam amplamente incorporadas na bicamada, e portanto não são expostas ao solvente.

Dentro da cavidade da LacY, o sítio de ligação se encontra a uma distância similar de ambos os lados da membrana, sustentando a ideia de que a LacY possui um único sítio de ligação alternadamente acessível a cada lado da membrana. Os resíduos envolvidos na ligação do substrato são mostrados na Figura 2.3. O sítio de ligação no domínio N-terminal é composto de resíduos das hélices I, IV e V. Já no domínio C-terminal, o sítio é composto de resíduos das hélices VII e XI. Os dois principais resíduos envolvidos na translocação da molécula de lactose são o $\mathrm{Glu}_{126}$ e o $\operatorname{Arg}_{144}$. Já os resíduos envolvidos na translocação e acoplamento do próton foram identificados por 


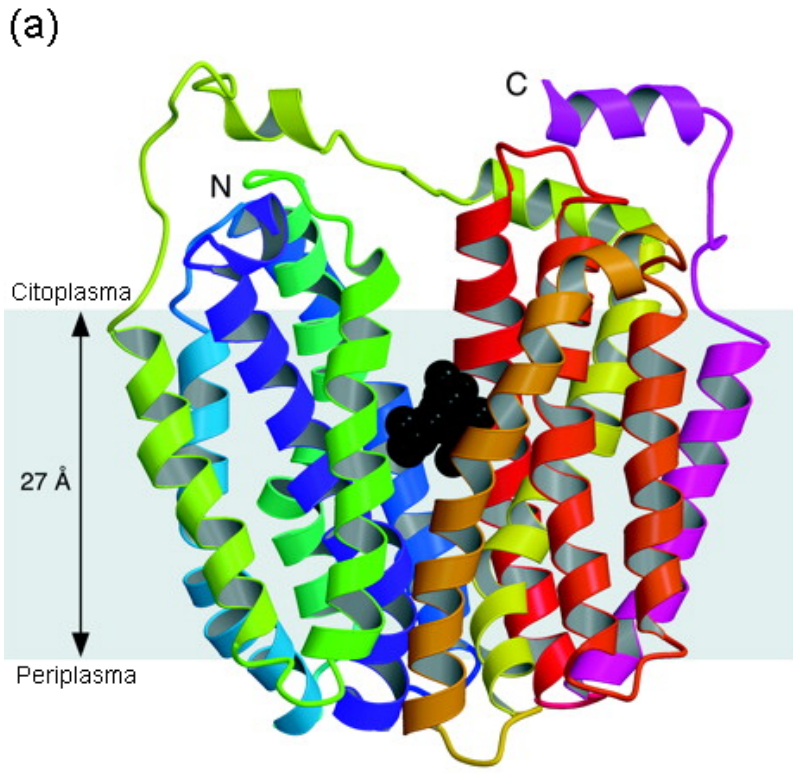

(b)
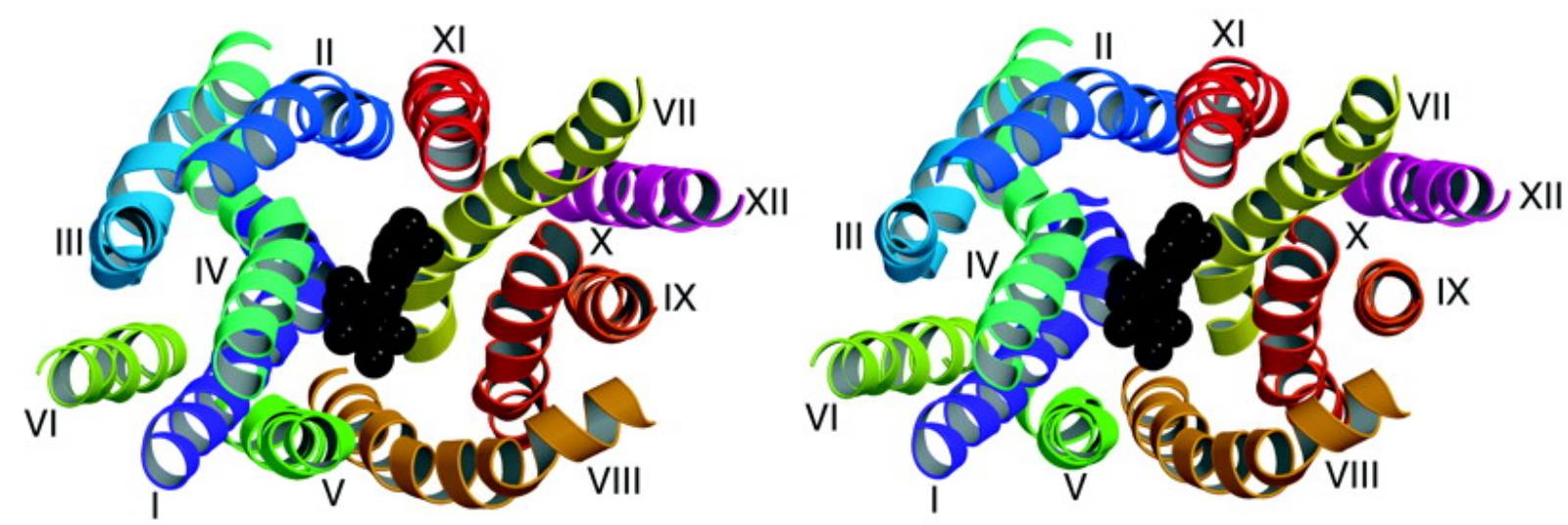

Figura 2.1: Estrutura geral da LacY. (a) Representação do mutante C154G em sua conformação voltada-para-dentro visto paralelamente à membrana celular. Esse mutante consiste de 12 hélices organizadas em dois pacotes com seis hélices cada. As hélices transmembranares são coloridas a partir do domínio N-terminal em roxo até o domínio C-terminal em rosa. O TDG é representado por esferas pretas. (b) Representação do mutante $\mathrm{C} 154 \mathrm{G}$ em sua conformação voltada-para-dentro visto ao longo da normal da membrana celular do lado citoplasmático. As 12 hélices estão numeradas com algarismos romanos. Fonte: modificado da Ref. [45]. 


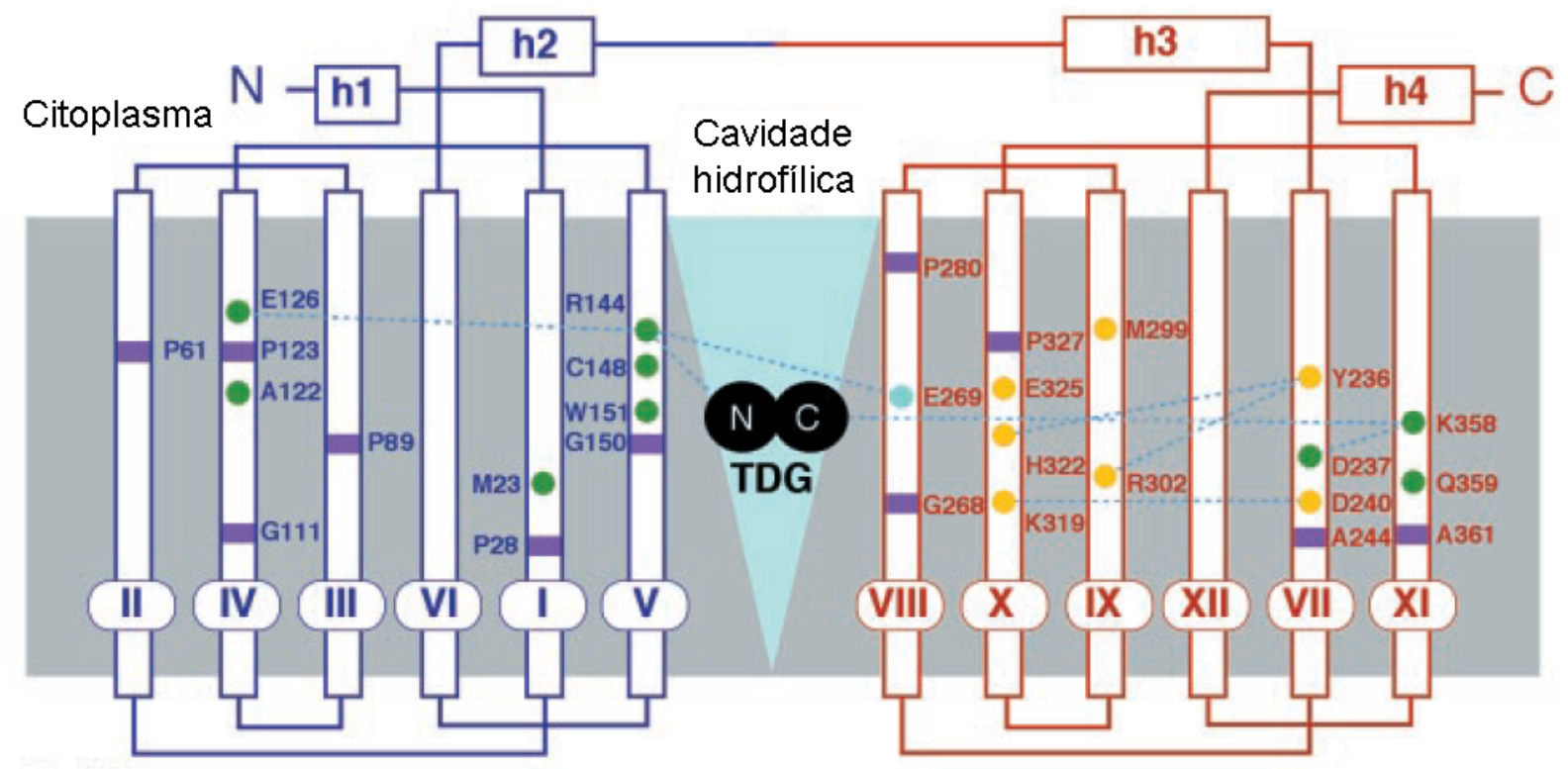

Periplasma

Figura 2.2: Esquema da estrutura secundária da LacY. Os domínios $\mathrm{N}$ - e C-terminal são mostrados em azul e vermelho, respectivamente. Os resíduos representados por círculos verdes e amarelos estão envolvidos na ligação do substrato e na translocação do próton, respectivamente. O resíduo $\mathrm{Glu}_{269}$, representado por um círculo azul claro, está envolvido tanto na ligação do substrato, quanto na transferência do próton. A cavidade hidrofílica é mostrada como um triângulo azul claro, e o TDG como dois círculos pretos. Fonte: modificado da Ref. [45].

meio da caracterização das propriedades de transporte de mutantes essenciais [48]. Estes resíduos são o $\mathrm{Glu}_{325}$ e o $\mathrm{Arg}_{302}$, que estão diretamente envolvidos na translocação do próton, e o $\mathrm{His}_{322}$ e o $\mathrm{Glu}_{269}$, que acoplam a translocação do próton e a ligação do substrato. Assim, completamos a lista dos seis resíduos que são essenciais para explicar o ciclo de transporte da lactose: $\mathrm{Glu}_{126}, \mathrm{Arg}_{144}, \mathrm{Glu}_{269}, \mathrm{Arg}_{302}, \mathrm{His}_{322}$, e $\mathrm{Glu}_{325}$. Além desses seis resíduos, o $\mathrm{Asp}_{240}$ e o Lys 319 , que não estão diretamente envolvidos na translocação do $\mathrm{H}^{+}$e do substrato, formam uma ponte salina que desempenha um papel importante no panorama energético da LacY [45], conforme será visto em detalhes adiante.

A estrutura de raio-X da LacY apresentada na Figura 2.1 se refere à conformação $\mathrm{C}_{\text {dentro }}$ com um substrato e um $\mathrm{H}^{+}$ligados. Nessa estrutura, a cavidade hidrofílica central está aberta somente para o lado citoplasmático da célula. No entanto, existe uma outra conformação, $\mathrm{C}_{\text {fora }}$, na qual a cavidade está aberta somente para o lado periplasmático. Essa conformação é atingida por meio de uma mudança estrutural entre as conformações $C_{\text {dentro }}$ e $C_{\text {fora }}$, mudança essa que envolve a rotação entre os 


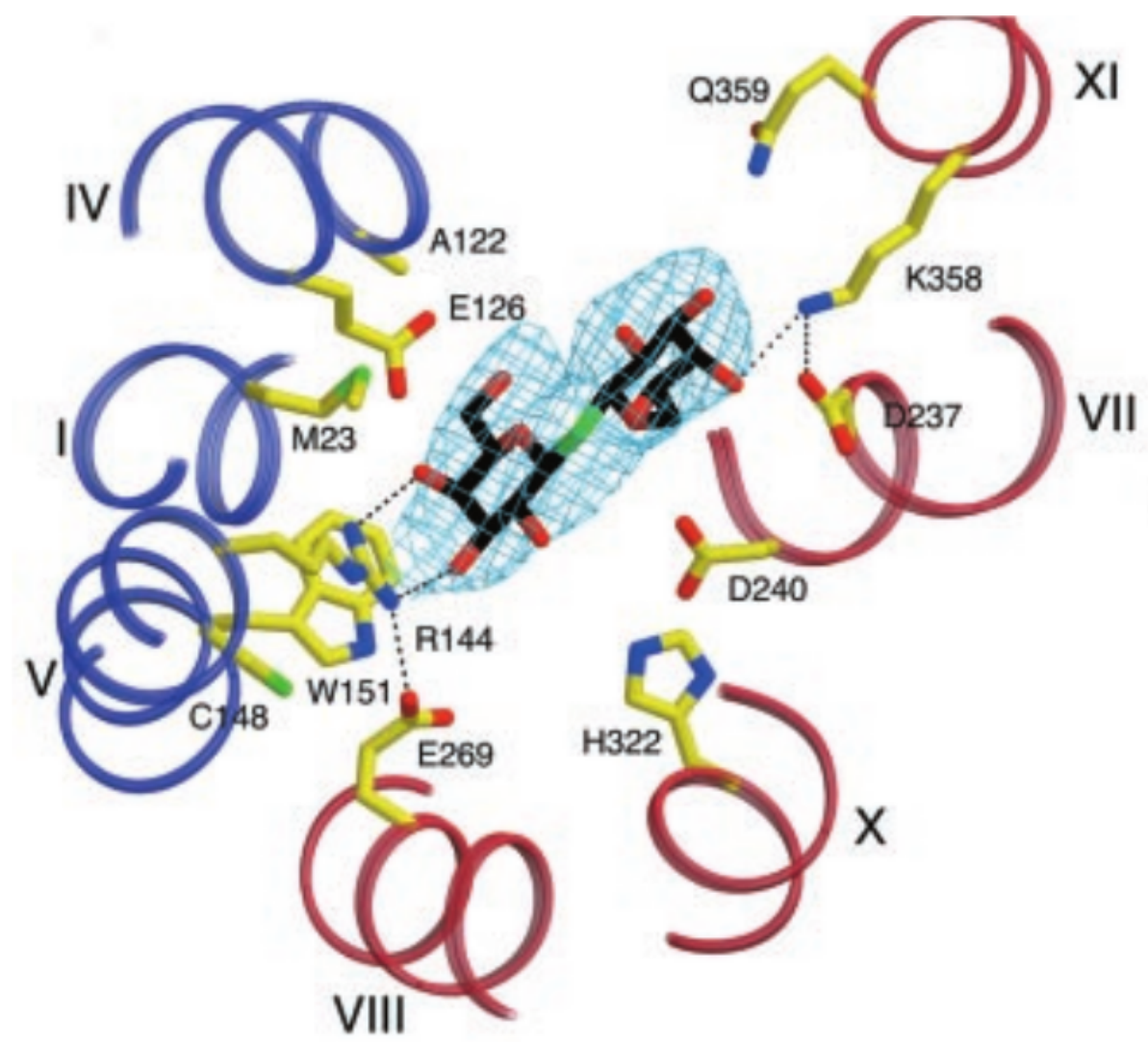

Figura 2.3: O sítio de ligação do substrato da LacY. São mostrados os resíduos envolvidos na ligação do TDG vistos ao longo da normal da membrana do lado citoplasmático. Possíveis ligações de hidrogênio e pontes salinas são representadas por linhas pretas tracejadas. As hélices transmembranares dos domínios $\mathrm{N}$ - e C- terminal estão coloridas em azul e vermelho, respectivamente. Fonte: modificado da Ref. [45].

domínios $\mathrm{N}$ - e C- terminal ao redor de um eixo paralelo à membrana. Essa rotação está associada a uma ligação de hidrogênio entre os resíduos $\mathrm{Glu}_{269}$ e $\operatorname{Arg}_{144}$ que é quebrada na transição da conformação $C_{\text {dentro }}$ para a conformação $C_{\text {fora. }}$.

\subsubsection{O modelo de Kaback}

Em 2001, Kaback e outros propuseram o modelo aceito atualmente para o mecanismo de transporte de lactose $/ \mathrm{H}^{+}$[48]. Esse modelo tem seis estados, iniciando com a LacY desprotonada na conformação $C_{\text {fora }}$ (Fig. 2.4, Estado 1). Neste estado, a LacY é protonada imediatamente $(1 \rightarrow 2)$, compartilhando o $\mathrm{H}^{+}$entre os resíduos $\mathrm{His}_{322} \mathrm{e}$ $\mathrm{Glu}_{269}$ (Fig. 2.4, Estado 2). Então, uma molécula de lactose se liga a LacY $(2 \rightarrow 3)$, sendo reconhecida pelo par de cargas entre os resíduos $\operatorname{Arg}_{144}$ e $\mathrm{Glu}_{126}$ (Fig. 2.4, Estado 3). Após a ligação do substrato, uma transição para a conformação $C_{\text {dentro }}$ ocorre $(3 \rightarrow 4)$. Essa transição está associada à ponte de hidrogênio formada entre 


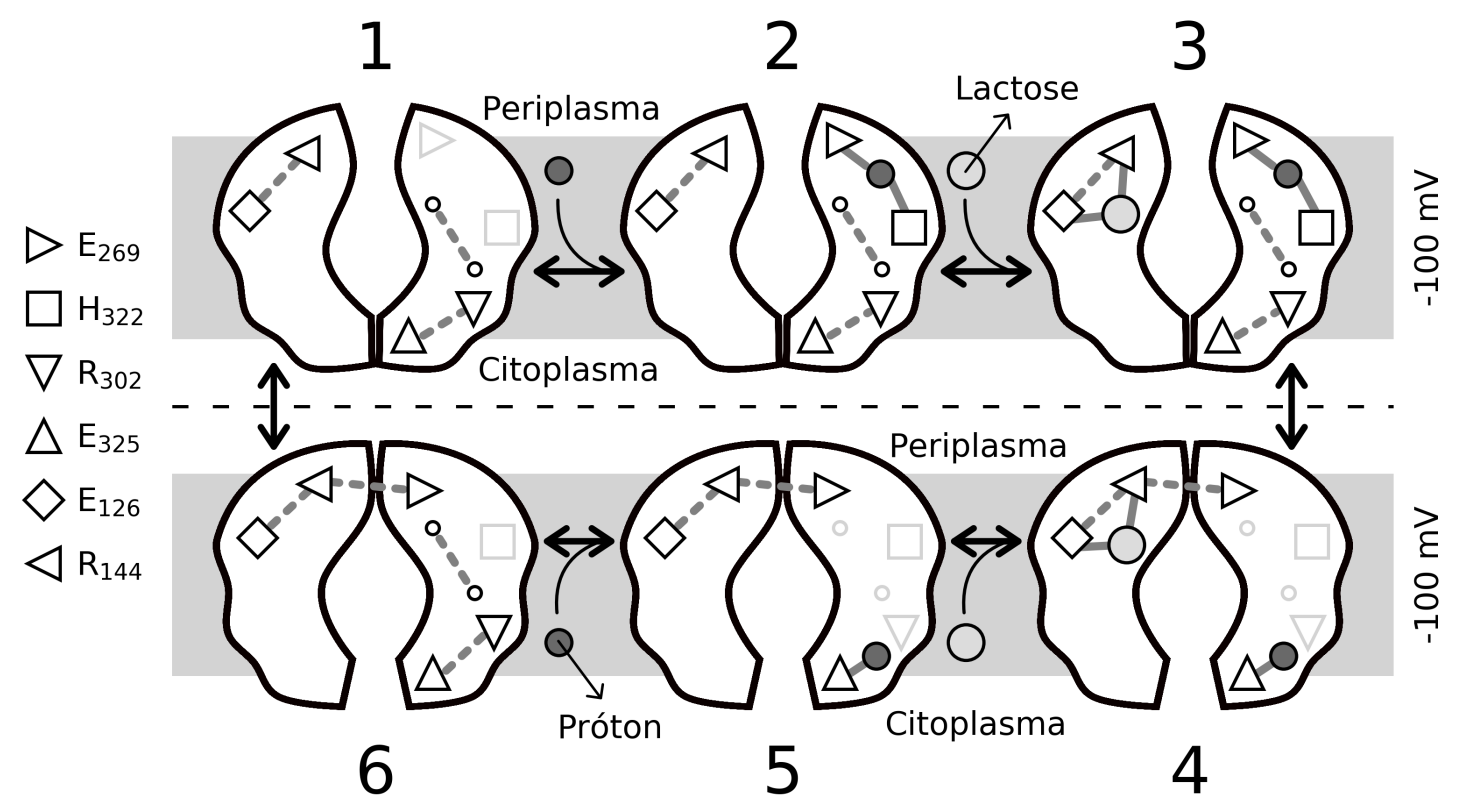

Figura 2.4: Mecanismo de transporte de lactose pela LacY. Os resíduos chave estão identificados. Um potencial elétrico de membrana de $-100 \mathrm{mV}$ está indicado. Ligações de hidrogênio e Van der Waals são mostradas como linhas tracejadas e sólidas, respectivamente. Também é mostrada a ligação de hidrogênio entre os resíduos $\mathrm{ASP}_{240}$ e Lys 319 , que são representados como pequenos círculos brancos. Esses resíduos não são essenciais para o modelo de Kaback, mas eles afetam a nossa curva de energia livre. A lactose e o $\mathrm{H}^{+}$são representados como círculos cinza claro e escuro, respectivamente.

o $\mathrm{Glu}_{269}$ e o $\operatorname{Arg}_{144}$ (Fig. 2.4, Estado 4). Adicionalmente, o $\mathrm{H}^{+}$é transferido para o $\mathrm{Glu}_{325}$. A lactose é então liberada no citoplasma $(4 \rightarrow 5)$, o que desencadeia uma mudança conformacional que permite que o $\operatorname{Arg}_{302}$ se aproxime do $\mathrm{Glu}_{325}$, resultando na desprotonação $(5 \rightarrow 6)$. Após liberar o $\mathrm{H}^{+}$, a transição para a conformação $\mathrm{C}_{\text {fora }}$ é induzida $(6 \rightarrow 1)$. Esse mecanismo de transporte corresponde ao transporte de lactose na direção de influxo, horária. No entanto, o transporte na direção anti-horária também pode ser explicado por este mesmo mecanismo, uma vez que o influxo e o efluxo são processos funcionalmente simétricos [45].

Apesar do fato de que existe esse modelo para o mecanismo de transporte da LacY, o qual é consistente com as observações experimentais, duas perguntas ainda permanecem em aberto. Essas duas perguntas, de acordo com Guan e Kaback [31], são: (i) Qual é o tempo de ocupação da LacY nas conformações $C_{\text {fora }}$ e $C_{\text {dentro }}$ ? e (ii) Por que a protonação é importante para a ligação da lactose? O modelo do caminho aleatório para a LacY que nós estamos propondo aqui responde essas perguntas em 


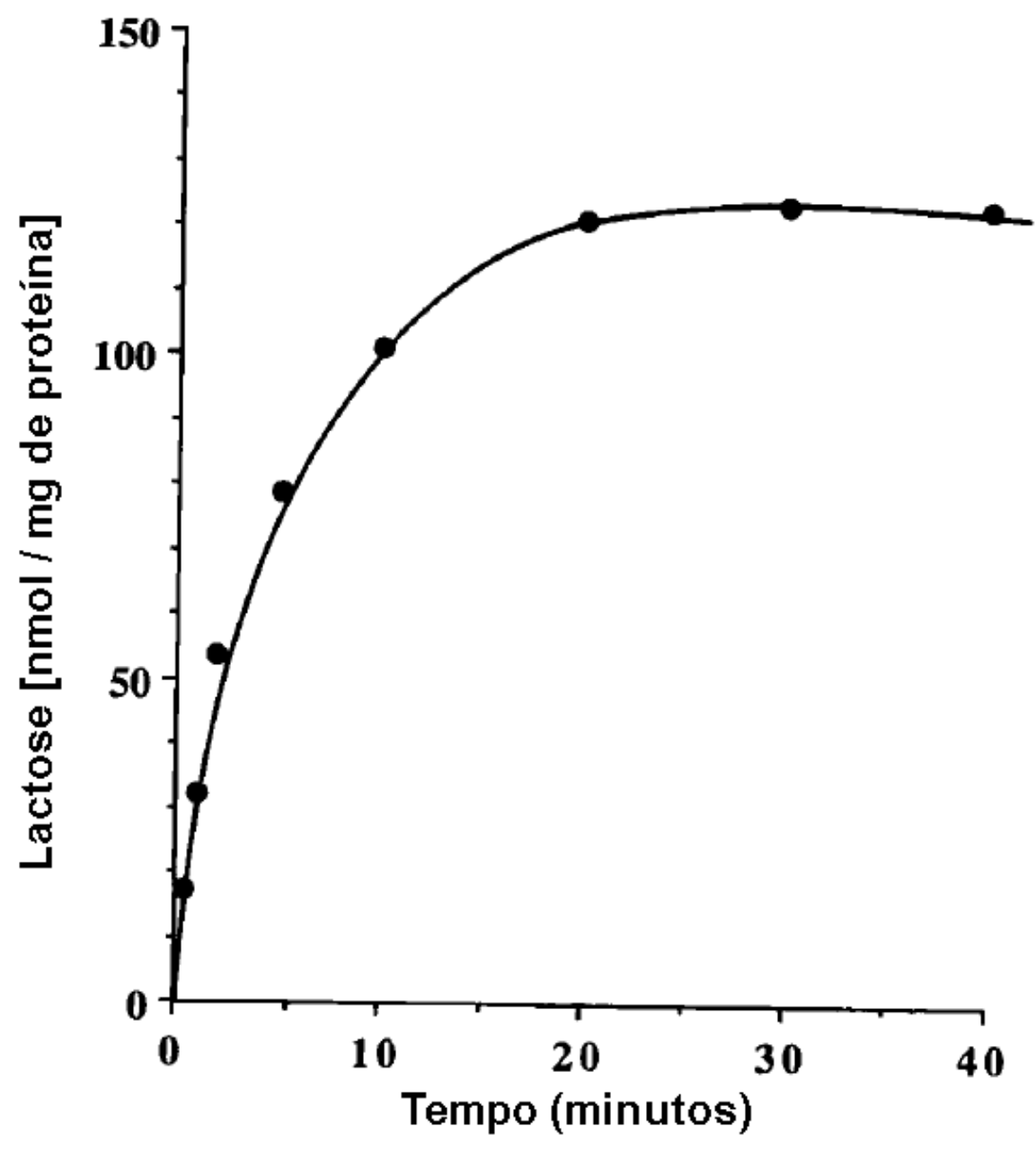

Figura 2.5: Evolução temporal do influxo de lactose em um experimento realizado por Ujwal e outros [49].

aberto e oferece um quadro teórico para descrever os dados experimentais.

\subsubsection{Síntese dos resultados experimentais}

Neste item, nós iremos apresentar uma síntese dos resultados experimentais que podem ser reproduzidos pelo nosso modelo de Monte Carlo para a LacY, o qual será discutido no capítulo seguinte. É importante destacar que, aqui, nós não iremos apresentar todos os resultados, mas somente os principais, sendo que os demais podem ser consultados nas referências indicadas.

O primeiro experimento consiste no transporte ativo de lactose em E. coli T184 expressando a permease do tipo selvagem. Esse experimento foi realizado por Ujwal e outros e corresponde à Figura 2 da Ref. [49], conforme reproduzimos no gráfico da Fig. 2.5. Esse gráfico mostra a evolução temporal do influxo de lactose. No experi- 


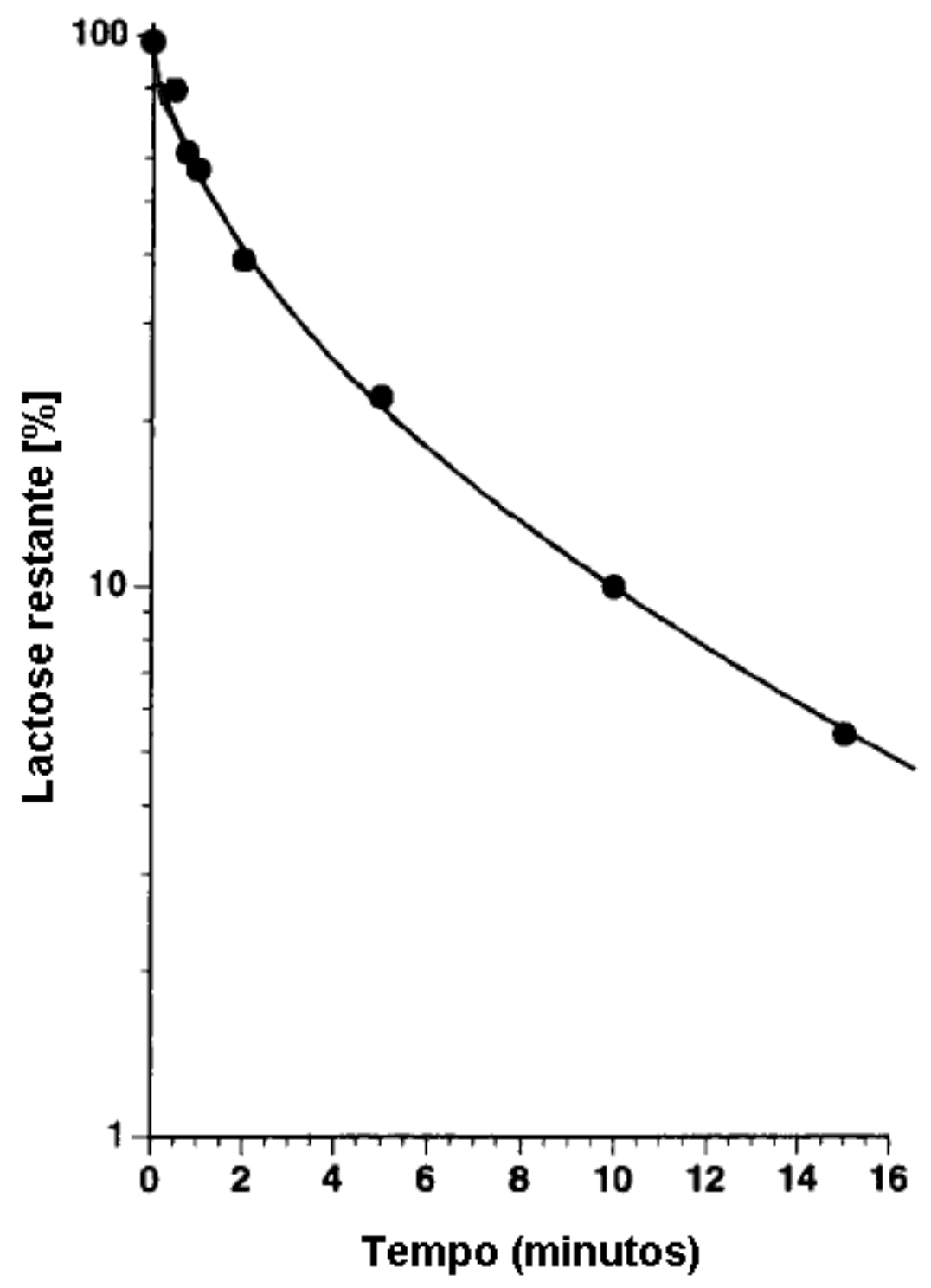

Figura 2.6: Evolução temporal do efluxo de lactose em um experimento realizado por Ujwal e outros [49].

mento, as concentrações de $\mathrm{H}^{+}$e lactose são tais que $\Delta G<0$, favorecendo termodinamicamente o influxo de lactose. Assim, estes dois solutos são transportados pela LacY do periplasma para o citoplasma da $E$. coli, o que causa uma diminuição nos seus respectivos gradientes. Em particular, o gradiente de lactose diminui até que o sistema atinja o equilíbrio ( $20 \mathrm{~min}$ ), quando o influxo inicial de lactose é compensado pelo seu efluxo, e $\Delta G=0$.

O segundo experimento, também realizado por Ujwal e outros, corresponde à Figura 4 da Ref. [49], conforme reproduzimos no gráfico da Fig. 2.6. Esse experimento é semelhante ao primeiro, com a diferença de que ele mostra a evolução temporal 


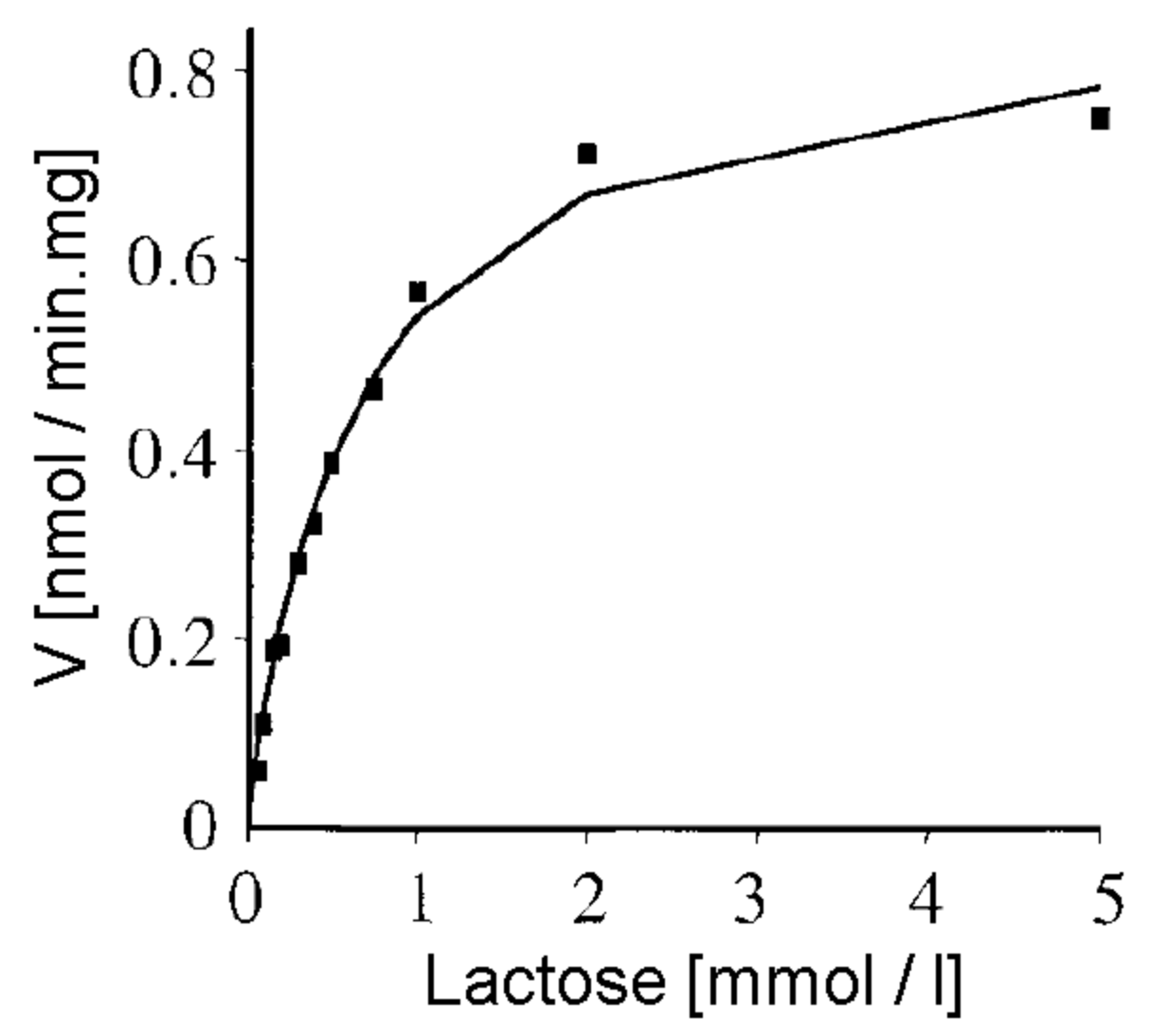

Figura 2.7: Taxa inicial de transporte, $V$, para concentrações de lactose variando de $40 \mathrm{umoll}^{-1}$ a $5 \mathrm{mmoll}^{-1}$. A equação de Michaelis-Menten foi ajustada aos dados. Fonte: modificado da Ref. [50].

do efluxo de lactose, não do influxo. Como é possível ver, inicialmente há uma certa quantidade de lactose no citoplasma, que corresponde a 100\%. Nesse experimento, as concentrações de $\mathrm{H}^{+}$e lactose são tais que $\Delta G>0$, favorecendo o efluxo de lactose. Assim, esses dois solutos são transportados do citoplasma para o periplasma até que o sistema atinja o equilíbrio, o que leva aproximadamente $10 \mathrm{~min}$.

Por fim, o terceiro experimento tem como objetivo estudar a dependência que há entre o transporte de lactose e a concentração da mesma. Esse experimento foi realizado por Weinglass e outros e corresponde à Figura 2 (B) da Ref. [50], conforme reproduzimos no gráfico da Fig. 2.7. Esse gráfico mostra a taxa inicial de transporte, $V$, para concentrações de lactose variando de $40 \mathrm{umoll}^{-1}$ a $5 \mathrm{mmoll}^{-1}$. A cinética de MichaelisMenten, expressa na Equação (1.4), foi ajustada a estes dados, sendo que os parâmetros $K_{\mathrm{M}}$ e $V_{\text {máx }}$ foram obtidos como sendo $0.65(5) \mathrm{mmoll}^{-1}$ e 810(90) $\mathrm{nmol} \mathrm{min}^{-1}$ por mg, respectivamente. 


\subsection{O translocador de triose-fosfato/fosfato}

\subsubsection{Visão geral}

Durante a assimilação de $\mathrm{CO}_{2}$, o ciclo de Calvin gera triose-P às custas do ATP e da NADPH gerados por reações fotossintéticas. A triose-P pode ser retida dentro dos cloroplastos ou para regenerar o aceitador de $\mathrm{CO}_{2}$, ou para alimentar a síntese do amido transitório [51]. Alternativamente, a triose-P pode ser exportada para o citosol para produzir sacarose. Para manter uma taxa ótima de fotossíntese, a taxa de exportação de triose-P do estroma dos cloroplastos para o citosol é ajustada às demandas de exportação de fotoassimilados. $O$ translocador de triose- $P / P_{i}$ medeia a exportação de triose-P estromal para o citosol em troca da importação de $P_{i}$ citosólico para o estroma. A taxa de exportação de triose-P é regulada principalmente pela disponibilidade de $\mathrm{P}_{\mathrm{i}}$ liberado pela síntese da sacarose citosólica.

Sabe-se que para o TPT transportar triose-P contra o seu gradiente de concentração, $\Delta \mu_{\mathrm{TP}}$, uma fonte de energia externa se faz necessária. Essa fonte de energia é o gradiente de concentração de $\mathrm{P}_{\mathrm{i}}, \Delta \mu_{\mathrm{P}_{\mathrm{i}}}$. Assim, a energia total do processo de transporte de triose-P é

$$
\Delta G=\Delta \mu_{\mathrm{TP}}+\Delta \mu_{\mathrm{P}_{\mathrm{i}}}
$$

que é igual ao valor negativo do calor liberado para o meio ambiente. No caso em que $\Delta G<0$, ocorre o efluxo de triose-P, ao passo que quando $\Delta G>0$, ocorre o influxo de triose-P. Além disso, como o TPT é uma proteína antiportadora, o efluxo de triose$\mathrm{P}$ corresponde ao influxo de $\mathrm{P}_{\mathrm{i}}$, e vice-versa. Neste presente trabalho, quando nos referirmos a um ciclo de influxo/efluxo do TPT, estamos nos referindo ao influxo/efluxo da triose-P, não do $P_{\mathrm{i}}$.

\subsubsection{Estrutura de raio-X}

A estrutura geral do TPT é mostrada na Figura 2.8. Para obter essa estrutura, Lee e outros usaram o GsGPT da alga vermelha termofílica Galdieria sulphuraria, que, de acordo com os autores, é funcionalmente semelhante ao TPT [34]. A estrutura do GsGPT foi resolvida com resolução de $2.2 \AA$ para um estado com 3-PGA ligado, como mostra a Figura 2.8 (a), e com resolução de $2.1 \AA$ para um estado com $\mathrm{P}_{\mathrm{i}}$ ligado, 

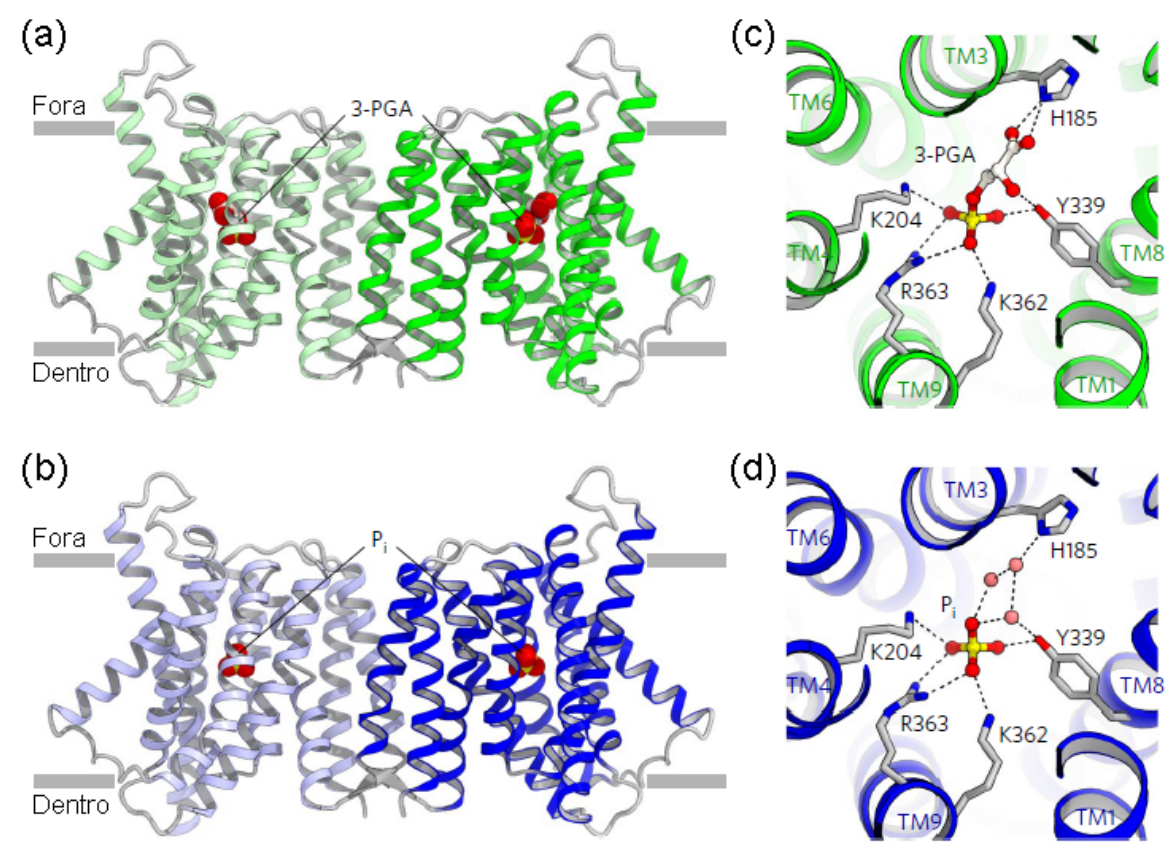

(e)
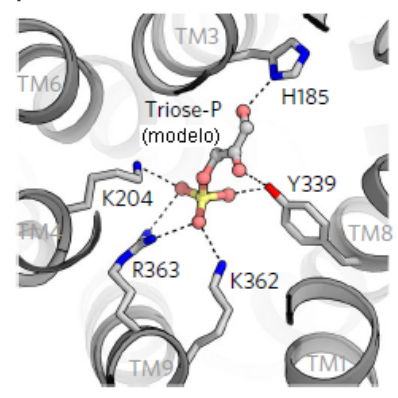

Figura 2.8: Estrutura geral do TPT. Representação do homólogo GsGPT em sua conformação oclusa com um 3-PGA ligado (a) e um $\mathrm{P}_{\mathrm{i}}$ ligado (b). (c), (d) Detalhes do sítio de ligação central. (e) Modelo de ligação da triose-P.

como mostra a Figura 2.8 (b). Esses dois estados correspondem à conformação oclusa ( $\mathrm{C}_{\text {oclusa }}$ ) da proteína. Nas Figuras 2.8 (c) e (d), os sítios de ligação do 3-PGA e do $\mathrm{P}_{\mathrm{i}}$, respectivamente, são mostrados em detalhes. Além disso, na Figura 2.8 (e), um modelo de como seria a ligação de uma triose-P no sítio de ligação central é apresentado.

\subsubsection{O modelo de Takemoto}

Em 2018, Takemoto e outros realizaram simulações de Dinâmica Molecular baseadas em um modelo simplificado que considera apenas o transporte de $P_{i}$ pelo TPT, sem triose-P [52]. Nós chamamos esse modelo simplificado de "modelo de Takemoto". Tal modelo tem sete estados, iniciando com o TPT sem $P_{i}$ ligado na conformação $C_{\text {dentro }}$ (Fig. 2.9, Estado $\mathrm{IF}_{\mathrm{a}}$ ). Neste estado, o TPT captura um $\mathrm{P}_{\mathrm{i}}$ do estroma $\left(\mathrm{IF}_{\mathrm{a}} \rightarrow \mathrm{IF}_{\mathrm{b}}^{\text {intra }}\right.$ ), compartilhando ele entre os resíduos Lys $_{271}$ e $\operatorname{Arg}_{266}$ (Fig. 2.9, Estado IF intra). Então, o $\mathrm{P}_{\mathrm{i}}$ é transferido para o sítio de ligação central $\left(\mathrm{IF}_{\mathrm{b}}^{\text {intra }} \rightarrow \mathrm{IF}_{\mathrm{b}}^{\text {cent }}\right)$, sendo reconhecido pelos resíduos Lys 362 , Lys $204, \mathrm{Arg}_{363}$, e Tyr 339 (Fig. 2.9, Estado IF essa transferência, uma transição para a conformação $\mathrm{C}_{\text {oclusa }}$ ocorre (IF cent $\rightarrow$ Occ ). Essa transição está associada às ligações de hidrogênio formadas entre o Lys $271 \mathrm{e}$ o Leu 347 , e entre o Lys 271 e o Val $_{350}$ (Fig. 2.9, Estado Occ). Na sequência, uma 


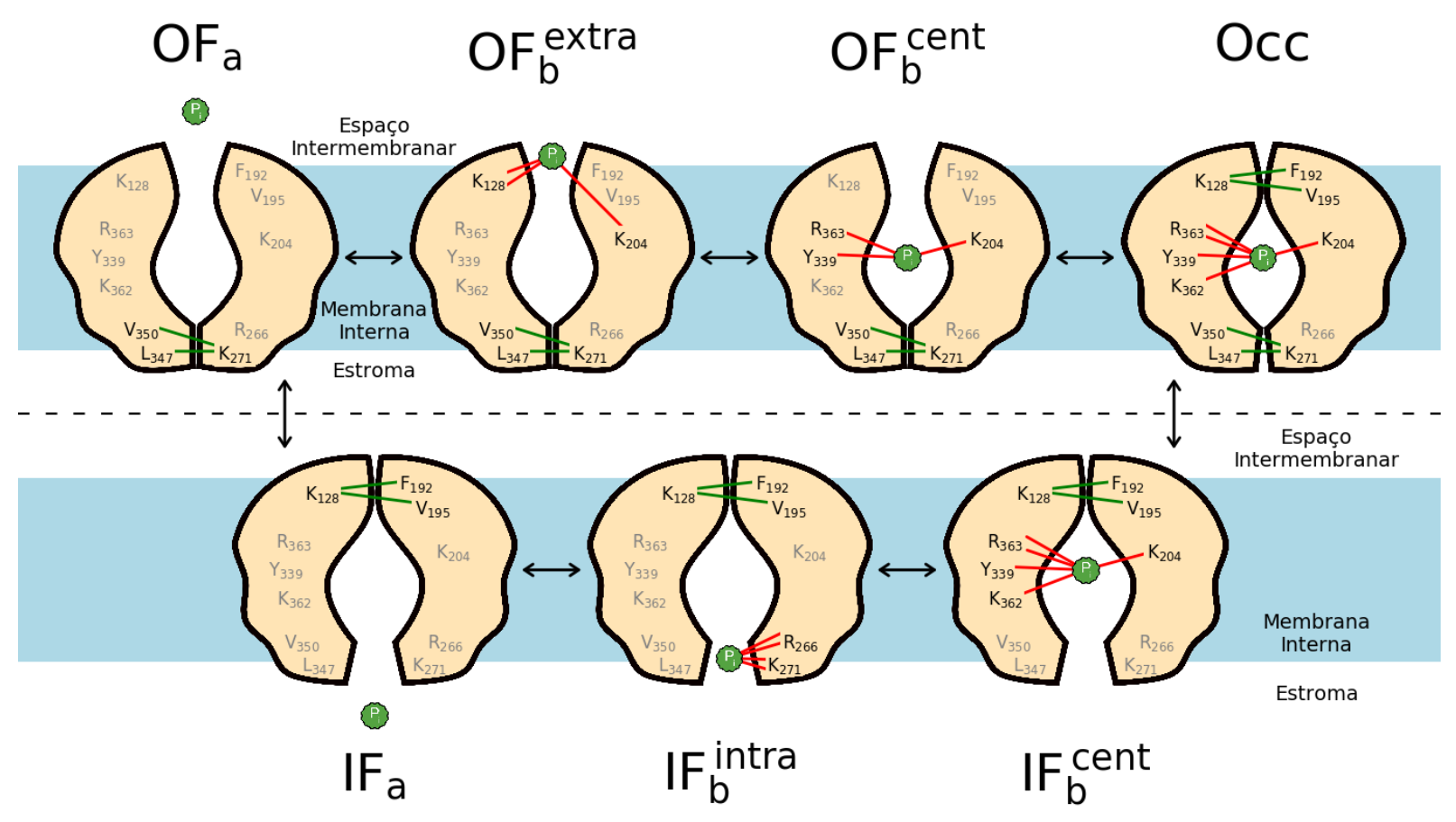

Figura 2.9: O modelo de Takemoto. Os resíduos principais estão identificados. Ligações de hidrogênio e de Van der Waals são mostradas como linhas verdes e vermelhas, respectivamente. $\mathrm{O}$ fosfato inorgânico, $\mathrm{P}_{\mathrm{i}}$, é representado como um círculo ondulado verde. Nesta figura, nós mantivemos a nomenclatura para os estados utilizada por Takemoto et al. na Ref. [52].

transição para a conformação $\mathrm{C}_{\text {fora }}$ ocorre $\left(\mathrm{Occ} \rightarrow \mathrm{OF}_{\mathrm{b}}^{\text {cent }}\right.$ ), estando essa transição associada à quebra das ligações de hidrogênio entre o Lys $_{128}$ e o Val ${ }_{195}$, e entre o Lys $_{128}$ e o Phe $_{192}$ (Fig. 2.9, Estado $\mathrm{OF}_{\mathrm{b}}^{\text {cent }}$ ). O $\mathrm{P}_{\mathrm{i}}$ é então transferido para o portão exterior do TPT ( $\mathrm{OF}_{b}^{\text {cent }} \rightarrow \mathrm{OF}_{\mathrm{b}}^{\text {extra }}$ ), onde ele interage com os resíduos Lys $\mathrm{s}_{128} \mathrm{e}$ Lys $_{204}$ (Fig. 2.9, Estado OF ${ }_{b}^{\text {extra }}$ ), sendo posteriormente liberado no espaço intermembranar $\left(\mathrm{OF}_{\mathrm{b}}^{\text {extra }} \rightarrow \mathrm{OF}_{\mathrm{a}}\right)$. Após liberar o $\mathrm{P}_{\mathrm{i}}$, uma transição para a conformação $\mathrm{C}_{\text {dentro }}$ é induzida $\left(\mathrm{OF}_{\mathrm{a}} \rightarrow \mathrm{IF}_{\mathrm{a}}\right)$. Este mecanismo de transporte corresponde ao transporte de $P_{\mathrm{i}}$ na direção de efluxo. No entanto, o transporte na direção de influxo também pode ser explicada pelo mesmo modelo, uma vez que o influxo e o efluxo são processos funcionalmente simétricos.

Além de apresentar esse modelo, Takemoto também obteve a curva de energia livre referente ao ciclo de transporte da Figura 2.9. Nós reproduzimos essa curva na Figura 2.10. Ela será utilizada no capítulo seguinte, onde iremos propor um modelo completo para o ciclo de transporte do TPT, incluindo a triose-P. 


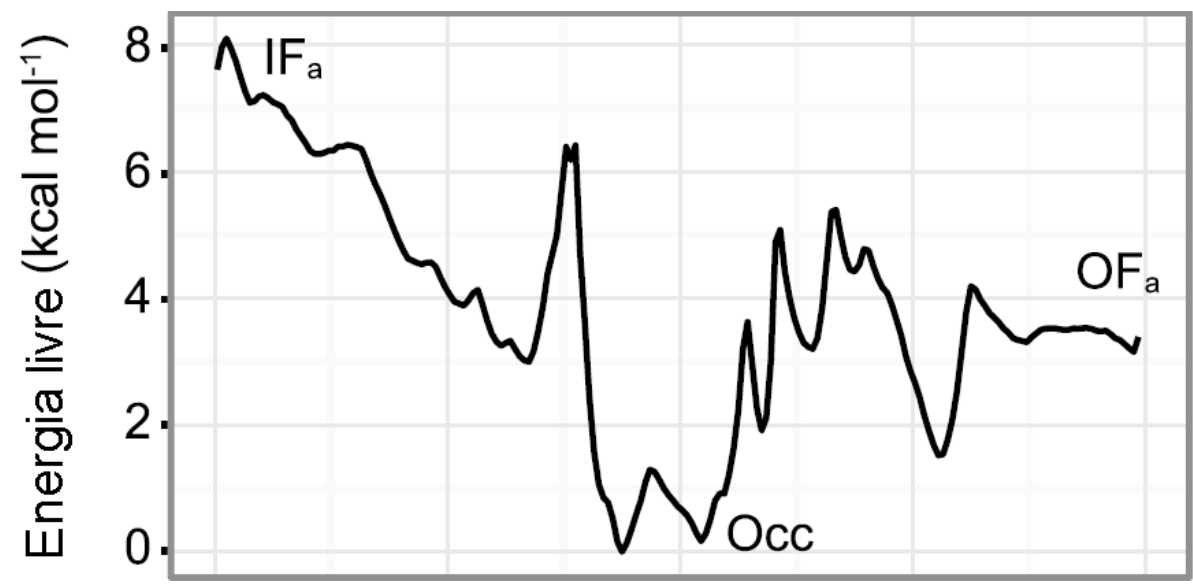

Figura 2.10: Curva de energia livre do modelo de Takemoto. Fonte: modificado da Ref. [52].

\subsubsection{Síntese dos resultados experimentais}

Neste item, nós iremos apresentar uma síntese dos resultados experimentais que podem ser reproduzidos pelo nosso modelo de Monte Carlo para o TPT, o qual será discutido no capítulo seguinte. É importante destacar que, aqui, nós não iremos apresentar todos os resultados, mas somente os principais, sendo que os demais podem ser consultados nas referências indicadas.

$\mathrm{O}$ primeiro experimento, realizado por Linka e outros, corresponde à Figura $1 \mathrm{C}$ da Ref. [53], conforme reproduzimos no gráfico da Figura 2.11 (a), e é semelhante ao primeiro resultado experimental apresentado na Seção 2.1.4. Esse gráfico mostra a evolução temporal do influxo de $\mathrm{P}_{\mathrm{i}}$. No experimento, $\Delta \mu_{\mathrm{P}_{\mathrm{i}}}<0$ e $\Delta \mu_{\mathrm{TP}}>0$, favorecendo termodinamicamente o influxo de $P_{i}$ e o efluxo de TP. Assim, $P_{i}$ é transportado pelo TPT do espaço intermembranar para o estroma, o que causa uma diminuição no seu gradiente até que o sistema atinja o equilíbrio (10 $\mathrm{min})$, quando o influxo inicial de $\mathrm{P}_{\mathrm{i}}$ é compensado pelo seu efluxo, e $\Delta \mu_{\mathrm{P}_{\mathrm{i}}}+\Delta \mu_{\mathrm{TP}}=0$.

Já o segundo experimento corresponde à Figura 1 (e) da Ref. [34], conforme reproduzimos no gráfico da Figura 2.11 (b). Tal gráfico mostra a quantidade de $\mathrm{P}_{\mathrm{i}}$ s transportados para o estroma para concentrações externas de $\mathrm{P}_{\mathrm{i}}$ variando de 0 a $10 \mathrm{mmol}^{-1}$. As barras de erro foram obtidas utilizando 3 réplicas. 

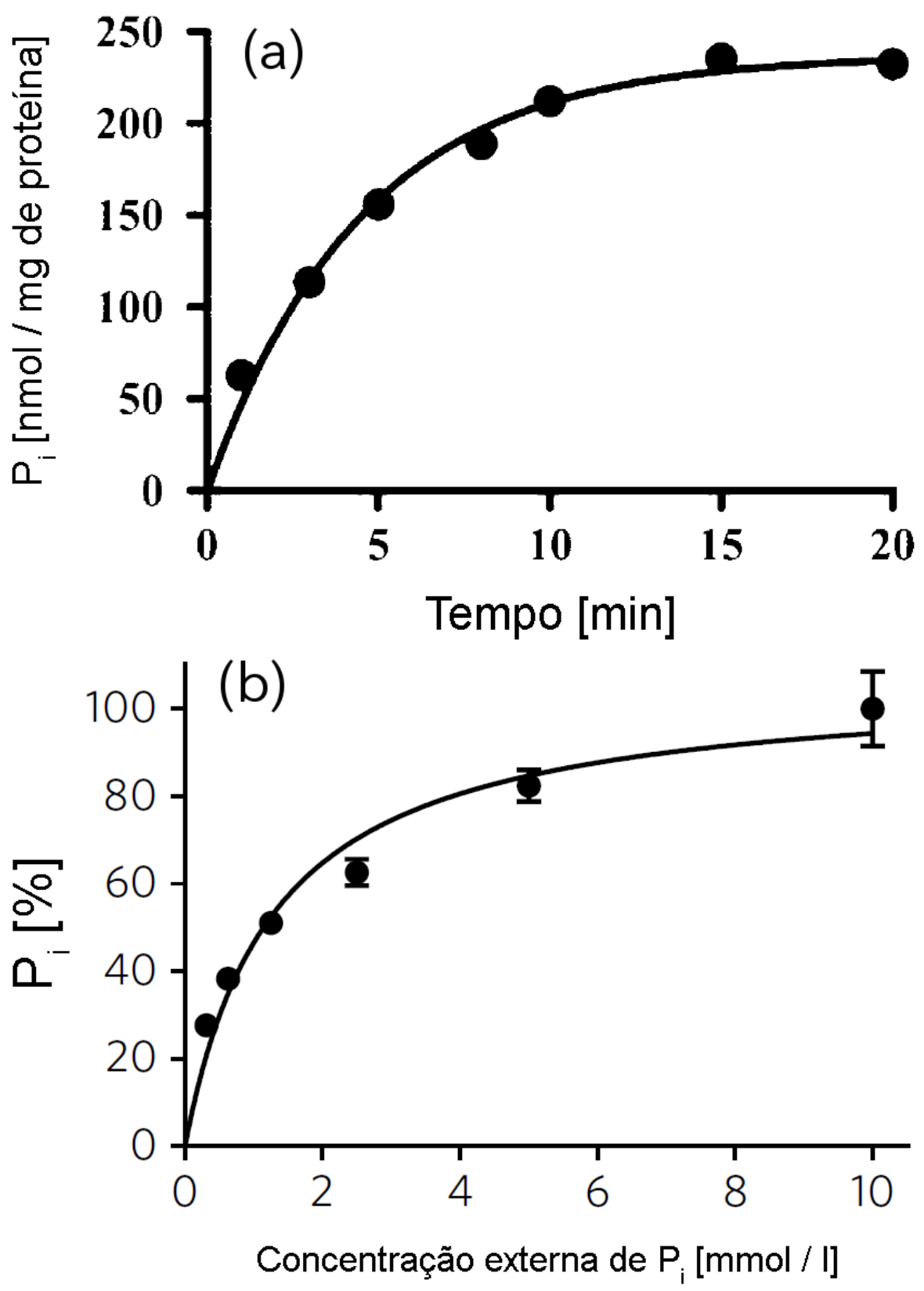

Figura 2.11: Resultados experimentais para o TPT. (a) Evolução temporal do influxo do fosfato inorgânico, $P_{\mathrm{i}}$, em um experimento realizado por Linka e outros [53]. (b) Quantidade de $\mathrm{P}_{\mathrm{i}} \mathrm{s}$ transportados para o estroma como função da concentração externa de $P_{\mathrm{i}}$. Fonte: modificado da Ref. [34]. 


\section{Capítulo 3}

\section{Metodologia}

Este capitulo apresenta todo o arcabouço teórico que utilizamos para o propor o nosso modelo de mecânica estatística para o transporte ativo secundário. Em um primeiro momento, introduzimos as bases do método de Monte Carlo por meio de um exemplo de integração numérica. Em seguida, falamos sobre os processos markovianos, onde deduzimos a equação mestra e descrevemos o algoritmo de Metropolis, que é essencial neste trabalho. Por fim, apresentamos o nosso modelo, elencando as diversas hipóteses que fizemos nele. 


\subsection{Métodos de Monte Carlo}

\subsubsection{Visão geral}

Nos últimos anos, refletindo a maior disponibilidade de recursos computacionais, as simulações em computadores deram início a uma verdadeira revolução na ciência, de tal modo que a velha divisão da física nos ramos experimental e teórico precisou ser acrescida de um terceiro ramo, o da simulação computacional. Neste contexto, os métodos de Monte Carlo usam amostragens estatísticas realizadas pelo computador a partir de geradores de números aleatórios para fornecer soluções aproximadas para uma série de problemas de física, química, biologia, matemática, etc. [54]. Esses problemas podem ser tanto problemas sem cunho probabilístico, quanto problemas que são essencialmente estatísticos, como os da mecânica estatística.

Um problema típico em mecânica estatística é o de calcular o valor médio de observáveis macroscópicos de um sistema para o qual a Hamiltoniana $H(\boldsymbol{x})$, onde $\boldsymbol{x}$ é um vetor do espaço de fase, é conhecida. Esse valor médio de algum observável macroscópico $A(\boldsymbol{x})$ é calculado no ensemble canônico como

$$
\langle A(\boldsymbol{x})\rangle_{T}=\frac{1}{Z} \int \mathrm{d} \boldsymbol{x} \exp \left[-H(\boldsymbol{x}) / k_{\mathrm{B}} T\right] A(\boldsymbol{x})
$$

onde

$$
Z=\int \mathrm{d} x \exp \left[-H(\boldsymbol{x}) / k_{\mathrm{B}} T\right]
$$

O método de Monte Carlo em mecânica estatística parte da ideia de aproximar a integral da Equação (3.1), onde se integra sobre todos os estados $\{\boldsymbol{x}\}$, cada qual com peso $Z^{-1} \exp \left[-H(\boldsymbol{x}) / k_{\mathrm{B}} T\right]$, por uma somatória, utilizando somente um subconjunto característico de pontos do espaço de fase $\left\{\boldsymbol{x}_{1}, \boldsymbol{x}_{2}, \ldots, \boldsymbol{x}_{N}\right\}$, que são usados como uma amostra estatística. É possível mostrar que, se considerarmos um processo onde os pontos do espaço de fase $\boldsymbol{x}_{i}$ são selecionados de acordo com uma probabilidade $P\left(\boldsymbol{x}_{i}\right)$, a estimativa da média térmica fica [54]:

$$
\langle A(\boldsymbol{x})\rangle_{T} \approx \frac{\sum_{i=1}^{N} \exp \left[-H\left(\boldsymbol{x}_{i}\right) / k_{\mathrm{B}} T\right] A\left(\boldsymbol{x}_{i}\right) / P\left(\boldsymbol{x}_{i}\right)}{\sum_{i=1}^{N} \exp \left[-H\left(\boldsymbol{x}_{i}\right) / k_{\mathrm{B}} T\right] / P\left(\boldsymbol{x}_{i}\right)}
$$


Note, se escolhermos a distribuição $P\left(\boldsymbol{x}_{i}\right) \propto \exp \left[-H\left(\boldsymbol{x}_{i}\right) / k_{\mathrm{B}} T\right]$, a estimativa da média térmica se reduz à média aritmética simples.

Dentre todos os métodos numéricos que fazem uso do cálculo de valores em $N$ pontos no espaço $d$-dimensional para produzir uma solução aproximada, o método de Monte Carlo tem erro absoluto da estimativa que diminui como função de $N^{-1 / 2}$, enquanto que todos os outros métodos, sem o uso de algum recurso ou estrutura especial, conseguem ter, no máximo, um erro absoluto que diminui proporcionalmente a $N^{-1 / d}$ [55]. Com isso, vê-se que, se em um determinado problema o número de pontos $N$ é dobrado, no método tradicional, o gasto computacional aumenta cerca de $2^{d}$ vezes, ao passo que, no método de Monte Carlo, o aumento é de apenas $2^{2}$ vezes. Portanto, o método de Monte Carlo possui uma vantagem considerável quando d, o "tamanho do problema", aumenta, o que é comum nos problemas de mecânica estatística.

\subsubsection{Erro de Monte Carlo}

Uma forma de estimar o valor da integral da função $y(x)=\operatorname{sen}\left(\frac{\pi}{2} x\right)$ no intervalo $x \in[0,1]$ é através da distribuição aleatória de pontos no interior do quadrado definido por $x \in[0,1]$ e $y \in[0,1]$, conforme mostra a Figura 3.1. Essa estimativa é dada pela fração entre o número de pontos sob a curva, $n$, e o número total de pontos, $N$, isto é, se $I$ é o valor da integral, ou área sob a curva, e $A_{\mathrm{q}}=1$ é a área do quadrado, então $I / A_{\mathrm{q}}=n / N$, de modo que podemos escrever

$$
I=\int_{0}^{1} \mathrm{~d} x \operatorname{sen}\left(\frac{\pi}{2} x\right) \approx \frac{n}{N}
$$

Essa estimativa será tão melhor quanto maior for $N$. No caso da Figura 3.1, em um total de $N=500$ pontos, temos $n=316$ pontos sob a curva, de modo que a estimativa para a integral fica $I \approx 0.632$. Para efeitos de comparação, o valor exato dessa integral é $2 / \pi \approx 0.637$, o que leva a um erro relativo de $0.7 \%$.

O exemplo acima é um método de Monte Carlo de integração numérica que pode ser usado no cálculo de diversas integrais, especialmente aquelas que não possuem solução analítica [56]. Vamos agora discutir o erro associado a estimativa que fizemos. Em primeiro lugar, note que a variável $n$ pode ser entendida como a soma de variáveis 


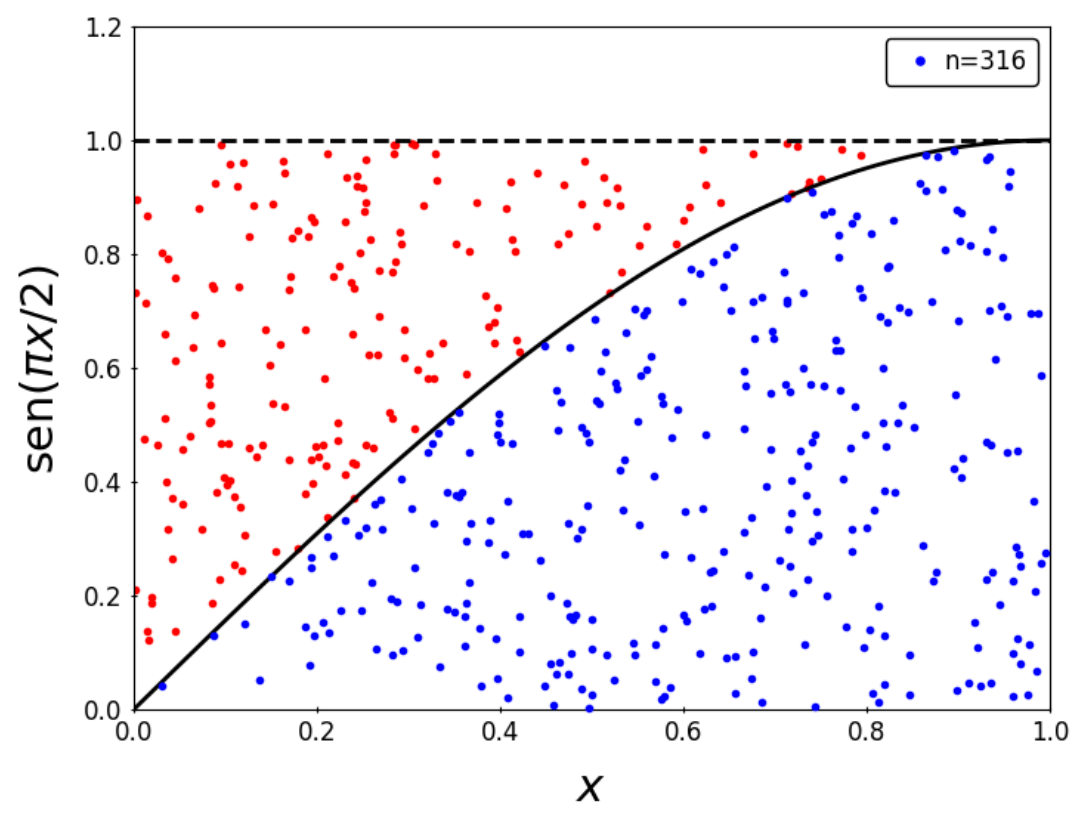

Figura 3.1: Integração de Monte Carlo. O gráfico mostra a curva da função $y(x)=$ $\operatorname{sen}\left(\frac{\pi}{2} x\right)$ no intervalo $x \in[0,1]$ e o quadrado definido por $x \in[0,1]$ e $y \in[0,1]$. Nós sorteamos 500 pontos aleatórios uniformemente distribuídos dentro do quadrado, e apresentamos em azul os 316 pontos que estão sob a curva, e em vermelho os que estão sobre a curva.

aleatórias independentes e igualmente distribuídas, $n_{i}$, que assumem o valor 1 se 0 ponto $i$ estiver sob a curva, e 0 caso contrário, ou seja,

$$
n=\sum_{i=1}^{N} n_{i}
$$

Com isso, como é possível ver da Equação (3.4), o valor da integral / é estimado por meio da média dos $N$ valores $n_{i}$. No entanto, como a soma de variáveis aleatórias também é uma variável aleatória, I pode ser entendido como uma variável aleatória flutuando ao redor do seu valor esperado com um certo desvio padrão.

Para encontrar esse desvio, usamos o fato de que as $n_{i}$ variáveis são independentes e igualmente distribuídas, e que o desvio padrão é constante para cada amostra de $n_{i}$, de modo que obtemos

$$
\sigma_{l}^{2}=\frac{1}{N^{2}} \sum_{i=1}^{N} \sigma_{n_{i}}^{2}=\frac{1}{N^{2}}\left(N \sigma_{n_{i}}^{2}\right)=\frac{1}{N} \sigma_{n_{i}}^{2}
$$


ou

$$
\sigma_{l}=\frac{1}{\sqrt{N}} \sigma_{n_{i}}
$$

que é um resultado que havíamos apresentado no item anterior, a saber, que o erro absoluto de Monte Carlo decresce proporcionalmente a $N^{-1 / 2}$. Apesar do fato de que fizemos essa demonstração para um exemplo simples, o comportamento indicado na equação acima é válida para todos os métodos de Monte Carlo [57].

\subsubsection{Gerador de números aleatórios}

Toda simulação de Monte Carlo supõe a existência de um gerador que forneça números aleatórios, os quais são definidos como números que pertencem a uma série numérica na qual nenhum membro pode ser previsto a partir dos membros anteriores da série. No entanto, os computadores digitais não são capazes de gerar números aleatórios, pois a existência de um algoritmo para gerar tais números seria contrária a própria definição de número aleatório. Mesmo assim, existem geradores que fornecem números pseudoaleatórios, que são números que aparentam terem sido tirados aleatoriamente de alguma distribuição conhecida. Em outras palavras, os geradores de números pseudoaleatórios geram números que parecem aleatórios, mas que na verdade são previsíveis, o que, não obstante, é suficiente para realizar qualquer simulação de Monte Carlo. Daqui pra frente, o prefixo "pseudo" será omitido por questões de simplicidade, ficando subentendido que um gerador de números aleatórios, na verdade, gera números pseudoaleatórios.

Assim, um bom gerador de números aleatórios deve possuir ao menos três características fundamentais. Em primeiro lugar, a sequência de números não deve se repetir, ou ao menos ela deve possuir um período de repetição suficientemente grande. Em segundo lugar, os números gerados devem estar uniformemente distribuídos entre 0 e 1. Por último, os números devem ser estatisticamente independentes entre si, ou, como ocorre na prática, a dependência entre eles não deve ser estatisticamente significativa.

Neste trabalho, nós iremos utilizar como gerador de número aleatórios a função random() do Python, que já vem como biblioteca padrão no Python 3. Essa função possui todas as três características mencionadas acima, e é suficiente para o nosso 
objetivo.

\subsubsection{Função de distribuição de probabilidade}

Para definir o que é uma função de distribuição de probabilidade (PDF, do inglês probability distribution function), é preciso distinguir entre varáveis aleatórias discretas e contínuas. A PDF de uma variável aleatória discreta $x$ é uma função que associa a cada possível ocorrência $x_{i}$ uma probabilidade $P\left(x_{i}\right)$. Por exemplo, se $x$ define a face de uma moeda não viciada quando ela é jogada, então

$$
P(x)=1 / 2, \quad x \in\{\text { Cara, Coroa }\}
$$

Para essa função, deve ser observado que

$$
0 \leq P(x) \leq 1 \quad \text { e } \quad \sum_{i} P\left(x_{i}\right)=1
$$

Já no caso das variáveis aleatórias contínuas, define-se a chamada função densidade de probabilidade, $f(x)$, de tal forma que a probabilidade $P(x)$ do valor da variável estar entre $x$ e $x+\mathrm{d} x$ é $f(x) \mathrm{d} x$. Semelhante ao caso da PDF de uma variável aleatória discreta, para essa função deve ser observado que

$$
f(x) \geq 0 \quad \text { e } \quad \int_{-\infty}^{+\infty} \mathrm{d} x f(x)=1
$$

Com isso, a probabilidade da variável $x$ estar entre a e $b$ é

$$
P(a \leq x \leq b)=\int_{a}^{b} \mathrm{~d} x f(x)
$$

Na Figura 3.2, é mostrado um exemplo de função densidade de probabilidade, a chamada função de distribuição gaussiana, ou distribuição normal, que é uma das distribuições que mais aparecem na descrição do comportamento de variáveis em fenômenos físicos, e que é definida como

$$
\varphi(x ; \mu, \sigma)=\frac{1}{\sigma \sqrt{2 \pi}} \exp \left[-\frac{1}{2}\left(\frac{x-\mu}{\sigma}\right)^{2}\right]
$$




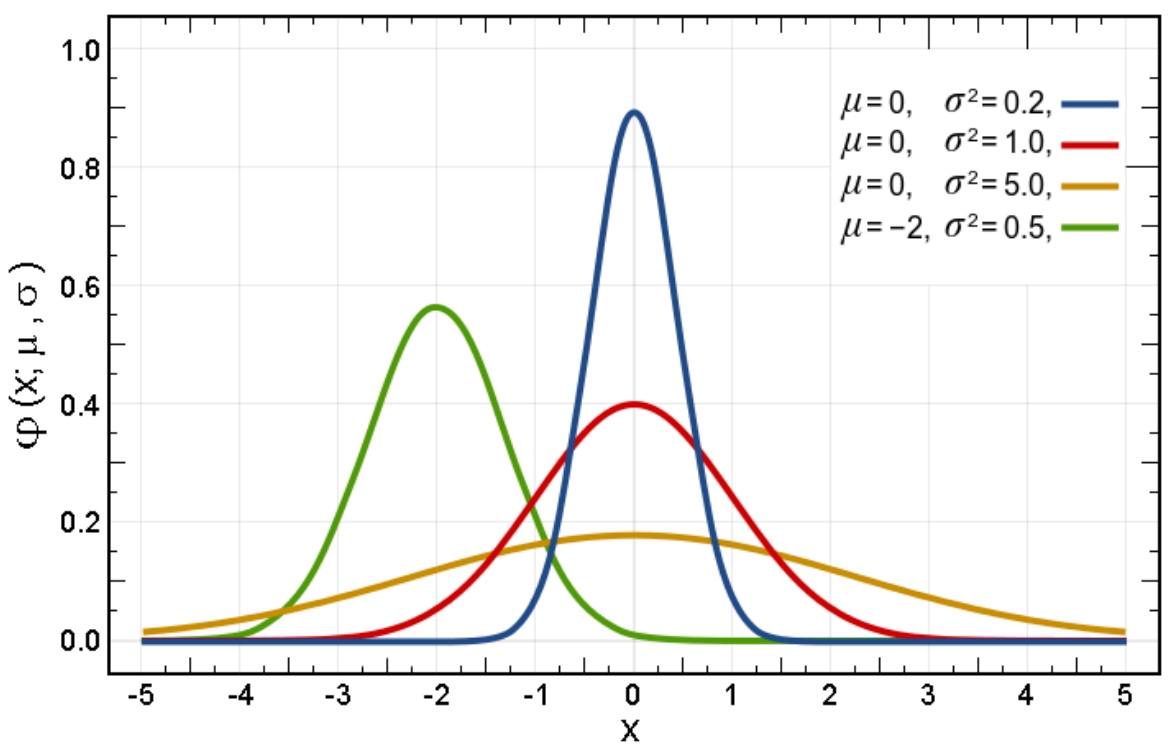

Figura 3.2: Função de distribuição gaussiana $\varphi(x ; \mu, \sigma)$ para diversos valores da média $\mu$ e do desvio padrão $\sigma$ da variável $x$.

onde $\mu \mathrm{e} \sigma$ representam a média e o desvio padrão da variável $x$, respectivamente.

\subsection{Cadeias de Markov}

\subsubsection{Processos estocásticos}

Uma variável aleatória que depende do tempo té chamada de variável estocástica. Assim, considere um processo em que o tempo possa ser discretizado como $t_{n}=n \tau$, onde $n=0,1,2, \ldots$, e que a variável estocástica $x\left(t_{n}\right)=x_{n}$ também seja discretizada. Esse processo fica completamente definido até o instante $t_{n}$ pela distribuição de probabilidade conjunta

$$
P_{n}\left(x_{0}, x_{1}, x_{2}, \ldots, x_{n}\right)
$$

de que $x$ assuma $o$ valor $x_{0}$ no instante $t_{0}, x_{1}$ no instante $t_{1}$, e assim por diante.

Agora, considere a probabilidade condicional

$$
P_{n+1}\left(x_{n+1} \mid x_{0}, x_{1}, x_{2}, \ldots, x_{n}\right)
$$

de que a variável $x$ assuma o valor $x_{n+1}$ no instante $t_{n+1}$ dado que ela assumiu o valor $x_{0}$ no instante $t_{0}, x_{1}$ no instante $t_{1}$, e assim por diante. No caso particular em que essa 
probabilidade é igual a probabilidade condicional

$$
P_{n+1}\left(x_{n+1} \mid x_{n}\right)
$$

o processo estocástico é conhecido como processo markoviano, que é um processo no qual a probabilidade condicional de uma variável estocástica assumir um determinado valor em um dado instante de tempo depende somente do valor que essa variável assumiu no instante de tempo imediatamente anterior.

A probabilidade $P_{n}\left(x_{n}\right)$ de que a variável $x$ assuma o valor $x_{n}$ no instante $t_{n}$ independente dos valores que ela tenha assumido nos instantes anteriores é dada por

$$
P_{n}\left(x_{n}\right)=\sum_{x_{0}, \ldots, x_{n-1}} P_{n}\left(x_{0}, x_{1}, x_{2}, \ldots, x_{n}\right)
$$

onde a somatória não se estende sobre $x_{n}$. Agora, a partir da definição de probabilidade condicional, e utilizando o fato de que $x$ assumir um determinado valor no instante de tempo $t_{n}$ não tem qualquer efeito sobre o valor assumido por $x$ no instante de tempo $t_{n-1}$, podemos reescrever a expressão (3.13) como

$$
P_{n}\left(x_{0}, x_{1}, x_{2}, \ldots, x_{n}\right)=P_{n}\left(x_{n} \mid x_{n-1}\right) \cdots P_{2}\left(x_{2} \mid x_{1}\right) P_{1}\left(x_{1} \mid x_{0}\right) P_{0}\left(x_{0}\right)
$$

Portanto, usando as equações (3.16) e (3.17), obtemos a seguinte relação de recorrência:

$$
P_{n}\left(x_{n}\right)=\sum_{x_{n-1}} P_{n}\left(x_{n} \mid x_{n-1}\right) P_{n-1}\left(x_{n-1}\right),
$$

onde usamos que $P_{n-1}\left(x_{n-1} \mid x_{n-2}\right)=P_{n-1}\left(x_{n-1}\right)$. A partir dessa relação de recorrência, e dado $P_{0}\left(x_{0}\right)$, é possível obter $P_{n}\left(x_{n}\right)$ em qualquer instante de tempo.

A probabilidade condicional da equação acima pode ser interpretada como uma probabilidade de transição do estado $x_{n-1}$ para o estado $x_{n}$. No caso geral, essa probabilidade de transição pode ser diferente para cada instante de tempo considerado. Já no caso particular dos processos markovianos, as probabilidades de transição não dependem do tempo, e neste caso podemos escrever

$$
P_{n+1}\left(x_{n+1} \mid x_{n}\right)=T\left(x_{n+1}, x_{n}\right)
$$


onde $T(i, j)$ são os elementos da matriz T, que é a chamada matriz estocástica. Assim, a Equação (3.18) fica

$$
P_{n}\left(x_{n}\right)=\sum_{x_{n-1}} T\left(x_{n}, x_{n-1}\right) P_{n-1}\left(x_{n-1}\right) .
$$

\subsubsection{A matriz estocástica}

Se analisarmos a Equação (3.17), veremos que um processo estocástico markoviano fica completamente definido pelas probabilidades de transição, e portanto pela matriz estocástica, e a probabilidade inicial $P_{0}\left(x_{0}\right)$. Para explicitar este fato, vamos reescrever a equação anterior em uma forma simplificada como

$$
P_{n}(i)=\sum_{j} T(i, j) P_{n-1}(j),
$$

onde estamos interpretando $P_{n}(i)$ como sendo os elementos da matriz coluna $\mathbf{P}_{n}$, de modo que a equação acima também pode ser escrita como um produto de matrizes da seguinte maneira:

$$
\mathbf{P}_{n}=\mathbf{T} \mathbf{P}_{n-1}
$$

Assim, dada a matriz coluna $\mathbf{P}_{0}$ com as probabilidades iniciais $P_{0}(i)$, pode-se obter $\mathbf{P}_{n}$ através de

$$
\mathbf{P}_{n}=\mathbf{T}^{n} \mathbf{P}_{0}
$$

de onde concluímos que, em um processo markoviano, o cálculo de $\mathbf{P}_{n}$ se reduz ao cálculo da $n$-ésima potência da matriz estocástica.

O problema fundamental dos processos markovianos é determinar quais são as propriedades da matriz estocástica T para que

$$
\lim _{n \rightarrow \infty} \mathbf{P}_{n}=\mathbf{P}
$$

onde $\mathbf{P}$ é a solução estacionária, isto é, a solução que satisfaz a equação

$$
\mathbf{T} \mathbf{P}=\mathbf{P} .
$$


A matriz T é uma matriz quadrada que possui as seguintes propriedades:

$$
T(i, j) \geq 0 \quad \text { e } \quad \sum_{i} T(i, j)=1
$$

A primeira propriedade está relacionada ao fato de que $T(i, j)$ é uma probabilidade, e, portanto, deve ser positiva. A segunda propriedade, que diz que a soma dos elementos de uma coluna qualquer deve ser 1, vem da normalização das probabilidades. Qualquer matriz quadrada que possua essas duas propriedades pode ser interpretada como uma matriz estocástica.

\subsubsection{A equação mestra}

O nosso objetivo é introduzir a equação mestra, que é uma equação que governa a evolução temporal dos processos estocásticos markovianos. Para isso, considere a matriz estocástica $T(i, j)$ de uma cadeia de Markov onde as transições ocorrem a cada intervalo de tempo $\tau$. Considere ainda que $\tau$ seja pequeno. Neste caso, a probabilidade de permanência no mesmo estado é muito próxima da unidade, enquanto que a probabilidade de transição entre dois estados diferentes é praticamente nula. Para explicitar isso, a matriz estocástica pode ser escrita como

$$
T(i, j)=\tau W(i, j)
$$

para $i \neq j, \mathrm{e}$

$$
T(i, i)=1-\tau T^{\prime}(i)
$$

A matriz $W(i, j)$ pode ser interpretada como uma probabilidade de transição do estado $j$ para o estado $i$ por unidade de tempo, ou taxa de transição de $j$ para $i$. Além disso, utilizando a segunda propriedade da relação (3.26), temos que

$$
T^{\prime}(i)=\sum_{j \neq i} W(i, j)
$$

A equação mestra é obtida a partir da relação de recorrência expressa na Equa- 
ção (3.21), a qual podemos escrever em uma forma ligeiramente diferente como

$$
P_{n+1}(i)=\sum_{j \neq i} T(i, j) P_{n}(j)+T(i, i) P_{n}(i),
$$

ou, usando as equações (3.27) e (3.28),

$$
P_{n+1}(i)=\tau \sum_{j \neq i} W(i, j) P_{n}(j)+P_{n}(i)-\tau T^{\prime}(i) P_{n}(i) .
$$

Assim, lembrando que o tempo $t$ é dado por $t_{n}=n \tau$, e definindo a notação $P_{n}(i)=$ $P(i, t)$, a equação acima fornece que

$$
\frac{P(i, t+\tau)-P(i, t)}{\tau}=\sum_{j \neq i} W(i, j) P(j, t)-T^{\prime}(i) P(i, t) .
$$

Por fim, tomando o limite $\tau \rightarrow 0$, o lado esquerdo da relação acima se torna a derivada temporal de $P(i, t)$, de modo que

$$
\frac{\mathrm{d}}{\mathrm{d} t} P(i, t)=\sum_{j \neq i}\{W(i, j) P(j, t)-W(j, i) P(i, t)\},
$$

onde usamos a Equação (3.29) para explicitar $T^{\prime}(i)$. A equação acima é conhecida como "equação mestra". Como se pode ver dela, toda a dificuldade no cálculo da evolução temporal de $P(i, t)$ reside na obtenção das taxas de transição $W(i, j)$. Em problemas físicos de interesse, devemos calcular essas probabilidades a partir de primeiros princípios, ou adotar formas consistentes com os aspectos físicos do problema em questão [27].

Como ilustração de aplicação da equação mestra, vamos considerar o problema do caminho aleatório generalizado. Esse problema é semelhante ao problema do caminho aleatório que introduzimos na Seção 1.3.2, exceto pelo fato de que as transições dependem da posição em que a partícula se encontra. Relembramos aqui que a partícula se desloca ao longo de um eixo a partir da origem dando passos de comprimento $\ell$, de modo que as posições possíveis ao longo do eixo são $x_{m}=m \ell$. Além disso, a cada intervalo de tempo $\tau$, pequeno, a partícula se move para a direita com probabilidade $\tau p_{m}$, ou para a esquerda com probabilidade $\tau q_{m}=1-\tau p_{m}$. Com isso, as taxas 
de transição são dadas por

$$
W(m+1, m)=p_{m} \quad \text { e } \quad W(m-1, m)=q_{m}
$$

sendo as outras taxas de transição nulas. Assim, a equação mestra se torna

$$
\frac{\mathrm{d} P_{m}}{\mathrm{~d} t}=q_{m+1} P_{m+1}+p_{m-1} P_{m-1}-\left(q_{m}+p_{m}\right) P_{m}
$$

No caso particular em que $p_{m}=\tau^{-1} p$ e $q_{m}=\tau^{-1} q$, nós retomamos a relação de recorrência do caminho aleatório usual, expressa na Equação (1.16).

\subsubsection{O algoritmo de Metropolis}

Nos estados estacionários, a probabilidade $P(i, t)$ não deve ser uma função do tempo, ou seja,

$$
\frac{\mathrm{d} P}{\mathrm{~d} t}=0
$$

na situação de equilíbrio. Portanto, uma condição suficiente para o equilíbrio é dada pela equação mestra como

$$
P(i) W(j, i)=P(j) W(i, j)
$$

Essa condição é conhecida como princípio do balanço detalhado, e indica que, na situação estacionária, devemos ter o mesmo número de transições de $i$ para $j$ e de $j$ para $i$.

Dentro da área das simulações de Monte Carlo, frequentemente as taxas de transição $W(i, j)$ são escolhidas a fim de satisfazer a equação do balanço detalhado quando $t \rightarrow \infty$, ou seja,

$$
P(i, t \rightarrow \infty) W(j, i)=P(j, t \rightarrow \infty) W(i, j)
$$

Essa escolha garante que, para tempos suficientemente grandes, o sistema atingirá um estado final de equilíbrio. Neste estado, sabe-se que as probabilidades devem 
tender para os valores de Gibbs,

$$
P(i, t \rightarrow \infty) \rightarrow \frac{1}{Z} \exp \left(-\beta E_{i}\right),
$$

onde $E_{i}$ é a energia do estado $i$. Assim, as taxas de transição devem ser escolhidas de tal forma que

$$
\frac{W(j, i)}{W(i, j)}=\exp \left(-\beta \Delta E_{i j}\right)
$$

onde $\Delta E_{i j}=E_{j}-E_{i}$.

Existem diversas escolhas para as taxas $W(i, j)$ que satisfazem a equação acima. Uma escolha muito frequente em simulações de Monte Carlo é a escolha de Metropolis, dada por

$$
W_{\mathrm{M}}(j, i)= \begin{cases}\exp \left(-\beta \Delta E_{i j}\right), & \Delta E_{i j}>0, \\ 1, & \Delta E_{i j} \leq 0 .\end{cases}
$$

É possível verificar que $W_{\mathrm{M}}(j, i)$ satisfaz a Equação (3.40). Computacionalmente, esta prescrição de Metropolis é implementada da seguinte forma. Em primeiro lugar, começamos por um estado qualquer, $S_{0}$. Então, o estado seguinte, $S_{1}$, é gerado pelo chamado algoritmo de Metropolis. Tal algoritmo consiste em escolhermos aleatoriamente um estado qualquer da vizinhança de $S_{0}$, digamos $S_{0}^{\prime}$, e calcularmos a diferença $\Delta E=E_{S_{0}^{\prime}}-E_{S_{0}}$. Com isso,

(i) Se $\Delta E \leq 0$, então o novo estado será de fato $S_{0}^{\prime}$, isto é, $S_{1}=S_{0}^{\prime}$.

(ii) Se $\Delta E>0$, então calculamos $p=\exp (-\beta \Delta E)$ e geramos um número aleatório $R$ uniformemente distribuído entre 0 e 1 . Se $R \leq p$, então $S_{1}=S_{0}^{\prime}$, caso contrário, $S_{1}=S_{0}$, isto é, o estado não se altera.

Após gerar o estado $S_{1}$, nós usamos ele para gerar o estado $S_{2}$ por meio do algoritmo de Metropolis, e após isso nós usamos o estado $S_{2}$ para gerar o estado $S_{3}$, e assim por diante, de modo que o algoritmo descrito acima permite obter uma sequência de estados $S_{0}, S_{1}, S_{2}, S_{3}, \ldots$ que constituem uma cadeia de Markov. O estado de equilíbrio é obtido após um certo número de estados, sendo esse número um parâmetro individual de cada problema. 


\subsection{Hipóteses de trabalho}

Neste item, nós iremos aplicar o arcabouço teórico apresentado acima às informações do nosso levantamento bibliográfico e, com isso, propor um modelo de mecânica estatística que descreve quantitativamente a dinâmica do transporte ativo secundário.

\subsubsection{Modelo do caminho aleatório para a LacY}

Nosso ponto de partida é o fato de que a curva de energia livre para o ciclo de transporte representado na Figura 2.4 não está estabelecido na literatura. A única informação que nós temos é a de que o Estado 2 é o estado fundamental [45]. Portanto, o seguinte procedimento foi adotado para obter essa curva de energia livre. Em primeiro lugar, nós assumimos que as interações resíduo-resíduo são ligações de hidrogênio, que variam entre 2 e $5 k_{\mathrm{B}} T$, e que as interações próton-resíduo e lactose-resíduo são ligações de Van der Waals, que variam entre 1 e $2 k_{\mathrm{B}} T$. Esta suposição é baseada em uma descrição detalhada das interações entre os elementos do modelo de Kaback [31] e dados da literatura sobre ligações de hidrogênio em proteínas [58]. Então, com base nas diferenças no número de ligações de hidrogênio e Van der Waals entre os estados da LacY e o estado fundamental, o que pode ser facilmente obtido da Figura 2.4, nós determinados um intervalo $\left(0, \Delta E_{S}^{\text {máx }}\right]$ de valores possíveis para cada uma das cinco variações de energia livre $\Delta E_{S}=E_{S}-E_{2}>0$, onde $S$ são os estados. Após isso, nós incorporamos nesses intervalos o efeito de uma diferença de potencial elétrico $\Delta \Psi$ através da membrana celular, que em todas as células vivas é de tipicamente $-100 \mathrm{mV}$ [59], correspondendo ao gradiente elétrico $\Delta \mu_{\Psi} \approx-4 k_{\mathrm{B}} T$. Isso pode ser feito por meio do mapeamento dos intervalos dos estados protonados $(S=\{2,3,4,5\})$ em $\left(-4 k_{\mathrm{B}} T, \Delta E_{S}^{\text {máx }}-4 k_{\mathrm{B}} T\right]$, ou, equivalentemente, por meio do mapeamento dos intervalos dos estados desprotonados $(S=\{1,6\})$ em $\left[4 k_{\mathrm{B}} T, \Delta E_{S}^{\text {máx }}+4 k_{\mathrm{B}} T\right]$. Por conveniência, nós escolhemos a última opção, uma vez que ela tem a vantagem de manter o estado fundamental inalterado. Os intervalos resultantes estão indicados na Figura 3.3.

Em seguida, nós consideramos de cada intervalo valores discretos igualmente espaçados por $\delta k_{\mathrm{B}} T$, onde $\delta$ é um parâmetro livre. Valores de $\delta$ acima de 1 reduzem consideravelmente a precisão do nosso modelo. Valores de $\delta$ abaixo de 0.25 geram 


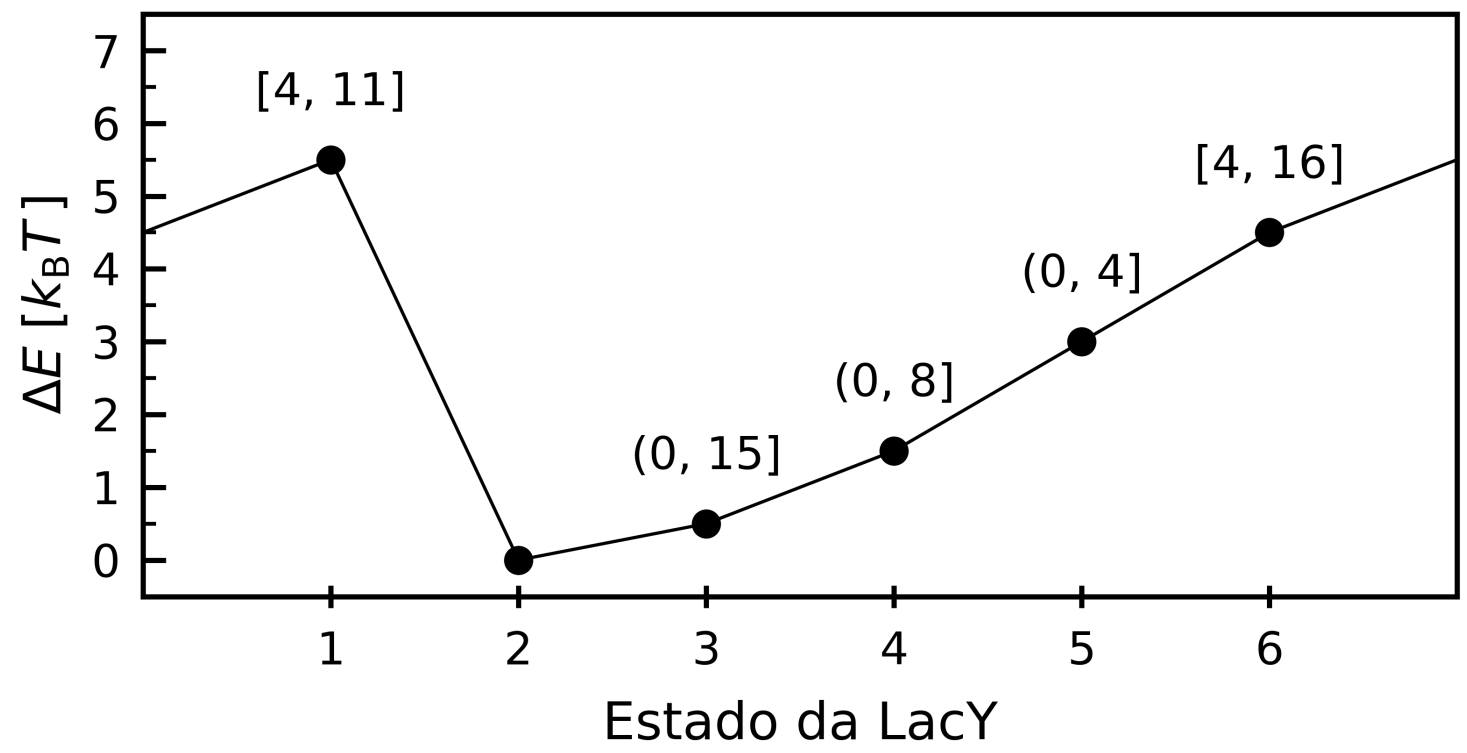

Figura 3.3: Variações de energia livre entre os estados da LacY e o estado fundamental. Também são mostrados os intervalos de valores possíveis para cada $\Delta E_{S}=E_{S}-E_{2}>0$ que foram usados para encontrar a melhor curva de energia livre.

muitas curvas de energia livre para serem testadas, e estão muito além da precisão dos dados experimentais disponíveis na literatura. Assim, aqui nós usamos $\delta=0.5$. Nós testamos todas as possíveis combinações desses valores e descartamos as combinações que não seguem as três condições de contorno (CCs) estabelecidas na literatura que a LacY deve seguir [31]. A primeira CC é quando há um $\Delta \tilde{\mu}_{\mathrm{H}^{+}}$alto apontando do citoplasma para o periplasma. Nessa condição, o influxo de lactose deve predominar sobre o efluxo. Para implementar essa CC, nós realizamos simulações com $\Delta \tilde{\mu}_{\mathrm{H}^{+}} \ll 0$ e contamos, para cada combinação possível, o número de ciclos de influxo e efluxo. Após isso, nós descartamos as combinações nas quais o número de ciclos de efluxo é menor que o número de ciclos de influxo na média. Em segundo lugar, o passo determinante de taxa (em inglês, turnover number) do ciclo de transporte quando $\Delta \mu_{\mathrm{H}^{+}}=0$ deve ser a desprotonação $2 \rightarrow 1$. Essa $\mathrm{CC}$ foi implementada realizando simulações com $\Delta \mu_{\mathrm{H}^{+}}=0$ para as combinações que não foram descartadas na primeira CC. Em cada simulação, o passo determinante de taxa foi definido pelo tempo de ocupação da LacY em cada um dos seus seis estados. Nós descartamos as combinações nas quais o passo determinante de taxa não foi a desprotonação $2 \rightarrow 1$. Finalmente, a terceira condição de contorno é que, quando $\Delta \mu_{\mathrm{H}^{+}}=0$, o fluxo de lactose deve ser 


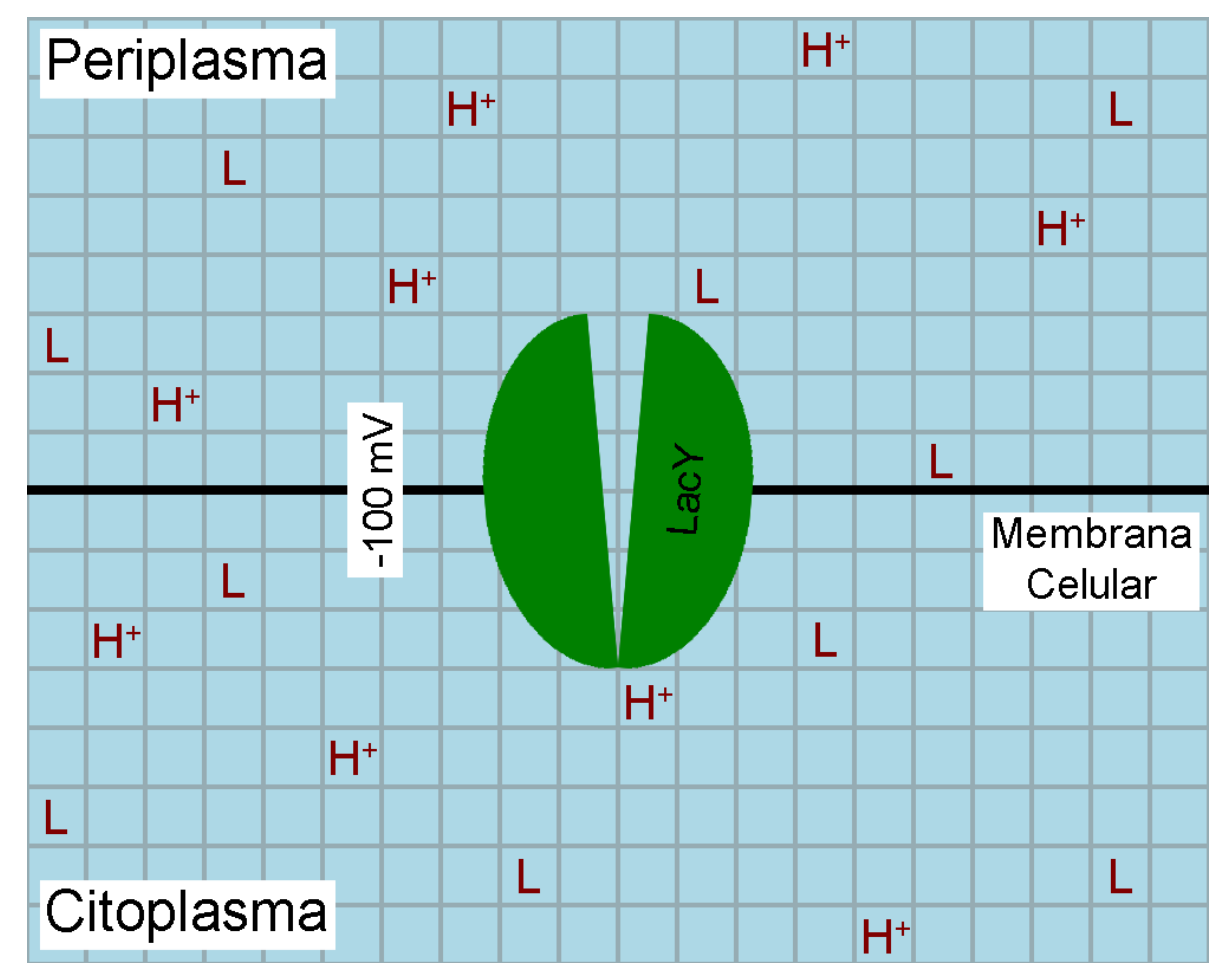

Figura 3.4: Modelo do caminho aleatório para a LacY.

controlado exclusivamente por $\Delta \mu_{\mathrm{L}}$. Isso foi implementado definindo concentrações iguais de $\mathrm{H}^{+}$em ambos os lados da membrana, digamos $\mathrm{C}_{\mathrm{H}^{+}}$, e então testando se as frações de lactose no equilíbrio se mantém inalteradas para $0.1 C_{\mathrm{H}^{+}}, 10 C_{\mathrm{H}^{+}}$, e $100 C_{\mathrm{H}^{+}}$. Nós descartamos as combinações nas quais as frações de lactose mudaram significativamente. Após isso, nós escolhemos dentre as poucas combinações restantes a combinação que apresenta o menor número de ciclos de efluxo completados na média quando o sistema é submetido a um $\Delta \tilde{\mu}_{\mathrm{H}^{+}} \gg 0$, uma vez que o efluxo de lactose deve ser nulo nesta condição. A curva de energia livre resultante está mostrada na Figura 3.3.

Nosso sistema consiste de um citoplasma e um periplasma com volumes $V_{c}$ e $V_{p}$, respectivamente, separados por uma membrana celular de tamanho desprezível com uma LacY embutida. Os volumes do citoplasma e do periplasma são divididos em uma rede de $\Omega_{\mathrm{c}}$ e $\Omega_{\mathrm{p}}$ caixas, respectivamente. Em cada simulação, nós definimos um número inicial de moléculas de lactose no citoplasma e no periplasma, $N_{\mathrm{L}, \mathrm{c}} \mathrm{e}$ $N_{\mathrm{L}, \mathrm{p}}$, respectivamente, e um número inicial de prótons no citoplasma e no periplasma, $N_{\mathrm{H}^{+}, \mathrm{c}}$ e $N_{\mathrm{H}^{+}, \mathrm{p}}$, respectivamente. A energia total disponível para realizar trabalho nesse sistema é dada pela mudança na energia livre de Gibbs através da membrana, $\Delta G=$ 
$\Delta \mu_{\mathrm{H}^{+}}+\Delta \mu_{\Psi}+\Delta \mu_{\mathrm{L}}$, onde

$$
\frac{\Delta \mu_{\mathrm{H}^{+}}}{k_{\mathrm{B}} T}=\ln \left(\frac{N_{\mathrm{H}^{+}, \mathrm{c}} / \Omega_{\mathrm{c}}}{N_{\mathrm{H}^{+}, \mathrm{p}} / \Omega_{\mathrm{p}}}\right),
$$

e

$$
\frac{\Delta \mu_{\mathrm{L}}}{k_{\mathrm{B}} T}=\ln \left(\frac{N_{\mathrm{L}, \mathrm{c}} / \Omega_{\mathrm{c}}}{N_{\mathrm{L}, \mathrm{p}} / \Omega_{\mathrm{p}}}\right) .
$$

Tal sistema está representado na Figura 3.4. Em nossas simulações, assume-se que a probabilidade de que haja um soluto próximo da entrada da LacY disponível para ser capturado é dada pela Equação (1.12), ou seja,

$$
\begin{gathered}
\Pi_{\mathrm{L}, \mathrm{c}}=N_{\mathrm{L}, \mathrm{c}} / \Omega_{\mathrm{c}}, \\
\Pi_{\mathrm{L}, \mathrm{p}}=N_{\mathrm{L}, \mathrm{p}} / \Omega_{\mathrm{p}}, \\
\Pi_{\mathrm{H}^{+}, \mathrm{c}}=N_{\mathrm{H}^{+}, \mathrm{c}} / \Omega_{\mathrm{C}}, \\
\Pi_{\mathrm{H}^{+}, \mathrm{p}}=N_{\mathrm{H}^{+}, \mathrm{p}} / \Omega_{\mathrm{p}} .
\end{gathered}
$$

A cada passo de MC, a LacY tem a mesma probabilidade de se mover na direção horária e anti-horária. No entanto, esse movimento pode ser frustrado ou pela limitação da concentração, ou pelo algoritmo de Metropolis, conforme descrito na Seção 3.2.4.

Este modelo que nós propusemos aqui é um caminho aleatório não-homogêneo, onde as probabilidades de transição da cadeia de Markov são determinadas pela curva de energia livre da Figura 3.3 e as concentrações dos substratos no citoplasma e no periplasma [60]. A título de exemplo, iremos apresentar o algoritmo do nosso modelo quando o sistema se encontra no Estado 2 da Figura 2.4. Em primeiro lugar, sorteamos um número aleatório $R_{1}$ uniformemente distribuído no intervalo [0,1]. Se $R_{1}>\Pi_{\mathrm{L}, \mathrm{p}}$, então não há nenhuma lactose disponível no periplasma para ser capturada, e consequentemente o sistema tentará a transição do Estado 2 para o Estado 1. Para determinar se essa transição de fato irá ocorrer, utilizamos o algoritmo de Metropolis. Primeiro, sorteamos um número aleatório $R_{2}$. Se $R_{2} \leq \exp \left(-\beta \Delta E_{21}\right)$, então a transição ocorre, caso contrário, a transição não ocorre, e o sistema permanece no Estado 2 neste passo de Monte Carlo. Por outro lado, se $R_{1} \leq \Pi_{\mathrm{L}, \mathrm{p}}$, então há uma 
lactose disponível no periplasma para ser capturada. Neste caso, sorteamos um número aleatório $R_{3}$. Se $R_{3}>0.5$, então o sistema tentará a transição $2 \rightarrow 1$, da mesma forma como explicamos anteriormente. Agora, se $R_{3} \leq 0.5$, então o sistema tentará a transição $2 \rightarrow 3$. Para determinar se essa transição de fato ocorre, nos valemos novamente do algoritmo de Metropolis, com $i=2$ e $j=3$. Assim se encerra um passo de Monte Carlo.

Os algoritmos para os demais estados são similares a esse algoritmo que descrevemos acima, e todos eles estão no Apêndice A, onde apresentamos o código computacional que desenvolvemos em linguagem Python para implementar nosso modelo do caminho aleatório não-homogêneo. Por fim, note que, a partir desses algoritmos, pode-se determinar a matriz estocástica da LacY como

$$
\mathbf{T}_{\mathrm{LacY}}=\frac{1}{2}\left[\begin{array}{cccccc}
0 & \frac{\xi_{\mathrm{L}, \mathrm{p}}}{e^{5.5}} & 0 & 0 & 0 & \frac{\xi_{\mathrm{H}^{+}, \mathrm{c}}}{e} \\
\Pi_{\mathrm{H}^{+}, \mathrm{p}} & 2-\frac{\xi_{\mathrm{L}, \mathrm{p}}}{e^{5.5}}-\frac{\Pi_{\mathrm{L}, \mathrm{p}}}{e^{0.5}} & 1 & 0 & 0 & 0 \\
0 & \frac{\Pi_{\mathrm{L}, \mathrm{p}}}{e^{0.5}} & \eta_{1} & 1 & 0 & 0 \\
0 & 0 & \frac{1}{e} & \eta_{1.5} & \Pi_{\mathrm{L}, \mathrm{c}} & 0 \\
0 & 0 & 0 & \frac{1}{e^{1.5}} & \xi_{\mathrm{L}, \mathrm{c}} \eta_{1.5} & \Pi_{\mathrm{H}^{+}, \mathrm{c}} \\
\xi_{\mathrm{H}^{+}, \mathrm{p}} & 0 & 0 & 0 & \frac{\xi_{\mathrm{L}, \mathrm{c}}}{e^{1.5}} & \xi_{\mathrm{H}^{+}, \mathrm{c}} \eta_{1}
\end{array}\right],
$$

onde definimos

$$
\xi=2-\Pi \text { e } \eta_{\alpha}=1-e^{-\alpha}
$$

\subsubsection{Modelo do caminho aleatório para o TPT}

Em 2018, Takemoto e outros realizaram simulações de Dinâmica Molecular para o TPT baseadas em um modelo simplificado que considera apenas o transporte de $\mathrm{P}_{\mathrm{i}}$, sem triose-P, conforme descrevemos na Seção 2.2.3. Por outro lado, neste presente trabalho, nós estamos propondo, com base no modelo de Takemoto, um mecanismo completo para o ciclo de transporte do TPT, incluindo a triose-P. Nosso modelo possui sete estados, iniciando com o TPT na conformação $\mathrm{C}_{\text {fora }}$ com uma TP no sítio de liga- 


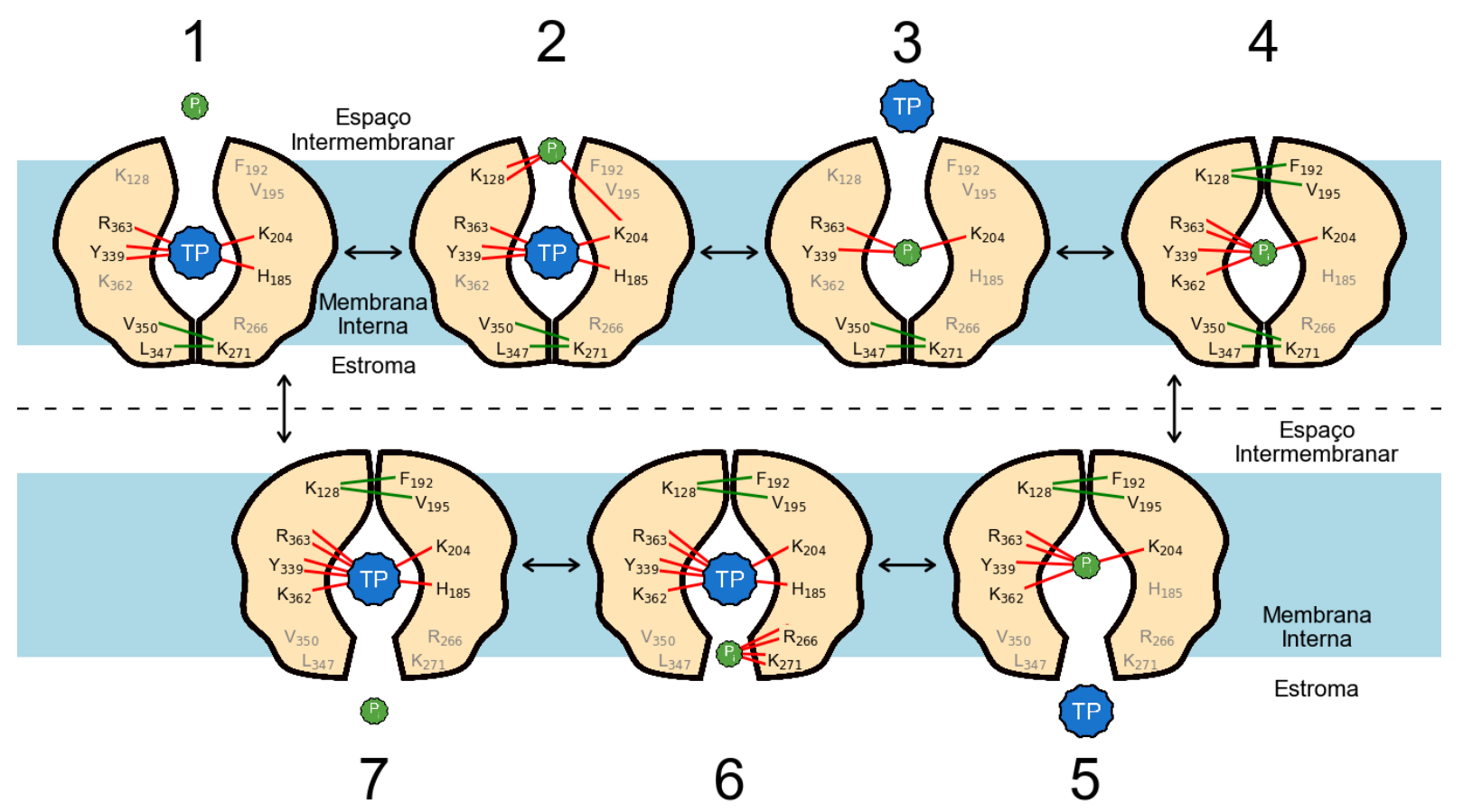

Figura 3.5: Mecanismo do transporte de triose-fosfato pelo TPT. Os resíduos principais estão identificados. Ligações de hidrogênio e de Van der Waals são mostradas como linhas verdes e vermelhas, respectivamente. A triose-fosfato (TP) e o fosfato inorgânico $\left(P_{i}\right)$ são representados como círculos ondulados azul e verde, respectivamente.

ção central (Fig. 3.5, Estado 1). Então, um $\mathrm{P}_{\mathrm{i}}$ é capturado do espaço intermembranar pelos resíduos $\mathrm{K}_{128}$ e $\mathrm{K}_{204}(1 \rightarrow 2)$. Neste estado, a TP e o $\mathrm{P}_{\mathrm{i}}$ mudam de posição $(2 \rightarrow 3)$, liberando a TP no espaço intermembranar (Fig. 3.5, Estado 3). Após isso, uma transição para a conformação $\mathrm{C}_{\text {oclusa }}$ ocorre $(3 \rightarrow 4)$. Essa transição está associada com as duas ligações de hidrogênio formadas entre os resíduos $K_{128}, F_{192}$ e $V_{195}$ (Fig. 3.5, Estado 4). No passo seguinte, as duas ligações de hidrogênio entre os resíduos $V_{350}, L_{347}$ e $K_{271}$ são rompidas, levando a uma transição para a conformação $\mathrm{C}_{\text {dentro }}(4 \rightarrow 5)$. Uma TP é então capturada do estroma do cloroplasto $(5 \rightarrow 6)$, mudando de posição com o $\mathrm{P}_{\mathrm{i}}$ no sítio de ligação central (Fig. 3.5, Estado 6). Finalmente, o $\mathrm{P}_{\mathrm{i}}$ é liberado no estroma $(6 \rightarrow 7)$, permitindo uma transição para a conformação $\mathrm{C}_{\text {fora }}$ $(7 \rightarrow 1)$. Esse mecanismo de transporte corresponde ao transporte de TP na direção de efluxo, horária. No entanto, o transporte na direção de influxo, anti-horária, também pode ser explicada por este modelo, uma vez que o influxo e o efluxo são processos funcionalmente simétricos. Esse mecanismo para o ciclo de transporte do TPT que propusemos é inteiramente baseado nas imagens de raio-X obtidas na Ref. [34].

O ponto de partida para mapearmos este ciclo de transporte descrito acima em 


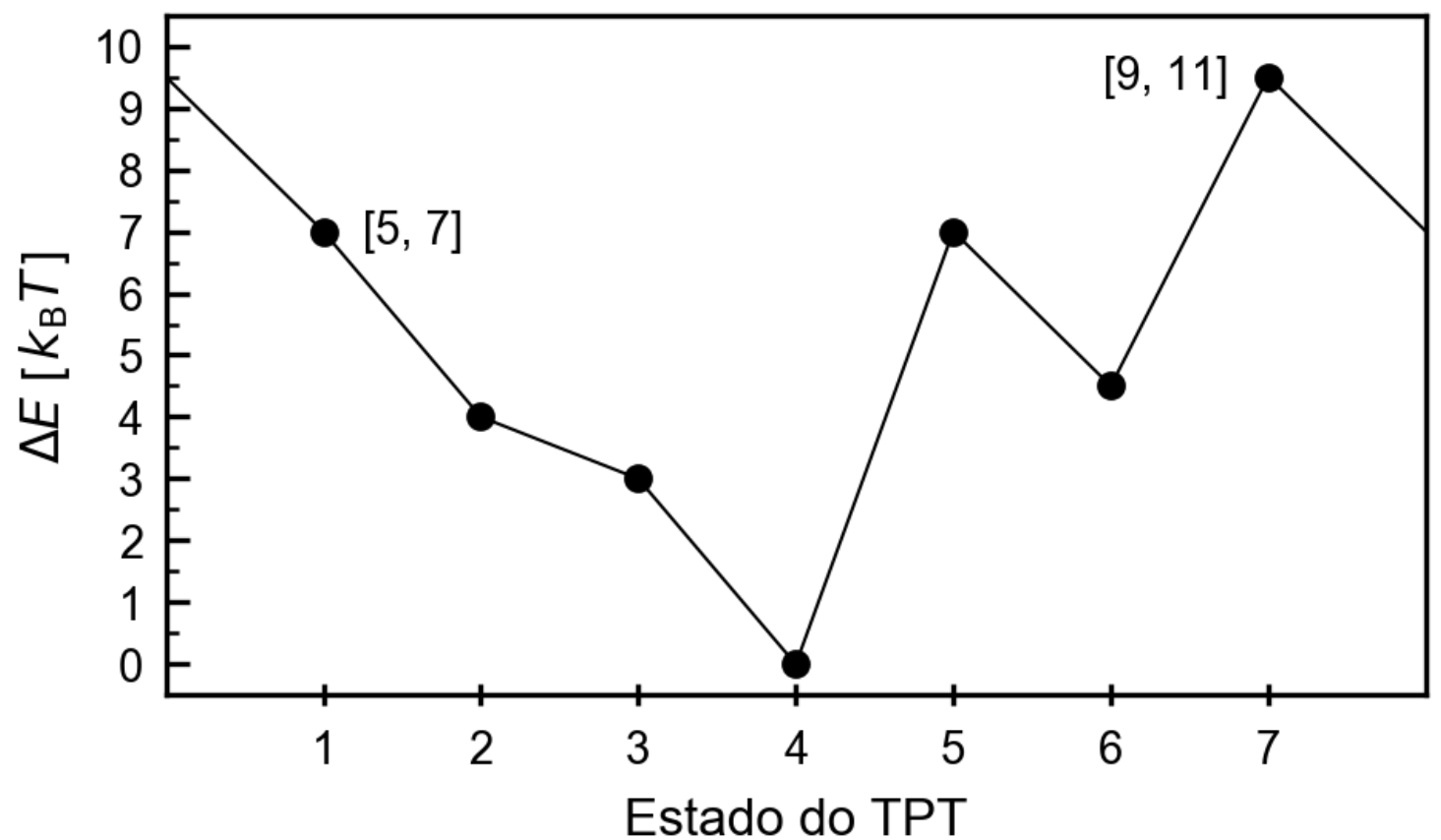

Figura 3.6: Variações de energia livre entre os estados do TPT e o seu estado fundamental. Também são mostrados os intervalos de valores possíveis para $\Delta E_{1}$ e $\Delta E_{7}$ que foram usados para encontrar a melhor curva de energia livre.

um modelo de mecânica estatística são os valores das variações de energia livre entre os estados do TPT e o seu estado fundamental. Apesar do fato desses valores não estarem estabelecidos na literatura, nós temos a informação de que o Estado 4 é o estado fundamental [52], além de termos a curva de energia livre do modelo de Takemoto, conforme reproduzimos na Figura 2.10. Assim, para se obter os seis $\Delta E_{S}=E_{S}-E_{4}$, foi adotado o seguinte procedimento. Em primeiro lugar, pode-se ver que as transições $4 \rightarrow 3$ e $4 \rightarrow 5$ são equivalentes às transições $\mathrm{Occ} \rightarrow \mathrm{OF}_{\mathrm{b}}^{\text {cent }} \mathrm{e}$ $\mathrm{Occ} \rightarrow \mathrm{IF}_{\mathrm{b}}^{\text {cent }}$ do modelo de Takemoto, respectivamente. Consequentemente, $\Delta E_{3}=$ $3 k_{\mathrm{B}} T$ e $\Delta E_{5}=7 k_{\mathrm{B}} T$. Em segundo lugar, os estados 1 e 7 são iguais aos estados $\mathrm{OF}_{\mathrm{b}}^{\text {cent }}$ e $\mathrm{IF}_{\mathrm{b}}^{\text {cent }}$, respectivamente, mas com uma TP no lugar do $\mathrm{P}_{\mathrm{i}}$. Em termos de suas interações, a diferença entre os estados 1 e OF $_{b}^{\text {cent }}$ são duas ligações de Van der Waals. O mesmo para a diferença entre os estados 2 e $\mathrm{IF}_{\mathrm{b}}^{\text {cent }}$. Com isso, como nós sabemos que a energia de uma ligação de Van der Waals varia entre 1 e $2 k_{\mathrm{B}} T$, nós temos que $\Delta E_{1}=[5,7]$ e $\Delta E_{7}=[9,11]$. Em terceiro lugar, a variação de energia livre entre os estados 2 e 1 é igual a variação de energia livre entre $\mathrm{OF}_{\mathrm{b}}^{\text {extra }}$ e $\mathrm{OF}_{\mathrm{a}}$, resultando em $\Delta E_{2}=\Delta E_{1}-3 k_{\mathrm{B}} T$. Por um raciocínio semelhante, nós obtemos que 
$\Delta E_{6}=\Delta E_{7}-5 k_{\mathrm{B}} T$. Os intervalos de valores possíveis para as variações de energia livre $\Delta E_{1}$ e $\Delta E_{7}$ estão indicadas na Figura 3.6.

Em seguida, nós consideramos de cada um desses dois intervalos valores discretos igualmente espaçados por $0.5 k_{\mathrm{B}} T$. Nós testamos todas as 25 combinações com esses valores e descartamos as combinações que não seguem as duas condições de contorno estabelecidas na literatura que o TPT deve seguir. A primeira condição de contorno é que, quando há um $\Delta \mu_{\mathrm{P}_{\mathrm{i}}}$ alto apontando do estroma para o espaço intermembranar, o efluxo de TP deve predominar sobre o influxo. A segunda condição é que, quando $\Delta \mu_{\mathrm{P}_{\mathrm{i}}}=0$, o fluxo de TP deve ser controlado exclusivamente por $\Delta \mu_{\mathrm{TP}}$. Após isso, nós escolhemos dentre as poucas combinações restantes a combinação que apresentou o menor número de ciclos de influxo completados na média quando o sistema é submetido a um $\Delta \mu_{\mathrm{P}_{\mathrm{i}}} \gg 0$, uma vez que o influxo de TP deve ser nulo nesta condição. A curva de energia livre resultante está mostrada na Figura 3.6.

Nosso sistema termodinâmico para o TPT é muito parecido com o sistema termodinâmico da LacY que descrevemos no item anterior, com a diferença de que aqui estamos considerando uma diferença de potencial elétrico nula, $\Delta \Psi=0$. Por esse motivo, não iremos entrar em detalhes sobre o sistema do TPT. Todos os algoritmos referentes a cada um dos sete estados do nosso modelo estão no Apêndice $B$, onde apresentamos o código computacional que desenvolvemos em linguagem Python para o TPT. Além disso, a partir desses algoritmos, nós determinamos a matriz estocástica do TPT como sendo

$$
\mathbf{T}_{\mathrm{TPT}}=\frac{1}{2}\left[\begin{array}{ccccccc}
\xi_{\mathrm{P}_{\mathrm{i}}, \mathrm{I}} \eta_{2.5} & \frac{1}{e^{3}} & 0 & 0 & 0 & 0 & \xi_{\mathrm{P}_{\mathrm{i}}, \mathrm{E}} \\
\Pi_{\mathrm{P}_{\mathrm{i}}, \mathrm{I}} & \eta_{3} & \frac{\Pi_{\mathrm{TP}, \mathrm{I}}}{e} & 0 & 0 & 0 & 0 \\
0 & 1 & \Pi_{\mathrm{TP}, \mathrm{I}} \eta_{1} & \frac{1}{e^{3}} & 0 & 0 & 0 \\
0 & 0 & \xi_{\mathrm{TP}, \mathrm{I}} & \eta_{7}+\eta_{3} & \xi_{\mathrm{TP}, \mathrm{E}} & 0 & 0 \\
0 & 0 & 0 & \frac{1}{e^{7}} & 0 & \frac{1}{e^{2.5}} & 0 \\
0 & 0 & 0 & 0 & \Pi_{\mathrm{TP}, \mathrm{E}} & \eta_{5}+\eta_{2.5} & \Pi_{\mathrm{P}_{\mathrm{i}}, \mathrm{E}} \\
\frac{\xi_{\mathrm{P}_{\mathrm{i}}, \mathrm{I}}}{e^{2.5}} & 0 & 0 & 0 & 0 & \frac{1}{e^{5}} & 0
\end{array}\right] \text {, }
$$


onde os subscritos "I" e "E" se referem ao espaço intermembranar e ao estroma, respectivamente. 


\section{Capítulo 4}

\section{Resultados}

Este capitulo apresenta os resultados que obtivemos para a permease de lactose da Escherichia coli e o translocador de triose-fosfato/fosfato. Em um primeiro momento, mostramos que as curvas de energia livre de ambos os nossos modelos estão de acordo com as condições de contorno estabelecidas na literatura. Em seguida, os modelos são validados por meio da reprodução de diversos experimentos. Por fim, mostramos que nossas curvas de energia livre são as que melhor reproduzem os dados experimentais. 


\subsection{O simporte de lactose e $\mathrm{H}^{+}$}

\subsubsection{Condições de contorno}

Conforme descrevemos na Seção 3.3.1, a curva de energia livre do simporte de lactose $\mathrm{e}^{+}$foi obtida com base em três condições de contorno estabelecidas na literatura que a LacY deve seguir. Neste item, nós iremos mostrar que a curva de energia livre do nosso modelo está de acordo com essas condições de contorno.

Para fazer isso, vamos começar pela primeira condição de contorno, que diz que, quando há um alto gradiente eletroquímico de $\mathrm{H}^{+}$apontando do citoplasma para $\mathrm{o}$ periplasma, o influxo de lactose deve predominar sobre o efluxo. Esta exigência de um $\Delta \tilde{\mu}_{\mathrm{H}^{+}} \ll 0$ pode ser atendida facilmente até mesmo sob condições fisiológicas. Por exemplo, vamos assumir que os pHs do citoplasma e periplasma sejam $7.6 \mathrm{e}$ 5.6, respectivamente [61]. Esse pH periplasmático é consistente com os ambientes ácidos onde a $E$. coli pode ser encontrada, como o trato gastrointestinal humano. Assim, segue que $C_{\mathrm{H}^{+}, \mathrm{p}}=100 C_{\mathrm{H}^{+}, \mathrm{c}}$, onde $C_{\mathrm{H}^{+}, \mathrm{c}}=N_{\mathrm{H}^{+}, \mathrm{c}} \Omega_{\mathrm{c}}^{-1}$ e $C_{\mathrm{H}^{+}, \mathrm{p}}=N_{\mathrm{H}^{+}, \mathrm{p}} \Omega_{\mathrm{p}}^{-1}$ são as concentrações de $\mathrm{H}^{+}$no citoplasma e periplasma, respectivamente. Agora, substituindo esta relação entre as concentrações de $\mathrm{H}^{+}$na Equação (3.42) e considerando que $\Delta \mu_{\Psi} \approx-3.9 \mathrm{k}_{\mathrm{B}} T$, obtemos o gradiente eletroquímico de $\mathrm{H}^{+}$como sendo $\Delta \tilde{\mu}_{\mathrm{H}^{+}} \approx-8.5 k_{\mathrm{B}} T$, o qual podemos considerar muito menor do que zero frente à escala de energia do problema determinada pela curva de energia livre da Figura 3.3. Com isso, para mostrar que o nosso modelo está de acordo com a primeira condição de contorno, nós realizamos simulações com $\Pi_{\mathrm{H}^{+}, \mathrm{p}}=100 \Pi_{\mathrm{H}^{+}, \mathrm{c}}$ e contamos, em cada simulação, o número total de ciclos de influxo, $N_{\text {in }}$, e efluxo, $N_{\text {ef }}$, como no gráfico da

\begin{tabular}{ccc}
\hline$C_{\mathrm{L}, \mathrm{c}} C_{\mathrm{L}, \mathrm{p}}^{-1}$ & $N_{\mathrm{in}}$ & $N_{\mathrm{ef}}$ \\
\hline 0.01 & 4731 & 0 \\
0.1 & 4070 & 1 \\
1 & 1487 & 11 \\
10 & 199 & 21 \\
100 & 39 & 23 \\
\hline
\end{tabular}

Tabela 4.1: Número total de ciclos de influxo, $N_{\text {in }}$, e efluxo, $N_{\text {ef }}$, para diversos valores da razão entre as concentrações de lactose no citoplasma e periplasma. Foram usados $5 \times 10^{5}$ passos de Monte Carlo e $10^{3}$ réplicas em cada simulação. 

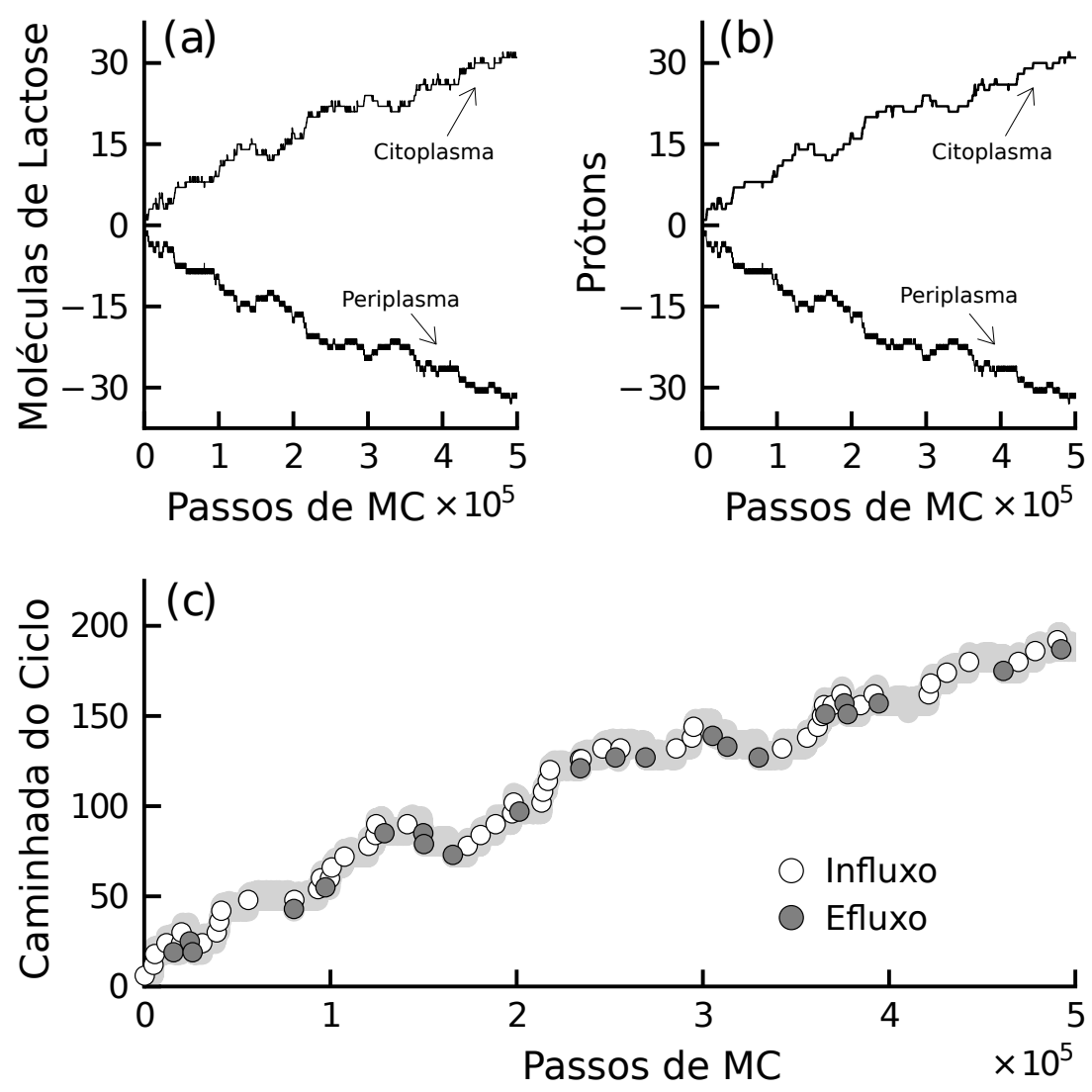

Figura 4.1: Dinâmica do transporte de lactose pela LacY. Nesta simulação, as probabilidades de encontrar uma lactose ou um $\mathrm{H}^{+}$perto da entrada da LacY não dependem do tempo. (a) Número de moléculas de lactose no citoplasma e periplasma. (b) Número de prótons no citoplasma e periplasma. (c) Ciclos de influxo (total de 53) e efluxo (total de 22) versus passo de Monte Carlo em que cada ciclo foi concluído. No início da simulação, Caminhada do Ciclo é igual a zero, e nós adicionamos +1 para cada passo na direção de influxo, e -1 para cada passo na direção de efluxo.

Figura 4.1 (c). O esperado é que $N_{\text {in }}>N_{\text {eff }}$. Essas simulações foram realizadas com diversos valores da relação entre as concentrações de lactose, conforme está mostrado na Tabela 4.1. O motivo de termos adotado valores de $C_{\mathrm{L}, \mathrm{c}} C_{\mathrm{L}, \mathrm{p}}^{-1}$ no intervalo $[0.01,100]$ se deve ao fato de que, de acordo com observações experimentais, a LacY de tipo selvagem não é capaz de transportar lactose para além desse intervalo [31]. Como é possível ver dessa tabela, o influxo de lactose é sempre predominante quando $\Delta \tilde{\mu}_{\mathrm{H}^{+}} \ll 0$, como estávamos esperando.

Em seguida, vamos analisar a segunda condição de contorno, que diz que o passo determinante de taxa do ciclo de transporte quando o gradiente químico de $\mathrm{H}^{+}$é nulo deve ser a desprotonação $2 \rightarrow 1$. Para testar essa condição de contorno, nós consi- 

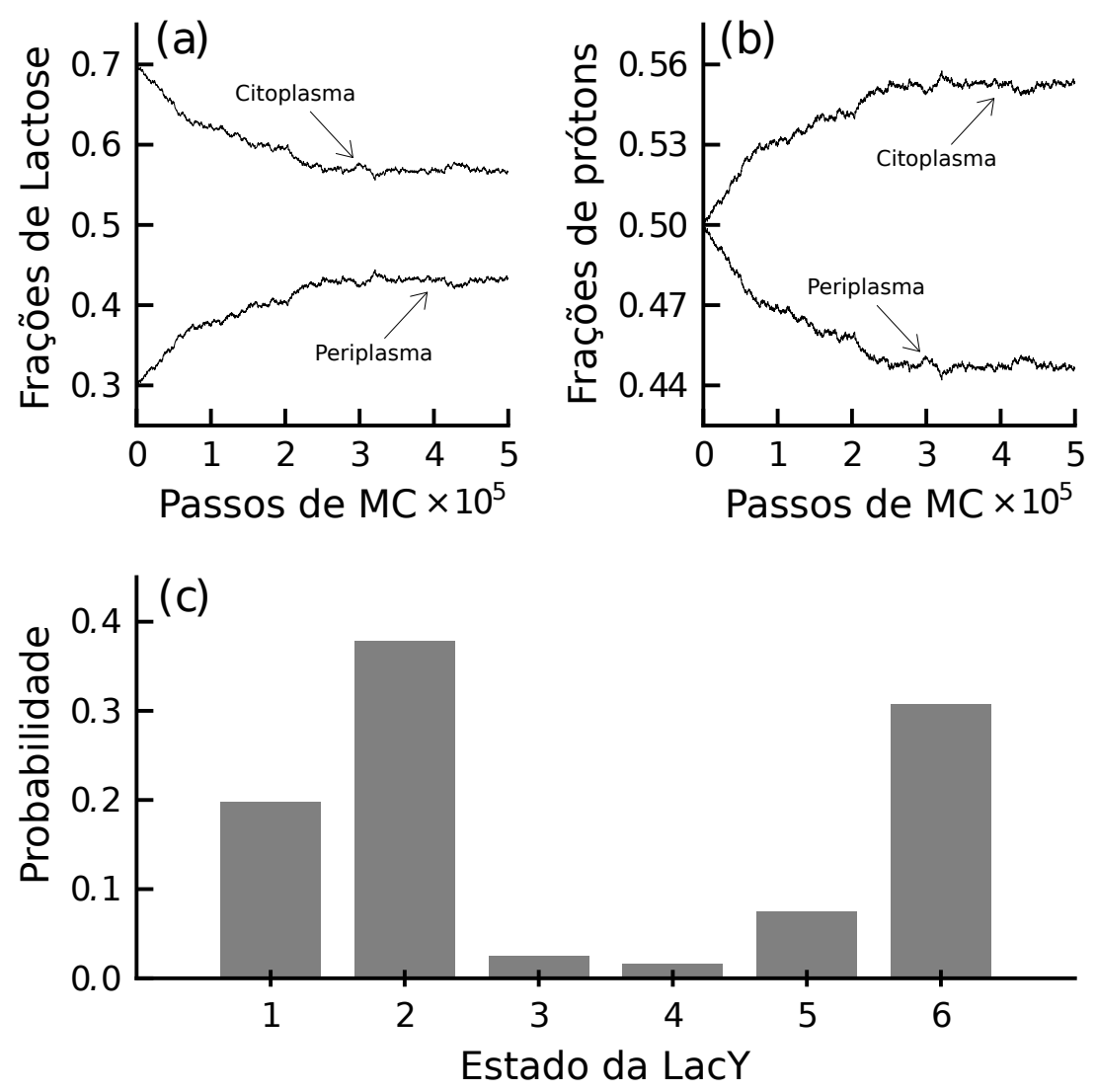

Figura 4.2: Dinâmica do transporte de lactose pela LacY. Nesta simulação, as concentrações dos substratos no citoplasma e periplasma podem variar no tempo. (a) Frações de lactose no citoplasma e periplasma. (b) Frações de prótons no citoplasma e periplasma. (c) Probabilidade do sistema ser encontrado em cada um dos seus seis estados.

deramos um sistema fechado onde as concentrações de lactose e $\mathrm{H}^{+}$no citoplasma e periplasma podem variar no tempo. Neste caso, como queremos testar o comportamento do nosso modelo na ausência de $\Delta \mu_{\mathrm{H}^{+}}$, o sistema foi inicializado com $50 \%$ dos prótons no citoplasma. Em cada simulação, o passo determinante de taxa foi definido pelo tempo de ocupação da LacY em cada um dos seus seis estados, como mostra a Figura 4.2 (c), onde o sistema foi inicializado com $70 \%$ das moléculas de lactose no citoplasma. Conforme é possível ver dessa figura, o passo determinante de taxa, que corresponde à transição mais lenta do ciclo de transporte, é a desprotonação $2 \rightarrow 1$, em acordo com a segunda condição de contorno. Na verdade, para além do exemplo que apresentamos, qualquer sistema inicializado com $\Delta \mu_{\mathrm{H}^{+}}=0$ terá a transição $2 \rightarrow 1$ como passo determinante de taxa. Nós comprovamos isso por meio de uma série de simulações para diversos valores da razão $C_{\mathrm{L}, \mathrm{c}}\left(C_{\mathrm{L}, \mathrm{c}}+C_{\mathrm{L}, \mathrm{p}}\right)^{-1}$. Os resultados 
estão apresentados na Tabela 4.2.

Por fim, vamos analisar a terceira condição de contorno, que diz que, quando $\Delta \mu_{\mathrm{H}^{+}}=0$, o fluxo de lactose deve ser controlado exclusivamente por $\Delta \mu_{\mathrm{L}}$. Para testar essa condição de contorno, nós consideramos, novamente, um sistema fechado onde as concentrações de lactose $\mathrm{e}^{+}$no citoplasma e periplasma podem variar no tempo. Neste caso, como estamos testando o comportamento do nosso modelo na ausência de $\Delta \mu_{\mathrm{H}^{+}}$, o sistema foi inicializado com concentrações iguais de $\mathrm{H}^{+}$em ambos os lados da membrana, digamos $\mathrm{C}_{\mathrm{H}^{+}}$. Em cada simulação, nós determinamos as frações de moléculas de lactose no equilíbrio, como no gráfico da Figura 4.2 (a). Essa figura mostra uma simulação onde $\Delta \mu_{\mathrm{L}} \approx 0.8 \mathrm{k}_{\mathrm{B}} T$ e a fração de moléculas de lactose no citoplasma após $2.5 \times 10^{5}$ passos de Monte Carlo é de aproximadamente 0.57. Então, nós testamos se essa fração se mantém inalterada para $0.1 C_{\mathrm{H}^{+}}, 10 C_{\mathrm{H}^{+}}$, e $100 C_{\mathrm{H}^{+}}$. O critério que estabelecemos para as nossas simulações é que, se a mudança nessa fração não for superior a $5 \%$, a terceira condição de contorno é satisfeita. Isso foi estabelecido tendo em vista a flutuação estatística do nosso modelo, que é de cerca de $3 \%$, uma vez que foram usadas aproximadamente $10^{3}$ moléculas de lactose nas simulações (veja a Seção 3.1.2). No caso da curva de energia livre da Figura 3.3, nós obtivemos por meio de uma série de simulações que ela satisfaz essa CC, porém não

\begin{tabular}{ccccccc}
\hline & \multicolumn{7}{c}{ Tempo de ocupação [\%] } \\
\cline { 2 - 7 }$C_{\mathrm{L}, \mathrm{c}}\left(C_{\mathrm{L}, \mathrm{c}}+C_{\mathrm{L}, \mathrm{p}}\right)^{-1}$ & Estado 1 & 2 & 3 & 4 & 5 & 6 \\
\hline 0 & 0.12 & 0.33 & 0.091 & 0.054 & 0.17 & 0.24 \\
0.1 & 0.12 & 0.35 & 0.092 & 0.055 & 0.15 & 0.23 \\
0.2 & 0.12 & 0.38 & 0.092 & 0.056 & 0.14 & 0.21 \\
0.3 & 0.12 & 0.40 & 0.092 & 0.056 & 0.13 & 0.21 \\
0.4 & 0.12 & 0.42 & 0.090 & 0.056 & 0.12 & 0.20 \\
0.5 & 0.12 & 0.44 & 0.088 & 0.055 & 0.11 & 0.19 \\
0.6 & 0.12 & 0.47 & 0.085 & 0.053 & 0.099 & 0.18 \\
0.7 & 0.12 & 0.49 & 0.080 & 0.051 & 0.091 & 0.17 \\
0.8 & 0.12 & 0.51 & 0.075 & 0.049 & 0.082 & 0.17 \\
0.9 & 0.12 & 0.53 & 0.070 & 0.046 & 0.074 & 0.16 \\
1 & 0.12 & 0.56 & 0.063 & 0.043 & 0.066 & 0.16 \\
\hline
\end{tabular}

Tabela 4.2: Tempo de ocupação da LacY em cada um dos seus seis estados para diversos valores da razão $C_{\mathrm{L}, \mathrm{c}}\left(C_{\mathrm{L}, \mathrm{c}}+C_{\mathrm{L}, \mathrm{p}}\right)^{-1}$, onde $C_{\mathrm{L}, \mathrm{c}}$ e $C_{\mathrm{L}, \mathrm{p}}$ são as concentrações de lactose no citoplasma e periplasma, respectivamente. Nestas simulações, $C_{\mathrm{H}^{+}, \mathrm{c}}=C_{\mathrm{H}^{+}, \mathrm{p}}$. Além disso, foram usados $2 \times 10^{6}$ passos de Monte Carlo. 
incluímos esses resultados aqui pois eles agregam muito pouco ao estudo do funcionamento da LacY. Assim, como é possível ver, a curva de energia livre que obtivemos para o ciclo de transporte da LacY segue as três condições de contorno estabelecidas na literatura para o simporte de lactose e $\mathrm{H}^{+}$, e portanto podemos utilizá-la para descrever a dinâmica da LacY.

\subsubsection{Comentários e discussão}

No presente trabalho, nós realizamos simulações para três casos. Em primeiro lugar, nós consideramos um sistema aberto onde as concentrações de lactose e $\mathrm{H}^{+}$ no citoplasma e periplasma são constantes. Para esse caso, nós assumimos que os pHs do citoplasma e periplasma são 7.6 e 5.6, respectivamente. Assim, segue que $\Pi_{\mathrm{H}^{+}, \mathrm{p}}=100 \Pi_{\mathrm{H}^{+}, \mathrm{c}}$. Além disso, nós assumimos que $\Pi_{\mathrm{L}, \mathrm{c}}=47.5 \Pi_{\mathrm{L}, \mathrm{p}}$, o que correspondo a um $\Delta G=-5 k_{\mathrm{B}} T$, favorecendo termodinamicamente o influxo de lactose. Em segundo lugar, nós consideramos um sistema fechado onde as concentrações de lactose $\mathrm{e}^{+}$no citoplasma e periplasma podem variar no tempo. Nesse caso, para testar o comportamento do nosso modelo na ausência de $\Delta \mu_{\mathrm{H}^{+}}$, o sistema foi inicializado com $50 \%$ dos prótons e $70 \%$ das moléculas de lactose no citoplasma, o que corresponde a um $\Delta G=-3 k_{\mathrm{B}} T$, favorecendo o influxo de lactose. Em terceiro lugar, nós validamos nosso modelo por meio da reprodução de dois experimentos de Ujwal et al. [49].

Os resultados para a primeira simulação são mostrados na Figura 4.1. Aqui, o gradiente eletroquímico de $\mathrm{H}^{+}$está apontando do citoplasma para o periplasma, enquanto o gradiente de concentração de lactose está apontando na direção oposta. Assim, é possível ver que o transporte de lactose contra o seu gradiente de concentração [ver Figura 4.1 (a)] está acoplado ao movimento de prótons a favor do gradiente eletroquímico $\Delta \tilde{\mu}_{\mathrm{H}^{+}}$[ver Figura 4.1 (b)]. Note que, apesar do fato de que esses dois gráficos parecem idênticos, o que se deve ao acoplamento entre o transporte de lactose e $\mathrm{H}^{+}$, eles não são iguais, uma vez que existem eventos raros onde uma lactose é transportada mas $\mathrm{o} \mathrm{H}^{+}$não é. Isso acontece, por exemplo, quando o ciclo avança do Estado 2 para o 5 e, então, retrocede para o Estado 2. É importante ressaltar que não se esperava que o sistema evoluísse para o equilíbrio, uma vez que nós fixamos as concentrações de lactose $\mathrm{e}^{+}$no citoplasma e periplasma. Na Figura 4.1 (c), nós mostramos todos os 
ciclos de influxo e efluxo e o passo de MC correspondente em que cada um foi concluído. Baseado nisso, o número de renovação (em inglês, turnover number) para a LacY pode ser calculado como a diferença absoluta $\left|N_{\text {in }}-N_{\text {ef }}\right|$ dividida pelo número total de passos de MC. O resultado obtido usando $10^{3}$ réplicas é $(5.3 \pm 0.4) \times 10^{-5}$ $(\text { Passos de } M C)^{-1}$. Assim, considerando o número de renovação de $16-20 \mathrm{~s}^{-1}$ que foi estimado para o transporte ativo de lactose na Ref. [62], pode-se concluir que um passo de Monte Carlo no nosso modelo é equivalente, em média, a 2.9 4 s. Nós vamos usar essa escala de tempo que estimamos para descrever os dados experimentais no próximo item.

Em seguida, nós apresentamos os resultados para a segunda simulação na Figura 4.2. Neste caso, o sistema é inicializado com um gradiente de concentração de lactose apontando do periplasma para o citoplasma, enquanto $\Delta \mu_{\mathrm{H}^{+}}=0$. Como se pode ver, o movimento de lactose a favor de seu gradiente de concentração, como mostra a Figura $4.2(\mathrm{a})$, inicialmente fornece energia para transportar prótons para o citoplasma, como mostra a Figura 4.2 (b), o que causa a geração de um $\Delta \mu_{\mathrm{H}^{+}} \neq 0$. Esse gradiente de $\mathrm{H}^{+}$aumenta até o sistema atingir o equilíbrio $\left(2.5 \times 10^{5}\right.$ Passos de $\mathrm{MC}$ ), quando o efluxo inicial de lactose é compensado pelo seu influxo.

As probabilidades do sistema ser encontrado em cada um dos seus seis estados são mostradas na Figura 4.2 (c). Baseado nelas, nós podemos discutir as duas questão de Guan e Kaback que apresentamos na Seção 2.1.3. Em primeiro lugar, pode-se ver dessa figura que a LacY passou aproximadamente $60 \%$ do seu tempo na conformação $C_{\text {fora }}$ e $40 \%$ na conformação $C_{\text {dentro. }}$ Em segundo lugar, é notável o fato o fato de que o sistema passou mais tempo no Estado 2 (38\%) do que em qualquer outro estado. Nós associamos esse fato com duas características do nosso modelo: (i) Existe uma probabilidade baixa de encontrar uma lactose perto da entrada da LacY na conformação $C_{\text {fora. }}$. Consequentemente, o sistema precisa gastar um tempo considerável nesse estado até que a proteína capture uma lactose do periplasma $(2 \rightarrow 3)$. (ii) Existe uma grande barreira de energia livre entre os estados 2 e 1 [ver Figura 3.3]. Essas duas características explicam a importância da protonação para a ligação da lactose. Quando a LacY captura um $\mathrm{H}^{+}(1 \rightarrow 2)$, o sistema vai do estado mais alto de energia para o mais baixo, o que cria a barreira de energia livre que mantém a proteína no Estado 2 enquanto uma lactose não é capturada. Portanto, de acordo com o nosso 

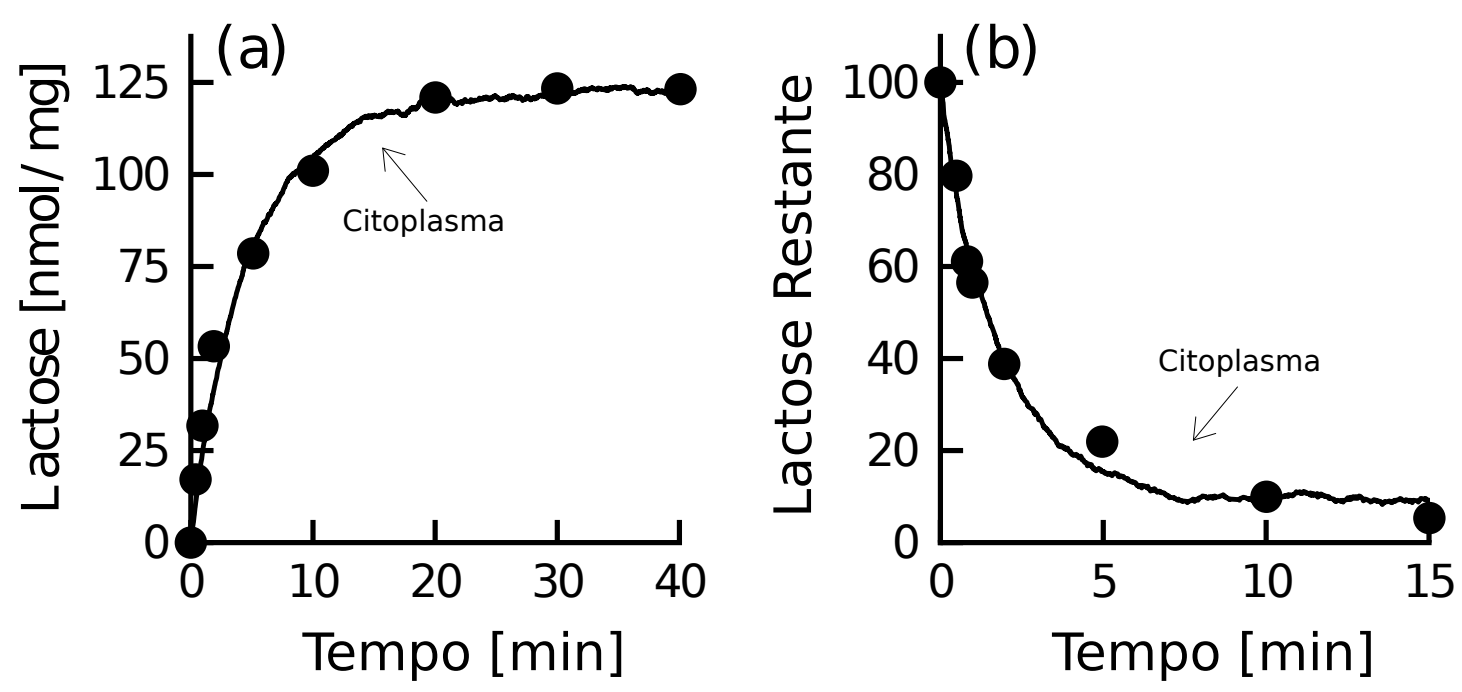

Figura 4.3: Curso temporal do transporte de lactose pela LacY. Círculos correspondem a dados experimentais extraídos da Ref. [49], enquanto linhas sólidas correspondem às nossas simulações. Aqui, um passo de Monte Carlo é equivalente a $2.9 \mu \mathrm{s}$. (a) Evolução temporal do influxo de lactose. (b) Evolução temporal do efluxo de lactose.

modelo, a importância da protonação está no fato de que a ligação do $\mathrm{H}^{+}$causa uma grande diminuição na energia livre do sistema, reduzindo a taxa de transição de 2 para 1, e permitindo que ocorra uma ligação relativamente lenta da lactose. Se houvesse uma taxa de transição apreciável de 2 para 1, então a LacY retornaria facilmente para o Estado 1, e então a próxima transição provavelmente seria a transição $1 \rightarrow 6$, não a $1 \rightarrow 2$, uma vez que a transição $1 \rightarrow 6$ é muito mais provável de ocorrer, haja visto que a transição $1 \rightarrow 2$ depende da disponibilidade de $\mathrm{H}^{+}$perto da entrada da LacY. Portanto, sem a barreira de energia livre entre 1 e 2, a LacY não gastaria a maior parte do seu tempo no Estado 2, conforme necessário para a ligação da lactose, e consequentemente o influxo de lactose seria quase impossível.

\subsubsection{Reprodução de dados experimentais}

Na Figura 4.3, nós usamos o nosso modelo para reproduzir dois experimentos de Ujwal et al. [49]. O primeiro experimento consiste no transporte ativo de lactose em E. coli T184 expressando a permease do tipo selvagem, conforme reproduzimos no gráfico da Figura 4.3(a). Para reproduzir esse experimento, nós consideramos um sistema fechado onde as concentrações de lactose $\mathrm{e}^{+}$no citoplasma e periplasma 
podem variar no tempo. Esse sistema foi inicializado com cerca de $18 \%$ dos prótons no citoplasma e $100 \%$ das moléculas de lactose no periplasma, o que confere à nossa simulação condições muito parecidas com as condições experimentais da Figura 2 do artigo de Ujwal. Essa configuração inicial corresponde a um $\Delta G \rightarrow-\infty$, levando inevitavelmente ao influxo de lactose. Conforme calculamos na seção anterior, um passo de Monte Carlo no nosso modelo é equivalente a $2.9 \mu \mathrm{s}$. Com isso, como o experimento se estende por $40 \mathrm{~min}$, foi preciso usar cerca de $8.3 \times 10^{8}$ passos de Monte Carlo. Além disso, a equivalência entre a unidade do eixo vertical utilizada pelos

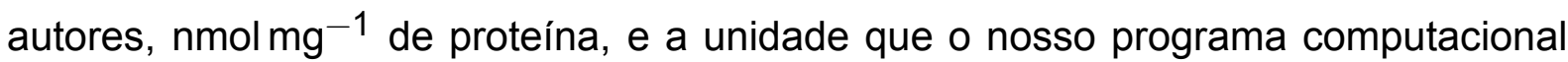
fornece, número de moléculas de lactose, pode ser obtida facilmente considerando que a massa molecular da LacY é de $4.5 \times 10^{4} \mathrm{Da}$ [63].

O segundo experimento é semelhante ao primeiro, com a diferença de que ele mostra a evolução temporal do efluxo de lactose, não do influxo, conforme reproduzimos no gráfico da Figura 4.3 (b). Para reproduzir esse experimento, nós consideramos, novamente, um sistema fechado onde as concentrações podem variar no tempo. Esse sistema foi inicializado com $100 \%$ dos prótons e das moléculas de lactose no citoplasma, conferindo à simulação condições parecidas com as condições experimentais da Figura 4 do artigo de Ujwal. Essa configuração inicial corresponde a um $\Delta G \rightarrow+\infty$, levando ao efluxo de lactose. Como esse segundo experimento se estende por apenas $15 \mathrm{~min}$, foi preciso usar cerca de $3.1 \times 10^{8}$ passos de Monte Carlo.

Como se pode ver da Figura 4.3, a semelhança entre as previsões do nosso modelo e os dados experimentais é boa, corroborando fortemente a escala de tempo que calculamos anteriormente. Isso é uma confirmação importante de que o nosso modelo capturou a física fundamental e essencial do simporte de lactose $\mathrm{e}^{+}$, e que ele é capaz de fornecer resultados confiáveis dentro da precisão da curva de energia livre que nós obtivemos aqui.

\subsubsection{Outras curvas de energia livre}

Com o intuito de mostrar que a curva de energia livre que obtivemos no presente trabalho é a que melhor reproduz os dados experimentais, nós realizamos simulações para o primeiro experimento da seção anterior usando várias outras curvas de energia livre. Na Figura 4.4, nós mostramos em vermelho as quatro simulações que mais se 
aproximaram dos resultados obtidos com a nossa curva. Cada uma dessas simulações foi feita com uma curva de energia livre cujos valores das cinco variações de energia livre, $\Delta E_{S}^{\prime}$, foram determinados a partir dos valores de $\Delta E_{S}$ da Figura 3.3 como

$$
\Delta E_{S}^{\prime}= \begin{cases}\Delta E_{S}-\gamma k_{\mathrm{B}} T, & S=1, \\ \Delta E_{S}+\gamma k_{\mathrm{B}} T, & S=3,4,5,6\end{cases}
$$

onde $\gamma$ é um parâmetro múltiplo de 0.5 . Os gráficos da Figura 4.4, de cima para baixo, correspondem a $\gamma=-0.5,0.5,1$, e 1.5 .

Como é possível ver dessa figura, apenas para $\gamma=+0.5$ houve uma proximidade com os resultados obtidos com a nossa curva de energia livre. Em todos os outros casos, ocorreu uma discrepância notável entre a simulação e os dados experimentais. É importante lembrar que, como foi dito, essas foram as curvas cujos resultados mais se aproximaram dos nossos. Portanto, a nossa curva de energia livre é a que reproduz mais satisfatoriamente os dados experimentais dentro da precisão do nosso modelo. Sobre o caso da curva $\gamma=0.5$, apesar da semelhança entre os resultados, a nossa curva foi a que apresentou menor número de ciclos de efluxo completados na média quando o sistema é submetido a um $\Delta \tilde{\mu}_{\mathrm{H}^{+}} \gg 0$, que foi um critério de escolha que estabelecemos na Seção 3.3.1. Assim, mesmo que a curva da Figura 4.4 (b) possa ser utilizada para descrever a dinâmica da LacY, pois tanto ela quanto a nossa curva fornecem os mesmo resultados dentro da variação estatística do nosso modelo, escoIhemos apresentar os resultados em termos da curva de energia livre da Figura 3.3, uma vez que ela obedece a todos os critérios de escolha que estabelecemos. Além da curva $\gamma=0.5$, não encontramos nenhuma outra que reproduza tão bem os dados experimentais. 
(a)

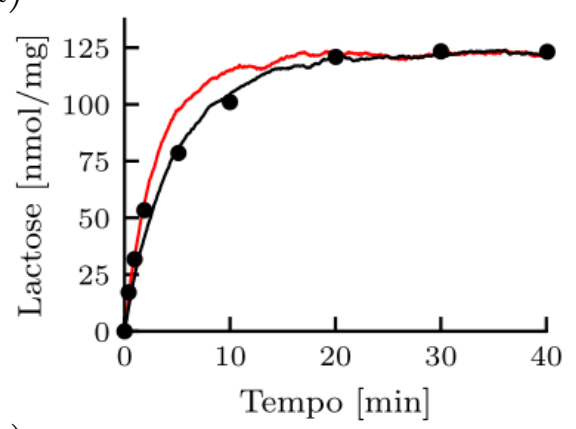

(b)

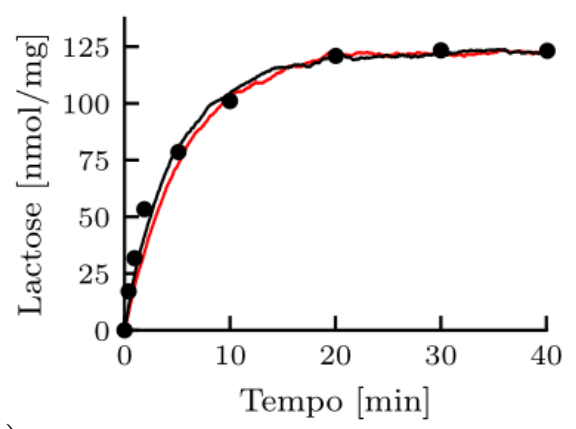

(c)

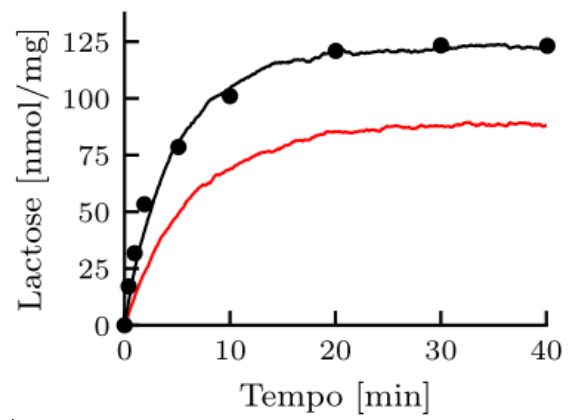

(d)

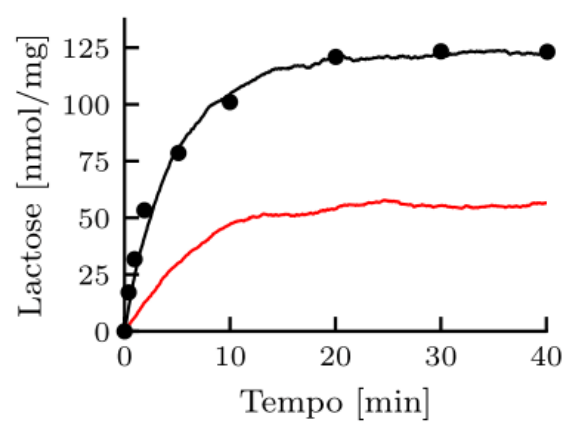

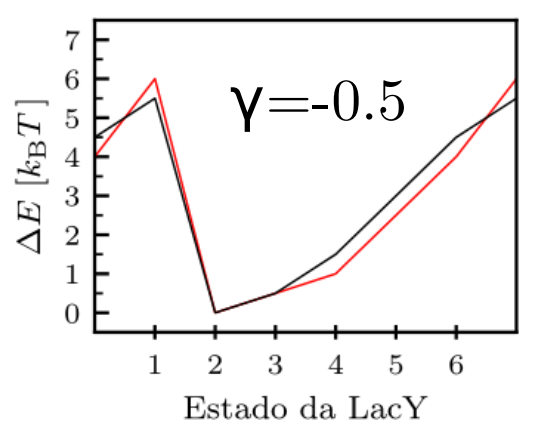
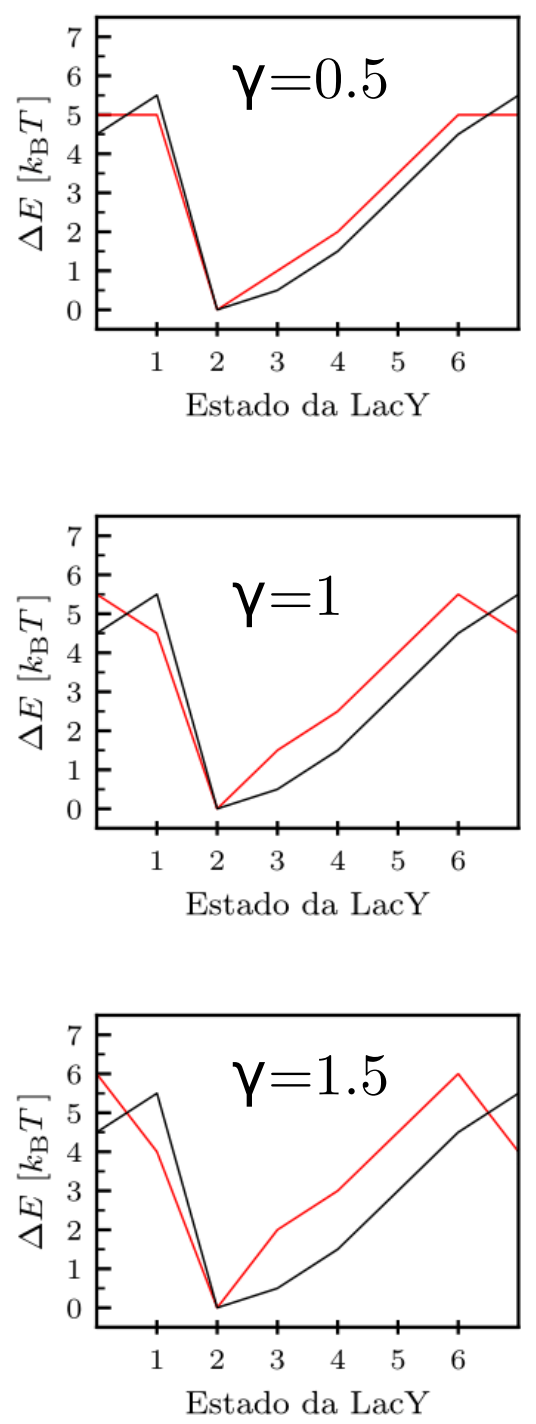

Figura 4.4: Simulações para um experimento realizado por Ujwal e outros usando várias curvas de energia livre. Círculos correspondem a dados experimentais extraídos da Ref. [49], enquanto linhas sólidas pretas correspondem às simulações com a curva de energia livre do nosso modelo, mostrada em preto à direita. Linhas sólidas vermeIhas correspondem às simulações para os quatro valores do parâmetro $\gamma$ indicados. Para mais detalhes, ver o texto. 


\subsection{O antiporte de triose-fosfato e $P_{i}$}

\subsubsection{Condições de contorno}

Conforme descrevemos na Seção 3.3.2, a curva de energia livre do antiporte de triose-fosfato e $P_{i}$ foi obtida com base em duas condições de contorno estabelecidas na literatura que o TPT deve seguir. Neste item, nós iremos mostrar que a curva de energia livre do nosso modelo está de acordo com essas condições de contorno.

Para fazer isso, vamos começar pela primeira condição de contorno, que diz que, quando há um $\Delta \mu_{\mathrm{P}_{\mathrm{i}}}$ alto apontando do estroma para o espaço intermembranar, o efluxo de TP deve predominar sobre o influxo. Esta exigência de um $\Delta \mu_{\mathrm{P}_{\mathrm{i}}} \ll 0$ pode ser atendida facilmente até mesmo sob condições fisiológicas. Para que seja possível comparar os nossos resultados com os resultados do simporte de lactose $\mathrm{e}^{+}$apresentados na Seção 4.1.1, vamos assumir que $C_{P_{\mathrm{i}}, \mathrm{I}}=100 C_{\mathrm{P}_{\mathrm{i}}, \mathrm{E}}$, onde $C_{\mathrm{P}_{\mathrm{i}}, \mathrm{I}}=N_{\mathrm{P}_{\mathrm{i}}, \mathrm{I}} \Omega_{\mathrm{l}}^{-1}$ e $C_{P_{\mathrm{i}}, \mathrm{E}}=N_{\mathrm{P}_{\mathrm{i}}, \mathrm{E}} \Omega_{\mathrm{E}}^{-1}$ são as concentrações de $\mathrm{P}_{\mathrm{i}}$ no espaço intermembranar e estroma, respectivamente. Agora, substituindo esta relação entre as concentrações de $\mathrm{P}_{\mathrm{i}}$ na Equação (1.1), obtemos o gradiente de $\mathrm{P}_{\mathrm{i}}$ como sendo $\Delta \mu_{\mathrm{P}_{\mathrm{i}}} \approx-4.6 k_{\mathrm{B}} T$, o qual podemos considerar muito menor do que zero frente à escala de energia do problema determinada pela Figura 3.6. Com isso, para mostrar que o nosso modelo está de acordo com a primeira condição de contorno, nós realizamos simulações com $\Pi_{P_{i}, I}=100 \Pi_{P_{i}}, E$ e contamos, em cada simulação, o número total de ciclos de influxo e efluxo, como no gráfico da Figura 4.5 (c). Diferente do caso do simporte, aqui o esperado é que $N_{\text {ef }}>N_{\text {in }}$. Essas simulações foram realizadas com valores da relação entre as concentrações de TP iguais aos valores de $C_{\mathrm{L}, c} C_{\mathrm{L}, \mathrm{p}}^{-1}$ da Tabela 4.1, conforme está

\begin{tabular}{ccc}
\hline$C_{\mathrm{TP}, \mathrm{E}} C_{\mathrm{TP}, \mathrm{I}}^{-1}$ & $N_{\mathrm{in}}$ & $N_{\mathrm{ef}}$ \\
\hline 0.01 & 0 & 1 \\
0.1 & 1 & 7 \\
1 & 1 & 56 \\
10 & 1 & 144 \\
100 & 0 & 154
\end{tabular}

Tabela 4.3: Número total de ciclos de influxo, $N_{\text {in }}$, e efluxo, $N_{\text {ef }}$, para diversos valores da razão entre as concentrações de triose-fosfato no estroma e espaço intermembranar. Foram usados $5 \times 10^{6}$ passos de Monte Carlo e $10^{3}$ réplicas em cada simulação. 

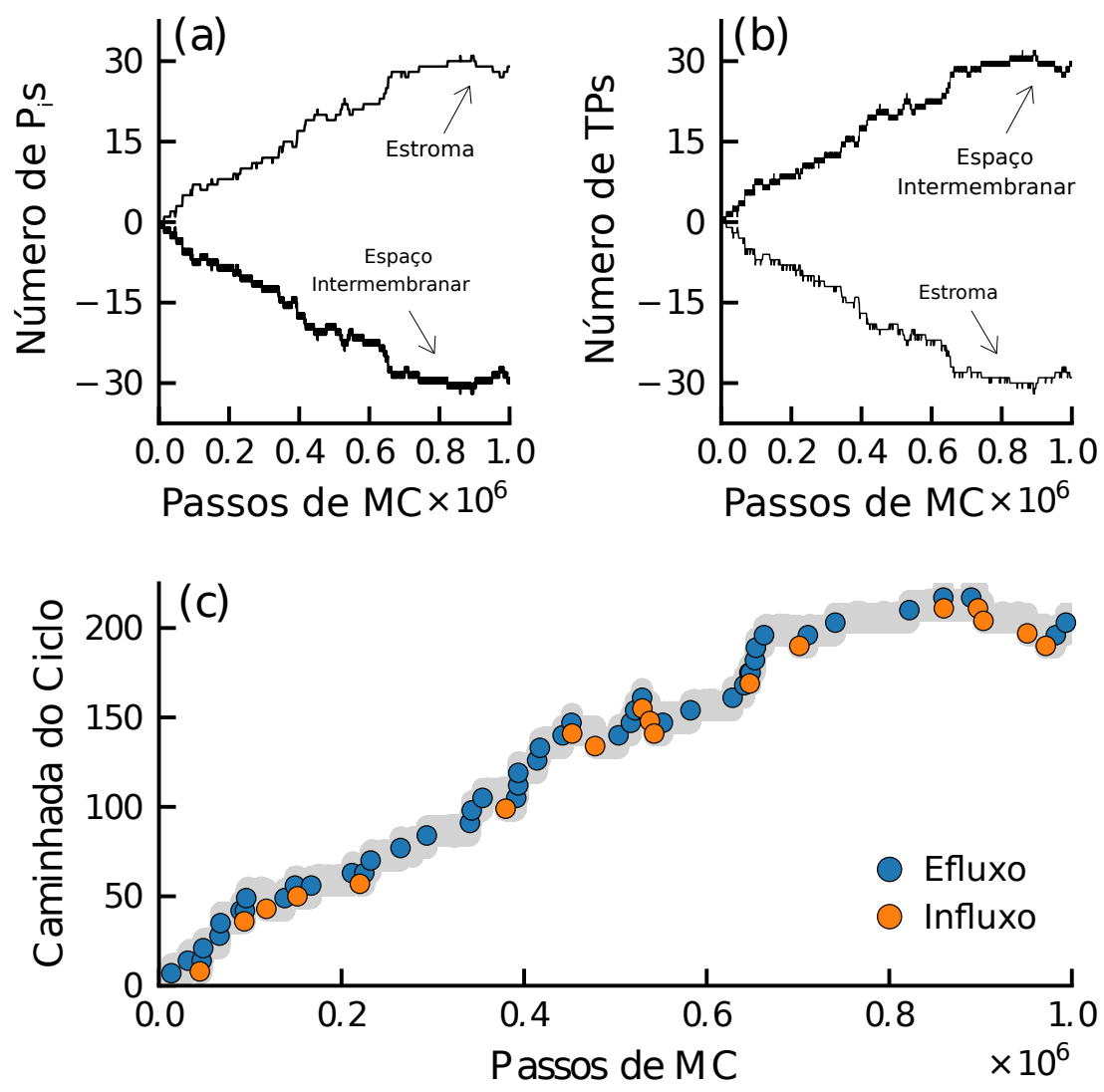

Figura 4.5: Dinâmica do transporte de triose-P pelo TPT. Nesta simulação, as probabilidades de encontrar uma triose-P ou um $P_{i}$ perto da entrada do TPT não dependem do tempo. (a) Número de $P_{\mathrm{i}} \mathrm{s}$ no estroma e espaço intermembranar. (b) Número de TPs no espaço intermembranar e estroma. (c) Ciclos de influxo (total de 18) e efluxo (total de 47) versus passo de Monte Carlo em que cada ciclo foi concluído. No início da simulação, Caminhada do Ciclo é igual a zero, e nós adicionamos +1 para cada passo na direção de influxo, e -1 para cada passo na direção de efluxo.

mostrado na Tabela 4.3. Como é possível ver dessa tabela, o efluxo de $\mathrm{P}_{\mathrm{i}}$ é sempre predominante quando $\Delta \mu_{\mathrm{P}_{\mathrm{i}}} \ll 0$, como estávamos esperando.

Em seguida, vamos analisar a segunda condição de contorno, que diz que, quando $\Delta \mu_{\mathrm{P}_{\mathrm{i}}}=0$, o fluxo de TP deve ser controlado exclusivamente por $\Delta \mu_{\mathrm{TP}}$. Para testar essa condição de contorno, nós consideramos um sistema fechado onde as concentrações de TP e $\mathrm{P}_{\mathrm{i}}$ no estroma e espaço intermembranar podem variar no tempo. Neste caso, como estamos testando o comportamento do nosso modelo na ausência de $\Delta \mu_{\mathrm{P}_{\mathrm{i}}}$, o sistema foi inicializado com concentrações iguais de $\mathrm{P}_{\mathrm{i}}$ em ambos os lados da membrana, digamos $C_{P_{\mathrm{i}}}$. Em cada simulação, nós determinamos as frações de moléculas de triose-P no equilíbrio, como no gráfico da Figura 4.6 (b). Essa figura 

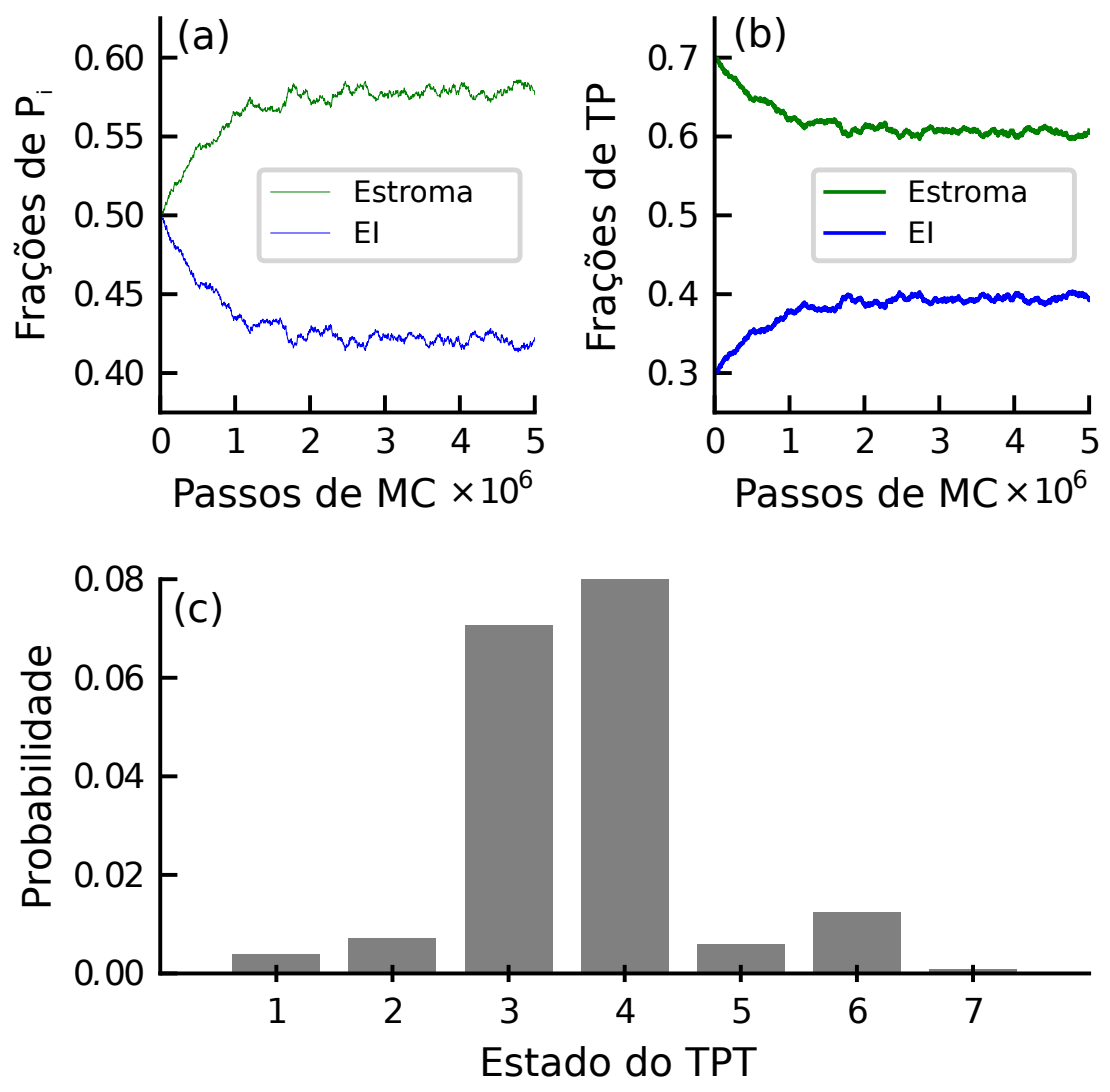

Figura 4.6: Dinâmica do transporte de triose-fosfato pelo TPT. Nesta simulação, as concentrações dos substratos no estroma e espaço intermembranar podem variar no tempo. (a) Frações de $P_{i}$ no estroma e espaço intermembranar. (b) Frações de TP no estroma e espaço intermembranar. (c) Probabilidade do sistema ser encontrado em cada um dos seus sete estados. A probabilidade do Estado 4, que não está mostrada por inteiro, é 0.9 .

mostra uma simulação onde $\Delta \mu_{\mathrm{TP}} \approx 0.8 \mathrm{k}_{\mathrm{B}} T$ e a fração de moléculas de triose-P no estroma após $2.5 \times 10^{6}$ passos de Monte Carlo é de aproximadamente 0.6. Então, nós testamos se esse fração se mantém inalterada para $0.1 C_{P_{\mathrm{i}}}, 10 C_{P_{\mathrm{i}}}$, e $100 C_{P_{\mathrm{i}}}$. O critério que estabelecemos para as nossas simulações é o mesmo que usamos para a LacY, isto é, se a mudança nessa fração não for superior a $5 \%$, a terceira condição de contorno é satisfeita. No caso da curva de energia livre da Figura 3.6, nós descobrimos que ela satisfaz essa condição de contorno, porém não estamos mostrando esses resultados. Assim, como é possível ver, a curva de energia livre que obtivemos para o ciclo de transporte do TPT segue as duas condições de contorno estabelecidas na literatura para o antiporte de triose-fosfato e $\mathrm{P}_{\mathrm{i}}$, e portanto podemos utilizá-la para descrever a dinâmica do TPT. 


\subsubsection{Comentários e discussão}

As análises que estamos apresentando para os resultados do TPT são semelhantes às análises da LacY, uma vez que, além de estudar os processos de transporte dessas duas proteínas, nós queremos discutir as diferenças e semelhanças entre o simporte e o antiporte em geral. Portanto, assim como no caso da LacY, nós realizamos simulações para três casos. O primeiro consiste em um sistema aberto com as concentrações de triose-P e $\mathrm{P}_{\mathrm{i}}$ constantes. Para esse caso, nós assumimos que $\Pi_{\mathrm{P}_{\mathrm{i}}, \mathrm{I}}=100 \Pi_{\mathrm{P}_{\mathrm{i}}, \mathrm{E}}$ e $\Pi_{\mathrm{TP}, \mathrm{I}}=47.5 \Pi_{\mathrm{TP}, \mathrm{E}}$. Em segundo lugar, nós consideramos um sistema fechado onde as concentrações de TP e $\mathrm{P}_{\mathrm{i}}$ no estroma e espaço intermembranar podem variar no tempo. Nesse caso, o sistema foi inicializado com $50 \%$ dos $\mathrm{P}_{\mathrm{i}} \mathrm{s}$ e $70 \%$ dos TPs no estroma. Por fim, nós validamos o nosso modelo por meio da reprodução do experimento correspondente à Figura $1 \mathrm{C}$ da Ref. [53].

Os resultados para a primeira simulação são mostrados na Figura 4.5. Aqui, tanto o gradiente de $\mathrm{P}_{\mathrm{i}}$ quanto o gradiente de TP estão apontando do estroma para o espaço intermembranar. Assim, é possível ver que o TPT está transportando $\mathrm{P}_{\mathrm{i}}$ a favor do seu gradiente de concentração [ver Figura 4.5 (a)] e usando a energia liberada nesse transporte para mover triose-P na contramão do seu gradiente [ver Figura 4.5 (b)]. Note que,

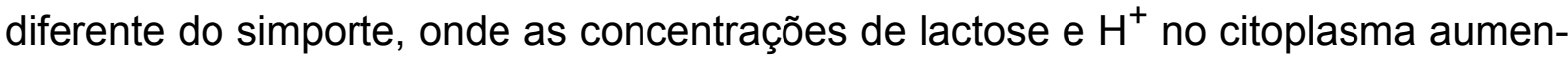
tam simultaneamente, no caso do antiporte, enquanto a concentração de $\mathrm{P}_{\mathrm{i}}$ no estroma aumenta, a concentração de TP no estroma diminui. Portanto, pode-se pensar, intuitivamente, que o TPT troca um $\mathrm{P}_{\mathrm{i}}$ que está no espaço intermembranar por uma TP que está no interior do cloroplasto, e por isso as proteínas antiportadoras muitas vezes são chamadas de trocadoras, como é o caso do trocador de sódio-cálcio, NCX. É importante ressaltar que não se esperava que o sistema evoluísse para o equilíbrio, uma vez que nós fixamos as concentrações de TP e $\mathrm{P}_{\mathrm{i}}$ no estroma e espaço intermembranar. Na Figura 4.5 (c), nós mostramos todos os ciclos de influxo e efluxo e o passo de MC correspondente em que cada um foi concluído. Nesse caso, não é possível comparar diretamente o simporte e o antiporte, uma vez que os nossos resultados mostram que a distribuição temporal dos ciclos de influxo e efluxo depende muito mais da curva de energia livre do que dos gradientes de concentração [64]. Como já era esperado, o número de ciclos de efluxo é maior do que o número de ciclos de influxo, uma vez que há um $\Delta \mu_{\mathrm{P}_{\mathrm{i}}} \ll 0$. 
Em seguida, nós apresentamos os resultados para a segunda simulação na Figura 4.6. Nesse caso, o sistema é inicializado com o gradiente de concentração $\Delta \mu_{\mathrm{TP}}=0.8 k_{\mathrm{B}} T$ apontando do espaço intermembranar para o estroma, enquanto $\Delta \mu_{\mathrm{P}_{\mathrm{i}}}=0$. A energia total disponível para realizar trabalho nesse sistema é dada pela mudança na energia livre de Gibbs através da membrana, $\Delta G=\Delta \mu_{\mathrm{TP}}+\Delta \mu_{\mathrm{P}_{\mathrm{i}}}=$ $0.8 k_{\mathrm{B}} T$. Conforme o tempo passa, a entropia total do sistema aumenta e, consequentemente, $\Delta G$ diminui, até que não haja mais energia disponível para realizar trabalho, isto é, $\Delta G=0$. Essa física está refletida nas Figuras 4.6 (a) e (b). Por exemplo, se o leitor observar o intervalo entre 0 e $1 \times 10^{6}$ passos de MC na Figura 4.6(a), verá que o ruído na curva da fração de $\mathrm{P}_{\mathrm{i}}$ no estroma é muito menor nesse intervalo do que no restante do tempo. Isso ocorre pois, inicialmente, existe um $\Delta G$ considerável, o que favorece termodinamicamente o efluxo de TP, fazendo com que $\Delta G$ diminua rapidamente. No entanto, conforme ocorre esse efluxo, $\mathrm{P}_{\mathrm{i}}$ é importado para o estroma, gerando um $\Delta \mu_{\mathrm{P}_{\mathrm{i}}} \neq 0$. Esse gradiente de $\mathrm{P}_{\mathrm{i}}$ aumenta até o sistema atingir o equilíbrio $\left(2.5 \times 10^{6}\right.$ Passos de $\left.\mathrm{MC}\right)$, quando o efluxo inicial de TP é compensado pelo seu influxo.

Um outro ponto interessante de se notar é que o TPT funciona de forma semelhante ao Demônio de Maxwell. Se olharmos apenas para a Figura 4.6 (a), podemos pensar no TPT como um ser sobrenatural que captura moléculas de $P_{i}$ do espaço intermembranar e as lança no estroma, diminuindo a entropia do sistema e, aparentemente, violando a Segunda Lei da termodinâmica. Esse demônio é exorcizado quando olhamos para a Figura 4.6 (b). Como é possível ver dessa figura, a diminuição da entropia relacionada às frações de $\mathrm{P}_{\mathrm{i}}$ é compensada e superada pelo aumento da entropia relacionada às frações de TP. Assim, a entropia total do sistema aumenta, conforme o esperado.

As probabilidades do sistema ser encontrado em cada um dos seus sete estados são mostradas na Figura 4.6 (c). Em primeiro lugar, pode-se ver dessa figura que o TPT passou aproximadamente $8 \%$ do seu tempo na conformação $C_{\text {fora }}, 90 \%$ na conformação $C_{\text {oclusa }}$, e $2 \%$ na conformação $C_{\text {dentro. Esse resultado está de acordo com }}$ a lenta mudança conformacional do estado ocluso para as conformações $C_{\text {dentro }} \mathrm{e}$ $\mathrm{C}_{\text {fora }}$ obtidas nas simulações de Dinâmica Molecular realizadas por Takemoto e outros na Ref. [52]. Curiosamente, a mudança conformacional $1 \rightleftharpoons 7$, que não está incluída 
no modelo de Takemoto, é muito mais rápida do que as mudanças $3 \rightleftharpoons 4 \rightleftharpoons 5$. Em segundo lugar, é notável o fato de que o sistema passou mais tempo no Estado 4 $(90 \%)$ do que em qualquer outro estado. Esse fato está associado à baixa probabilidade de transição do Estado 4 para o 5, que é, de acordo com a Equação (3.50), $\left(\mathbf{T}_{\text {TPT }}\right)_{54}=e^{-7} \approx 0.09 \%$. Diferente do caso da LacY, não existe uma razão física que justifique a importância da barreira de energia livre entre os Estados 4 e 5 . Aparentemente, essa barreira é uma propriedade intrínseca do sistema, e não desempenha um papel específico no ciclo de transporte do TPT. No entanto, aqui é importante atentar para o seguinte: o modelo de Kaback para a LacY não inclui estados oclusos entre as mudanças conformacionais. Se esse fosse o caso do modelo de Takemoto, isto é, se o Estado 4 fosse ignorado, então o Estado 3 seria enxergado como o estado fundamental, e então a transição hipotética $3 \rightarrow 5$ teria probabilidade de ocorrer de aproximadamente $2 \%, 20$ vezes maior do que a probabilidade de transição do Estado 4 para o 5. Isso constitui um alerta para a importância que um estado ocluso pode vir a ter no ciclo de transporte, e indica que isso deve ser investigado futuramente no caso da LacY e outras proteínas de transporte. 


\section{Capítulo 5}

\section{Conclusão}

Neste último capítulo, um resumo geral sobre o que foi realizado nesta dissertação é apresentado, com comentários sobre a motivação do trabalho, sobre os resultados obtidos, as dificuldades encontradas e os próximos passos possíveis na pesquisa. 


\subsection{Considerações gerais}

O intuito inicial deste trabalho era desenvolver um modelo de mecânica estatística para estudar a dinâmica dos processos de transporte através da membrana celular. Nesse estudo, nós deixamos de lado os canais iônicos e os transportadores ativos primários e consideramos apenas o transporte ativo secundário. Conforme já foi explicado, os transportadores ativos secundários são divididos em simportadores e antiportadores. Por isso, para que o nosso estudo fosse representativo, nós escolhemos uma proteína simportadora, a permease de lactose da Escherichia coli, conhecida como LacY, e uma proteína antiportadora, o translocador de triose-fosfato e fosfato inorgânico, conhecido como TPT. Os resultados para a LacY estão publicados em um artigo na revista Physical Review E [64], ao passo que os resultados para o TPT estão em um manuscrito em processo de revisão.

\subsection{Sobre os resultados}

Nesta dissertação, foram analisados os processos de transporte através da membrana celular para a LacY e o TPT. Em ambos os casos, nosso ponto de partida foi determinar a curva de energia livre do ciclo de transporte com base na estrutura bioquímica de cada estado. Então, usando o algoritmo de Metropolis em um modelo do caminho aleatório não-homogêneo, nós determinamos a dinâmica do ciclo expressa na curva de energia livre obtida anteriormente. Tanto no caso da LacY quanto no caso do TPT, a concordância entre as predições do nosso modelo e os dados experimentais sugere que a nossa curva de energia livre é apropriada para descrever os processos de transporte através da membrana plasmática.

\subsubsection{A permease de lactose da Escherichia coli}

O primeiro processo de transporte transmembranar analisado foi o simporte de lactose $\mathrm{e}^{+}$catalisado pela LacY. Trata-se de um problema bastante explorado na literatura, mas nunca antes sob a ótica da mecânica estatística. Os estudos da LacY são importantes pois ela é considerada representativa para os membros da superfamília dos facilitadores maioritários, uma superfamília que atualmente contém mais de 1000 
membros. Neste trabalho, foram obtidos:

- A curva de energia livre para o ciclo de transporte da LacY com resolução de $0.5 k_{\mathrm{B}} T$, conforme mostra a Figura 3.3.

- A distribuição temporal dos ciclos de influxo e efluxo de lactose e, com base nessa distribuição, o número de renovação para a LacY, conforme mostra a Figura 4.1.

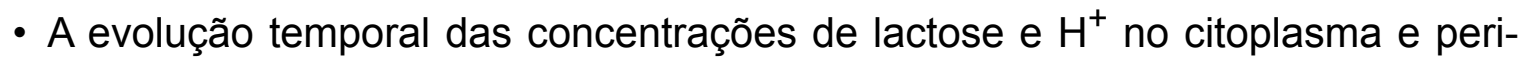
plasma e a probabilidade do sistema ser encontrado em cada um dos seus seis estados, conforme mostra a Figura 4.2.

Nossos resultados são confiáveis dentro da precisão do nosso modelo, que é de cerca de $3 \%$. Com base neles, nós respondemos na Seção 4.1.2 duas perguntas que estavam em aberto na literatura. A primeira pergunta é: (i) Qual é o tempo de ocupação da LacY nas conformações voltada-para-fora e voltada-para-dentro? No caso das condições iniciais que nós adotamos, a resposta é que a LacY passa aproximadamente $60 \%$ do seu tempo na conformação voltada-para-fora e $40 \%$ na conformação voltada-para-dentro. Caso seja necessário obter esses valores para uma outra condição inicial, pode-se utilizar o código computacional disponibilizado no Apêndice $A$. Nossos dados podem ser úteis na obtenção de estruturas de raio- $X$ da LacY em outras conformações, uma vez que só possuímos imagens dela em uma de suas seis conformações. Essas imagens seriam um grande passo no sentido de compreender mais a fundo o mecanismo de transporte da permease de lactose, e portanto do transporte ativo secundário em geral. A segunda pergunta que estava em aberto na literatura é: (ii) Por que a protonação é importante para a ligação da lactose? Nós descobrimos por meio da curva de energia livre da Figura 3.3 que a protonação causa uma grande diminuição na energia livre do sistema, o que permite que a LacY passe a maior parte do seu tempo na conformação voltada-para-fora tentando capturar uma lactose, um evento raro sob condições fisiológicas. Assim, sem a protonação, o influxo de lactose seria quase impossível. Nós acreditamos que essa barreira de energia livre da protonação é, na verdade, um aspecto fundamental e determinante da física do processo de transporte da LacY. Tudo isso está explicado em detalhes na Seção 4.1.2. 


\subsubsection{O translocador de triose-fosfato/fosfato}

O segundo processo de transporte transmembranar analisado foi o antiporte de triose-P e $\mathrm{P}_{\mathrm{i}}$ catalisado pelo TPT. No presente trabalho, o estudo do TPT foi importante para discutirmos as diferenças e semelhanças entre o simporte e o antiporte em geral. Nós obtivemos:

- A curva de energia livre para o ciclo de transporte do TPT com resolução de $0.5 k_{\mathrm{B}} T$, conforme mostra a Figura 3.6.

- A distribuição temporal dos ciclos de influxo e efluxo de TP, conforme mostra a Figura 4.5.

- A evolução temporal das concentrações de TP e $\mathrm{P}_{\mathrm{i}}$ no estroma e espaço intermembranar e a probabilidade do sistema ser encontrado em cada um dos seus sete estados, conforme mostra a Figura 4.6.

Na Seção 4.2.2, nós apresentamos uma discussão sobre a termodinâmica do ciclo de transporte do TPT. Na verdade, essa discussão que apresentamos é válida para qualquer transportador ativo secundário. Em suma, esses transportadores diminuem a entropia de um determinado soluto, carregando-o no sentido contrário ao de seu gradiente de concentração e, em compensação, aumentam a entropia de um outro soluto, carregando-o no mesmo sentido do seu gradiente. A entropia total aumenta para satisfazer a Segunda Lei da termodinâmica.

\subsection{Sugestões para trabalhos futuros}

Como o nosso trabalho foi o primeiro a mapear processos de transporte através da membrana celular em um modelo de mecânica estatística, naturalmente existem diversos pontos que poderiam ser melhor trabalhados e com potencial de evolução.

O primeiro ponto merecedor de atenção se refere ao número de proteínas de transporte embutidas na membrana. Enquanto uma célula pode conter um número grande de proteínas de transporte, o nosso modelo assume que existe apenas uma. Portanto, a primeira generalização que nós consideraríamos seria embutir $N$ proteínas de transporte na membrana. 
O segundo ponto que merece atenção se refere aos modelos de Kaback e Takemoto, que serviram de base para as simulações da LacY e TPT, respectivamente. No caso do modelo de Kaback, seria interessante incluir mais alguns estados para que o ciclo de transporte fique mais detalhado. Por exemplo, poderia ser incluído um estado ocluso entre a transição $3 \rightarrow 4$ e um outro estado ocluso entre a transição $6 \rightarrow 1$. No caso do modelo de Takemoto, seria interessante incluir um estado ocluso entre a transição $7 \rightarrow 1$.

Por fim, o terceiro ponto está relacionado ao fato de que o nosso modelo assume que a energia de ativação entre dois estados vizinhos é igual à diferença de energia entre esses estados. Isso se reflete no fator de Boltzmann, $\exp (-\beta \Delta E)$, e afeta diretamente as probabilidades de transição entre os estados. No presente momento, ainda não é possível estimar essas energias de ativação. No entanto, quando isso for possível, será muito importante que se inclua essas energias nos códigos computacionais disponibilizados nos Apêndices A e B. 


\section{Bibliografia}

[1] Eva Bianconi et al. An estimation of the number of cells in the human body. Annals of human biology, 40(6):463-471, 2013.

[2] B. Alberts, A. Johnson, J. Lewis, M. Raff, K. Roberts, and P. Walter. Molecular Biology of the Cell. Garland Science, 2007.

[3] Robert Hooke. Micrographia: or, Some physiological descriptions of minute bodies made by magnifying glasses. London: J. Martyn and J. Allestry, 1665.

[4] Roberto de Andrade Martins. Robert hooke e a pesquisa microscópica dos seres vivos. Filosofia e História da Biologia, 6(1):105-142, 2011.

[5] Paolo Mazzarello. A unifying concept: the history of cell theory. Nature cell biology, 1(1):E13, 1999.

[6] G. Karp. Cell and Molecular Biology: Concepts and Experiments. John Wiley \& Sons, 2009.

[7] C. Dobell. Antony Van Leeuwenhoek and His "Little Animals". Dover books on biology and medicine. Dover Publications, 1960.

[8] M.E.B. Prestes. Teoria celular: de Hooke a Schwann. Ponto de Apoio. Ed. Scipione, 1997.

[9] William Bechtel. The evolution of our understanding of the cell: A study in the dynamics of scientific progress. Studies in History and Philosophy of Science Part A, 15(4):309-356, 1984.

[10] S.R. Bolsover, E.A. Shephard, H.A. White, and J.S. Hyams. Cell Biology: A Short Course. Wiley, 2011. 
[11] S Jonathan Singer and Garth L Nicolson. The fluid mosaic model of the structure of cell membranes. Science, 175(4023):720-731, 1972.

[12] Harvey Lodish, Arnold Berk, S Lawrence Zipursky, Paul Matsudaira, David Baltimore, James Darnell, et al. Molecular cell biology, volume 3. WH Freeman New York, 1995.

[13] Geoffrey M Cooper and Robert E Hausman. The cell: Molecular approach. Medicinska naklada, 2004.

[14] G. Science. Molecular Biology of the Cell, 5th Ed, 2008: Cell. Molecular Biology of the Cell. Garland Science, 2008.

[15] D.G. Nicholls and S.J. Ferguson. Bioenergetics 3. Academic Press, 2002.

[16] Richard J Naftalin. The thermostatics and thermodynamics of cotransport. Biochimica et Biophysica Acta (BBA)-Biomembranes, 778(1):155-175, 1984.

[17] Dieter Walz and S Roy Caplan. The thermostatics and thermodynamics of cotransport revisited: a restatement of the zeroth law. Biochimica et Biophysica Acta (BBA)-Biomembranes, 859(2):151-164, 1986.

[18] Christopher Miller. Ion channels: doing hard chemistry with hard ions. Current opinion in chemical biology, 4(2):148-151, 2000.

[19] W. Stein. Transport And Diffusion Across Cell Membranes. Elsevier Science, 2012.

[20] Bertil Hille et al. Ion channels of excitable membranes, volume 507. Sinauer Sunderland, MA, 2001.

[21] M.A. Clark, J.H. Choi, and M.M. Douglas. Biology 2e. OpenStax, 2018.

[22] J.M. Berg, G.J. Gatto, J.L. Tymoczko, and L. Stryer. Biochemistry. Macmillan Higher Education, 2011.

[23] R. Phillips, J. Kondev, J. Theriot, and H. Garcia. Physical Biology of the Cell. CRC Press, 2012. 
[24] Adriano M Alencar, James P Butler, and Srboljub M Mijailovich. Thermodynamic origin of cooperativity in actomyosin interactions: The coupling of short-range interactions with actin bending stiffness in an ising-like model. Physical Review E, 79(4):041906, 2009.

[25] Noah Rosenblatt, Adriano M Alencar, Arnab Majumdar, Béla Suki, and Dimitrije Stamenović. Dynamics of prestressed semiflexible polymer chains as a model of cell rheology. Physical review letters, 97(16), 2006.

[26] Arnab Majumdar, Béla Suki, Noah Rosenblatt, Adriano M Alencar, and Dimitrije Stamenović. Power-law creep behavior of a semiflexible chain. Physical Review E, 78(4):041922, 2008.

[27] S.R.A. Salinas. Introdução a Física Estatística. EDUSP, 1997.

[28] Mário José de Oliveira Tânia Tomé. Dinâmica Estocástica e Irreversibilidade Vol. 35. EDUSP, 2001.

[29] Jeff Abramson, Irina Smirnova, Vladimir Kasho, Gillian Verner, So Iwata, and H Ronald Kaback. The lactose permease of escherichia coli: overall structure, the sugar-binding site and the alternating access model for transport. FEBS letters, 555(1):96-101, 2003.

[30] H Ronald Kaback. Structure and mechanism of the lactose permease. Comptes rendus biologies, 328(6):557-567, 2005.

[31] Lan Guan and H Ronald Kaback. Lessons from lactose permease. Annu. Rev. Biophys. Biomol. Struct., 35:67-91, 2006.

[32] Qinghu Ren, Katherine H Kang, and Ian T Paulsen. Transportdb: a relational database of cellular membrane transport systems. Nucleic acids research, 32(suppl 1):D284-D288, 2004.

[33] Qinghu Ren, Kaixi Chen, and lan T Paulsen. Transportdb: a comprehensive database resource for cytoplasmic membrane transport systems and outer membrane channels. Nucleic acids research, 35(suppl 1):D274-D279, 2007. 
[34] Yongchan Lee, Tomohiro Nishizawa, Mizuki Takemoto, Kaoru Kumazaki, Keitaro Yamashita, Kunio Hirata, Ayumi Minoda, Satoru Nagatoishi, Kouhei Tsumoto, Ryuichiro Ishitani, et al. Structure of the triose-phosphate/phosphate translocator reveals the basis of substrate specificity. Nature plants, 3(10):825, 2017.

[35] UI Flügge, Karsten Fischer, Armin Gross, Walter Sebald, Fritz Lottspeich, and Christoph Eckerskorn. The triose phosphate-3-phosphoglycerate-phosphate translocator from spinach chloroplasts: nucleotide sequence of a full-length cdna clone and import of the in vitro synthesized precursor protein into chloroplasts. The EMBO Journal, 8(1):39-46, 1989.

[36] Ulf-Ingo Flügge, Andreas Weber, Karsten Fischer, Fritz Lottspeich, Christoph Eckerskorn, Karin Waegemann, and Jürgen Soll. The major chloroplast envelope polypeptide is the phosphate translocator and not the protein import receptor. Nature, 353(6342):364, 1991.

[37] Andreas PM Weber and Nicole Linka. Connecting the plastid: transporters of the plastid envelope and their role in linking plastidial with cytosolic metabolism. Annual review of plant biology, 62:53-77, 2011.

[38] Andrea Hattenbach, Bernd Muller-Rober, Gabriele Nast, and Dieter Heineke. Antisense repression of both adp-glucose pyrophosphorylase and triose phosphate translocator modifies carbohydrate partitioning in potato leaves. Plant physiology, 115(2):471-475, 1997.

[39] Dieter Heineke, Anne Kruse, Ulf-Ingo Flügge, Wolf B Frommer, Jörg W Riesmeier, Lothar Willmitzer, and Hans W Heldt. Effect of antisense repression of the chloroplast triose-phosphate translocator on photosynthetic metabolism in transgenic potato plants. Planta, 193(2):174-180, 1994.

[40] Anja Schneider, Rainer E Häusler, Üner Kolukisaoglu, Reinhard Kunze, Eric Van Der Graaff, Rainer Schwacke, Elisabetta Catoni, Marcelo Desimone, and UlfIngo Flügge. An arabidopsis thaliana knock-out mutant of the chloroplast triose phosphate/phosphate translocator is severely compromised only when starch synthesis, but not starch mobilisation is abolished. The Plant Journal, 32(5):685699, 2002. 
[41] R. Krämer and C. Ziegler. Membrane Transport Mechanism: 3D Structure and Beyond. Springer Series in Biophysics. Springer Berlin Heidelberg, 2016.

[42] GN Cohen and HV Rickenberg. Etude directe de la fixation dun inducteur de la beta-galactosidase par les cellules descherichia-coli. COMPTES RENDUS HEBDOMADAIRES DES SEANCES DE L ACADEMIE DES SCIENCES, 240(4):466468, 1955.

[43] B. Müller-Hill. The Lac Operon: A Short History of a Genetic Paradigm. Walter de Gruyter, 1996.

[44] Dagmar E Büchel, Bruno Gronenborn, and Benno Müller-Hill. Sequence of the lactose permease gene. Nature, 283(5747):541, 1980.

[45] Jeff Abramson, Irina Smirnova, Vladimir Kasho, Gillian Verner, H Ronald Kaback, and So Iwata. Structure and mechanism of the lactose permease of escherichia coli. Science, 301(5633):610-615, 2003.

[46] Miklos Sahin-Toth, Rhonda L Dunten, Alberto Gonzalez, and H Ronald Kaback. Functional interactions between putative intramembrane charged residues in the lactose permease of escherichia coli. Proceedings of the National Academy of Sciences, 89(21):10547-10551, 1992.

[47] Lan Guan, Franklin D Murphy, and H Ronald Kaback. Surface-exposed positions in the transmembrane helices of the lactose permease of escherichia coli determined by intermolecular thiol cross-linking. Proceedings of the National Academy of Sciences, 99(6):3475-3480, 2002.

[48] H Ronald Kaback, Miklós Sahin-Tóth, and Adam B Weinglass. The kamikaze approach to membrane transport. Nature reviews Molecular cell biology, 2(8):610620, 2001.

[49] ML Ujwal, Miklós Sahin-Tóth, Bengt Persson, and H Ronald Kaback. Role of glutamate-269 in the lactose permease of escherichia coli. Molecular membrane biology, 11(1):9-16, 1994. 
[50] Adam B Weinglass, Melissa Sondej, and H Ronald Kaback. Manipulating conformational equilibria in the lactose permease of escherichia coli1. Journal of molecular biology, 315(4):561-571, 2002.

[51] Sang-Kyu Lee, Joon-Seob Eom, Lars M Voll, Christian M Prasch, Youn-II Park, Tae-Ryong Hahn, Sun-Hwa Ha, Gynheung An, and Jong-Seong Jeon. Analysis of a triose phosphate/phosphate translocator-deficient mutant reveals a limited capacity for starch synthesis in rice leaves. Molecular plant, 7(11):1705-1708, 2014.

[52] Lee Y. Ishitani R. Nureki O. Takemoto, M. Free energy landscape for the entire transport cycle of triose-phosphate/phosphate translocator. Structure, 26(9):1284-1296, 2018.

[53] Marc Linka, Aziz Jamai, and Andreas PM Weber. Functional characterization of the plastidic phosphate translocator gene family from the thermo-acidophilic red alga galdieria sulphuraria reveals specific adaptations of primary carbon partitioning in green plants and red algae. Plant physiology, 148(3):1487-1496, 2008.

[54] K. Binder and D. Heermann. Monte Carlo Simulation in Statistical Physics: An Introduction. Springer Berlin Heidelberg, 2010.

[55] G. Fishman. Monte Carlo: Concepts, Algorithms, and Applications. Springer Series in Operations Research and Financial Engineering. Springer New York, 2013.

[56] V.I. Krylov. Approximate Calculation of Integrals. Dover Books on Mathematics. Dover Publications, 2012.

[57] J.E. Gentle. Random Number Generation and Monte Carlo Methods. Statistics and Computing. Springer New York, 2013.

[58] G.A. Jeffrey and W. Saenger. Hydrogen Bonding in Biological Structures. Springer Berlin Heidelberg, 2012.

[59] Xuejun C Zhang, Yan Zhao, Jie Heng, and Daohua Jiang. Energy coupling mechanisms of mfs transporters. Protein Science, 24(10):1560-1579, 2015. 
[60] M. Menshikov, S. Popov, and A. Wade. Non-homogeneous Random Walks: Lyapunov Function Methods for Near-Critical Stochastic Systems. Cambridge Tracts in Mathematics. Cambridge University Press, 2016.

[61] Jessica C Wilks and Joan L Slonczewski. ph of the cytoplasm and periplasm of escherichia coli: rapid measurement by green fluorescent protein fluorimetry. Journal of bacteriology, 189(15):5601-5607, 2007.

[62] Irina Smirnova, Vladimir Kasho, Junichi Sugihara, and H Ronald Kaback. Opening the periplasmic cavity in lactose permease is the limiting step for sugar binding. Proceedings of the National Academy of Sciences, 108(37):15147-15151, 2011.

[63] G.G. Hammes. Spectroscopy for the Biological Sciences. Wiley, 2005.

[64] Yan B Barreto, Matheus L Rodrigues, and Adriano M Alencar. Transport cycle of escherichia coli lactose permease in a nonhomogeneous random walk model. Physical Review E, 99(5):052411, 2019. 


\section{Apêndice A}

\section{Código Python para a LacY}

1 from math import exp

2 from random import random

3

4 def metrop (dE): \# algoritmo de Metropolis

5

6

if $(\exp (-\mathrm{dE})>\operatorname{random}())$ :

met $=1$

7

else:

8

met $=0$

9

return met

10

$11 \mathrm{~N}=500000$ \# número de passos de Monte Carlo

$12 E=[5.5,0.5,1.5,3.0,4.5]$ \# energia dos estados $[1,3,4,5$,

6]

13 OmgC=5000 \# número de caixas da rede do citoplasma

14 OmgP=10000 \# número de caixas da rede do periplasma

$15 \mathrm{NIc}=700$ \# número inicial de lactoses no citoplasma

$16 \mathrm{NIp}=300$ \# número inicial de lactoses no periplasma

$17 \mathrm{Npc}=400$ \# número inicial de prótons no citoplasma

$18 \mathrm{Npp}=500$ \# número inicial de prótons no periplasma

19 nex=0 \# rótulo do próximo estado 


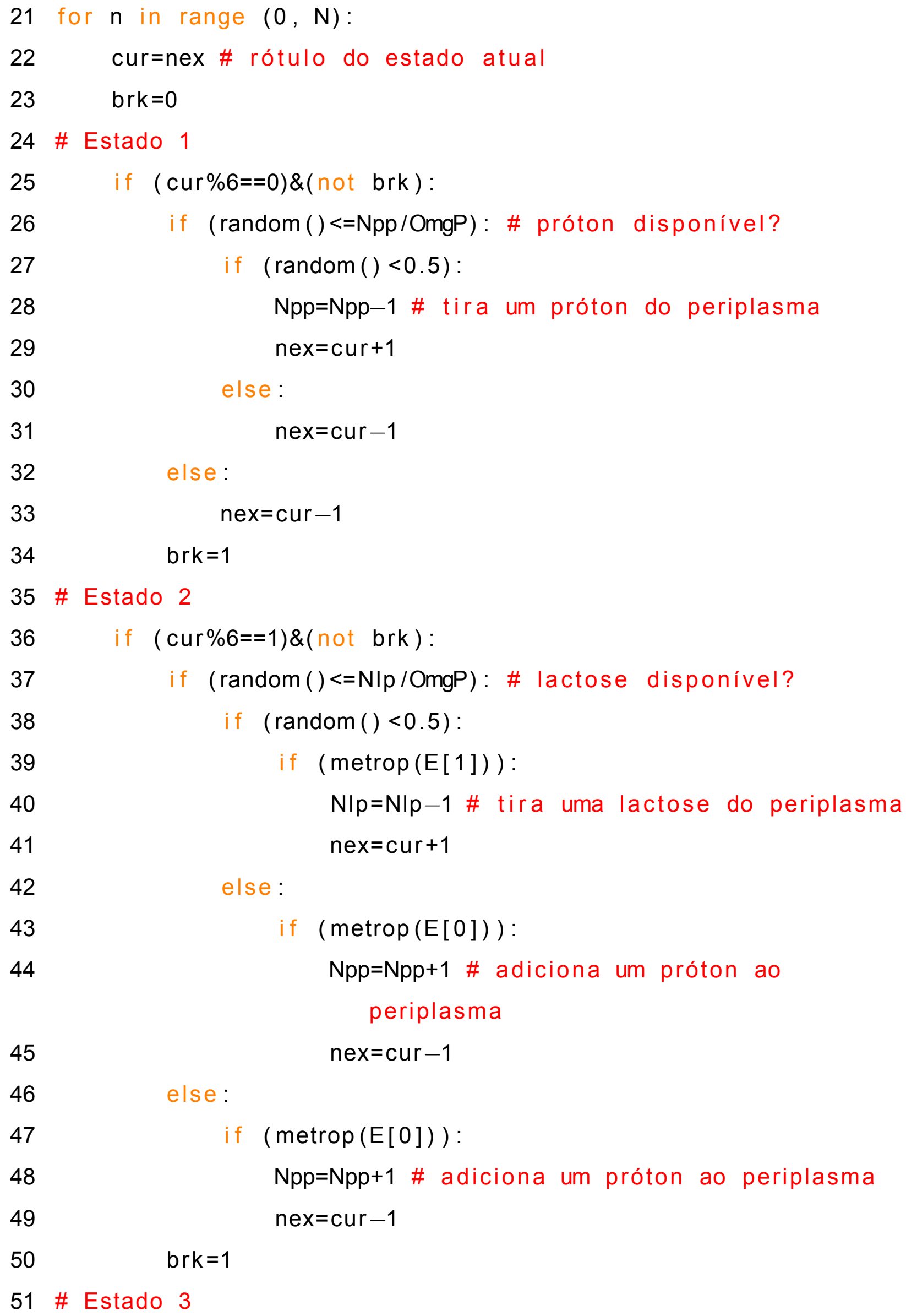

51 \# Estado 3 
52

53

54

55

56

57

58

59

60 \# Estado 4 if $($ cur\%6=-2)\&(not brk):

if $(\operatorname{random}()<0.5)$ :

if (metrop $(E[2]-E[1]))$ :

$$
\text { nex }=\text { cur }+1
$$

\section{else:}

$\mathrm{NIp}=\mathrm{NIp}+1$ \# adiciona uma lactose ao periplasma

$$
\text { nex }=\text { cur }-1
$$

brk $=1$

61

62

if $($ cur $\% 6==3) \&($ not brk $)$ :

63

if $(\operatorname{random}()<0.5)$ :

63

64

if (metrop $(E[3]-E[2]))$ :

65 $\mathrm{NIC}=\mathrm{N} / \mathrm{c}+1$ \# adiciona uma lactose ao citoplasma nex $=$ cur +1

66

else:

67

68

nex $=$ cur -1

brk $=1$

69 \# Estado 5

70

71

72

73

74

75

76

77

78

79

80

81

82 if $($ cur\%6= $=4) \&($ not brk $)$ :

if $(\operatorname{random}()<=\mathrm{NIc} / \mathrm{OmgC})$ : \# lactose disponível?

if $(\operatorname{random}()<0.5)$ :

if $(\operatorname{metrop}(E[4]-E[3]))$ :

$\mathrm{Npc}=\mathrm{Npc}+1$ \# adiciona um próton ao

citoplasma

nex $=$ cur +1

\section{else:}

$\mathrm{NIC}=\mathrm{NIC}-1$ \# tira uma lactose do citoplasma nex $=$ cur -1

else:

if $(\operatorname{metrop}(E[4]-E[3]))$ :

$\mathrm{Npc}=\mathrm{Npc}+1$

nex $=$ cur +1 
brk $=1$

84 \# Estado 6

85 if (cur\%6==5)\&(not brk) :

86

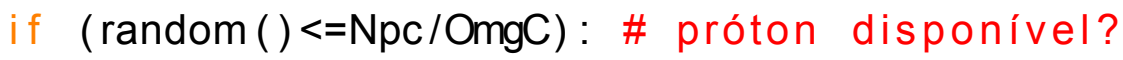

87

if $(\operatorname{random}()<0.5)$ :

88

if $(\operatorname{metrop}(E[0]-E[4]))$ :

89

$$
\text { nex }=\text { cur }+1
$$

90

else:

91

Npc=Npc-1 \# tira um próton do citoplasma

92

nex $=$ cur -1

93

else:

94

if (metrop (E[0]-E[4])) :

95

nex $=$ cur +1

96

brk $=1$ 


\section{Apêndice $B$}

\section{Código Python para o TPT}

1 from math import exp

2 from random import random

3

4 def metrop(dE): \# algoritmo de Metropolis

5

if $(\exp (-\mathrm{dE})>\operatorname{random}())$ :

6

met $=1$

7

else:

met $=0$

9

return met

10

$11 \mathrm{~N}=500000$ \# número de passos de Monte Carlo

$12 E=[7.0,4.0,3.0,7.0,4.5,9.5]$ \# energia dos estados [1, 2, $3,5,6,7]$

13 OmgE=5000 \# número de caixas da rede do estroma

14 Omgl=10000 \# número de caixas da rede do espaço intermembranar

15 Ntpe=700 \# número inicial de TPs no estroma

16 Ntpi=300 \# número inicial de TPs no espaço intermembranar

17 Npie=500 \# número inicial de Pis no estroma

$18 \mathrm{Npii}=500$ \# número inicial de Pis no espaço intermembranar

19 nex=0 \# rótulo do próximo estado 


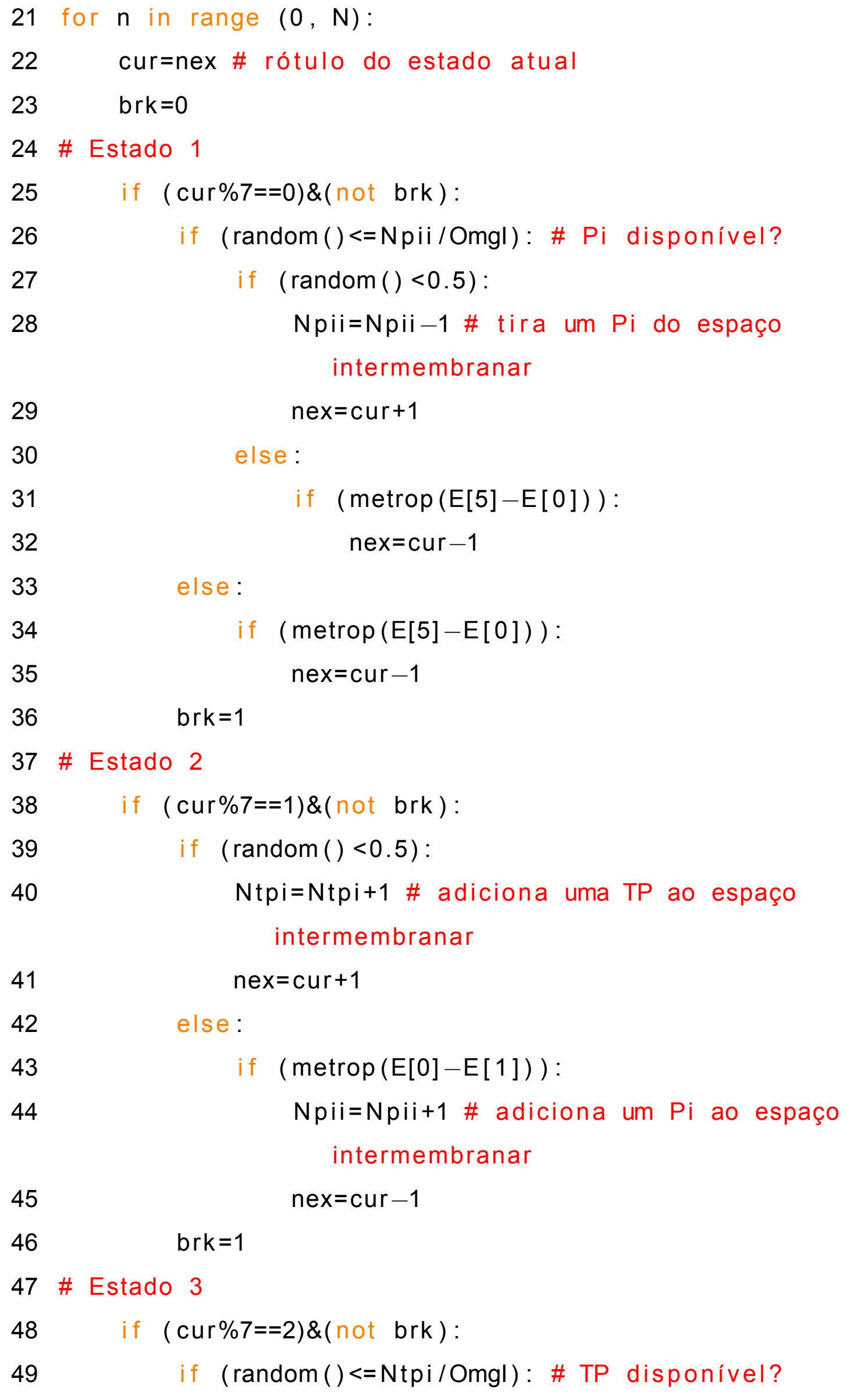

37 \# Estado 2

\section{\# Estado 2}

if ( cur\%7==1)\&(not brk):

if $(\operatorname{random}()<0.5)$ :

47 \# Estado 3

if $(\operatorname{metrop}(E[0]-E[1]))$ :

Npii=Npii+1 \# adiciona um $\mathrm{Pi}$ ao espaço intermembranar

$$
\text { nex }=\text { cur }-1
$$

$$
\text { brk }=1
$$

\# Estad

if (cur\%7==2)\&(not brk):

if (random ()$<=N$ tpi /Omgl): \# TP disponível? 
50

51

52

53

54

55

56

57

58

59 \# Estado 4

60

61

62

63

64

65

66

67

68 \# Estado 5

69

70

71

72

73

74

75

76

77

78

79 \# Estado 6

if $($ random ()$<0.5)$ :

$$
\text { nex }=\text { cur }+1
$$

\section{else:}

if $(\operatorname{metrop}(E[1]-E[2]))$ :

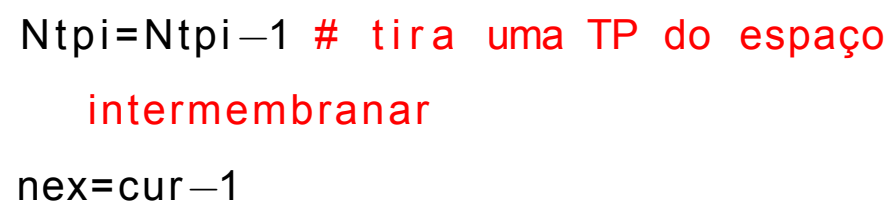

if (random ()$<=N t p e / O m g E):$ \# TP disponível?

80 if $($ random ()$<0.5)$ :

Ntpe=Ntpe-1 \# tira uma TP do estroma nex $=$ cur +1

else:

$$
\text { nex }=\text { cur }-1
$$

else:

$$
\text { nex }=\text { cur }-1
$$

brk $=1$

if $($ cur $\% 7==5) \&($ not brk $)$ : 
if $(\operatorname{random}()<0.5)$ :

82

if $(\operatorname{metrop}(E[5]-E[4]))$ :

83 Npie=Npie +1 \# adiciona um Pi ao estroma nex $=$ cur +1

85 else:

86 Ntpe=Ntpe+1 \# adiciona uma TP ao estroma nex $=$ cur -1

90 \# Estado 7

91

92 if $($ cur $\% 7==6) \&($ not brk $)$ :

93

if (random ()$<=$ Npie/OmgE): \# Pi disponível?

94 if $($ random ()$<0.5)$ :

95

$$
\text { nex }=\text { cur }+1
$$

96

\section{else:}

97

Npie=Npie-1 \# tira um Pi do estroma

98 nex $=$ cur -1

99 else:

100

$$
\text { nex }=\text { cur }+1
$$

brk $=1$ 